University of Louisville

ThinkIR: The University of Louisville's Institutional Repository

Electronic Theses and Dissertations

$5-2018$

\title{
Constructs of collaboration : a multi-case embedded study of a community-wide partnership for school-age youth.
}

Charles Curtis Davis Jr.

University of Louisville

Follow this and additional works at: https://ir.library.louisville.edu/etd

Part of the Education Commons

\section{Recommended Citation}

Davis, Charles Curtis Jr., "Constructs of collaboration : a multi-case embedded study of a community-wide partnership for school-age youth." (2018). Electronic Theses and Dissertations. Paper 2952.

https://doi.org/10.18297/etd/2952

This Doctoral Dissertation is brought to you for free and open access by ThinkIR: The University of Louisville's Institutional Repository. It has been accepted for inclusion in Electronic Theses and Dissertations by an authorized administrator of ThinkIR: The University of Louisville's Institutional Repository. This title appears here courtesy of the author, who has retained all other copyrights. For more information, please contact thinkir@louisville.edu. 


\title{
CONSTRUCTS OF COLLABORATION: A MULTI-CASE EMBEDDED STUDY OFA COMMUNITY-WIDE PARTNERSHIP FOR SCHOOL-AGE YOUTH
}

\author{
By \\ Charles Curtis Davis, Jr. \\ B.S., Eastern Michigan University, 2004 \\ M.Ed., Antioch University McGregor, 2007

\begin{abstract}
A Dissertation
Submitted to the Faculty of the

College of Education and Human Development of the University of Louisville

In Partial Fulfillment of the Requirements

For the Degree of
\end{abstract} \\ Doctor of Education in Educational Leadership and Organizational \\ Development \\ Department of \\ Educational Leadership, Evaluation, and Organizational Development \\ University of Louisville \\ Louisville, Kentucky
}

May 2018 
Copyright 2018 by Charles Curtis Davis, Jr.

All rights reserved 

CONSTRUCTS OF COLLABORATION: A MULTI-CASE

\section{EMBEDDED STUDY OF A COMMUNITY-WIDE PARTNERSHIP}

FOR

SCHOOL-AGE YOUTH

By

Charles Curtis Davis, Jr.

B.S., Eastern Michigan University, 2004

M.Ed., Antioch University McGregor, 2007

A Dissertation Approved on

April 5, 2018

By the following Dissertation Committee:

\begin{tabular}{|c|}
\hline $\begin{array}{c}\text { W. Kyle Ingle } \\
\text { Professor Directing Dissertation }\end{array}$ \\
\hline $\begin{array}{c}\text { Michèle Foster } \\
\text { Committee Member }\end{array}$ \\
\hline $\begin{array}{l}\text { Mary Brydon-Miller } \\
\text { Committee Member }\end{array}$ \\
\hline $\begin{array}{c}\text { Matthew Berry } \\
\text { Outside Committee Member }\end{array}$ \\
\hline
\end{tabular}

ii 


\section{DEDICATION}

This dissertation would not be possible without the people in my life who have believed in me when I have not always believed in myself.

To my parents Thelma and Charles Sr., who were not only my my first educators, but the educators of thousands of students over their careers.

To my big sister Traci who has consistently provided the exemplar by which to shape my life's journey.

To my nephew Donny who gave me my first lessons on the importance in being in a young child's life.

To my wife Latrica who as my life partner has provided me with love and unwaivering support in this endeavor.

And finally to my son Charles III.

You are truly my greatest accomplishment. 


\section{ACKNOWLEDGEMENTS}

There are many individuals who have walked with me not only during this course of study, but over my life who have helped me complete this endeavor. For these companions, I must thank God for every individual He has placed in my life that has brought me to this point. The most important of these companions are my wife Dr. Latrica Best, my son Charles III, my sister Dr. Traci Davis and nephew Donny. My mother Thelma J. Davis an educator for over 30 years, and continues to love and teach me daily. My father Charles Sr. was here at the beginning of this journey, but was not able to see me finish my course. I hope that I have made you proud dad, and brought honor to the name that you gave me.

I would next like to thank my dissertation committee, Dr. W. Kyle Ingle, Dr. Mary-Brydon Miller, Dr. Michèle Foster, and Dr. Matthew Berry for their guidance and support. Each of you assumed the posture of a "critical friend"; challenging me to produce my best work, but never providing critique without an equal or greater level of resource and support. My dissertation journey was not by any means a straight line. Through the twists and turns, both personally and professionally, my chair Dr. Ingle served as a steady beacon guiding me to shore through many a storm. For that steadying presence in this process, I am truly grateful.

There two additional scholars I will note who did not serve in an official capacity along this journey but have aided me in ways they may never know. The first is Dr. Marian Glancy, Director of the School of Education at Antioch University Midwest. Dr. Glancy was the first individual to communicate to me the idea of the educator as a scholar. She taught me that education was not a passive discipline, and that we should continually strive to explore ways that we can reach all children through the merging of 
theory with practice. The second scholar I would like to thank is Dr. Mavis Sanders. I do not know Dr. Sanders, and in fact have only communicated with her a handful of times via e-mail. When I had challenges on how to frame my study I took a chance and reached out to her. Not only did she respond to my inquiry, but ultimately led me to the framework that guided this entire study. I can't begin to thank her for taking time out of her busy schedule to help a graduate student she didn't know, who was halfway across the country, and was not under her charge.

Last but not least, I would like to acknowledge the newest additions to my extended family, the Block' 17 cohort. Many of you completed this journey before me, some will complete this journey with me, and some will complete this journey shortly after me. I am proud of each of you, and it has been a pleasure to watch each of you develop your scholarly acumen in your own individual ways. I am happy to call you all both colleagues and friends. 


\title{
ABSTRACT \\ CONSTRUCTS OF COLLABORATION: A MULTI-CASE EMBEDDED STUDY OF A COMMUNITY-WIDE PARTNERSHIP FOR SCHOOL-AGE YOUTH
}

\author{
Charles C. Davis, Jr.
}

April 5, 2018

Observing the efficacy of school-community partnerships has historically been a challenge for researchers. This study seeks to investigate a city-wide partnership between the community and local educational agency through the lens of the cross-sector collaboration theoretical framework. The three components of the theoretical framework which will guide this study are observing the antecedent conditions present in collaboration, the processual dimensions of collaborations and lastly making sense of the perceived public value created by collaboration. By utilizing a multi-case embedded case study design, this research seeks to analyze the bounded case of the CARDS partnership to determine the reasons for choosing a multi-organizational partnership model, to explain the perceived benefits and/or challenges of a multi-organizational partnership model and examining the ways that external stakeholders make sense of the public value of a multi-organizational partnership.

Findings from my study indicate a clearly defined explanation for this initiative to operate within a multi-organizational partnership model. Data also reveal the benefits and challenges for organizations working within a multi-organizational partnership. Finally, organizations that are a part of the CARDS partnership communicate how they make sense of their participation in the CARDS partnership. Finally, my study will conclude with implications for policy, practice and future research. 
TABLE OF CONTENTS

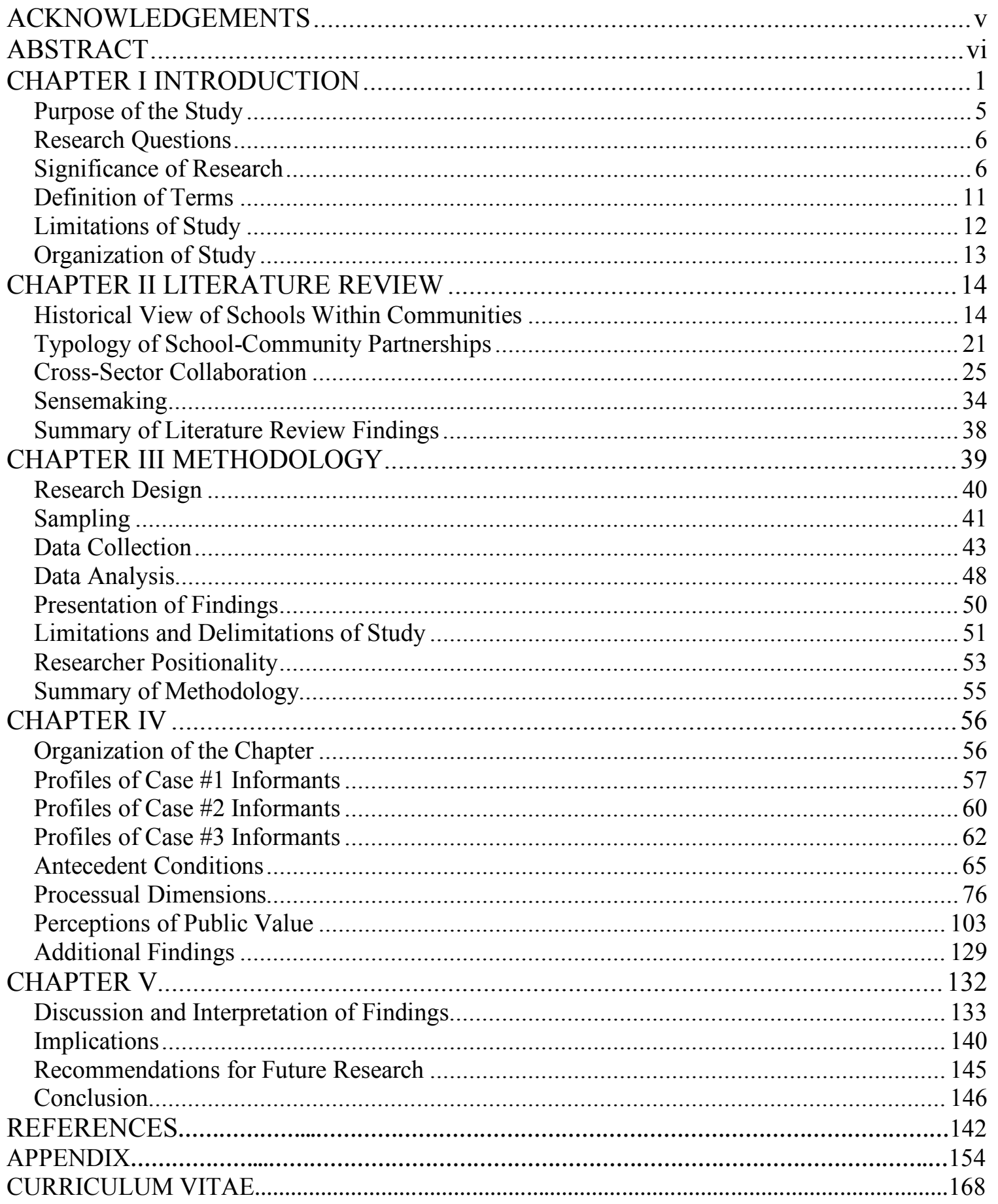




\section{LIST OF TABLES}

Table 1 Participation in clubs or activities supported by school.................................. 8

Table 2 Participation in clubs or activities supported by community groups................... 9

Table 3 Defining Local Cross-Sector Collaborations for Education .............................24

Table 4 Composition of embedded cases within current study .................................. 42

Table 5 Cross-sector collaboration propositions with associated interview protocol ...... 45

Table 6 Deductive codes related to cross-sector collaboration theoretical framework......51

Table 7 Demographic Information of Case \#1 Informants...........................................58

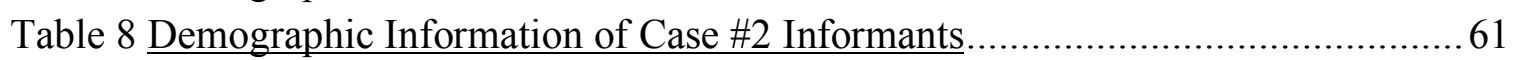

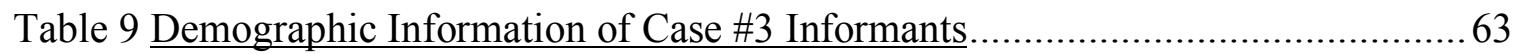

Table 10 Roles of partner organizations listed in the Wallace Foundation Grant ............82

Table 11 Cases \#1 and \#2 perspectives on CARDS Partnership ................................ 100 


\section{LIST OF FIGURES}

Figure 1: Organizational home of the Wallace Grantees' coordinating entity .................4

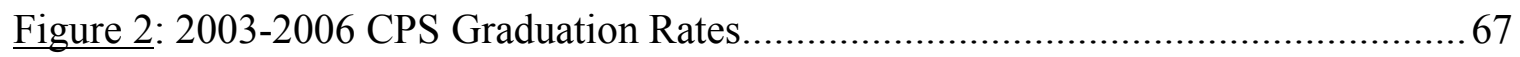

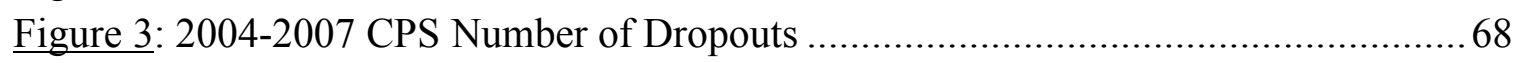

Figure 4: 2008 OST Coordinating Council Organizational Structure............................. 83

Figure 5: Leadership changes of CARDS' founding partners ................................... 84

Figure 6: 2016 CARDS Governance Structure.......................................................... 96

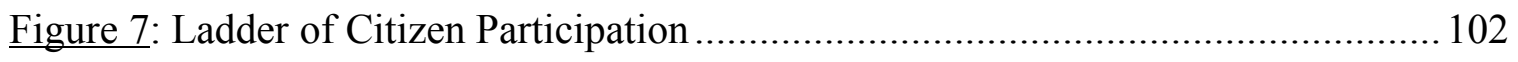

Figure 8: Typology of Embedded Case \#3 CARDS Partnership Organizations ............ 104

Figure 9: Innes and Booher (1999) Outcomes of Collaborative Planning Efforts.......... 119

Figure 10: Reported CARDS First, Second and Third Order Effects ........................ 120

Figure 12: Coded responses to CARDS' Long-Term Institutional Viability ................. 122

Figure 11: CARDS' Loose Coupled Organizational Structure.................................. 130 


\section{CHAPTER I}

\section{INTRODUCTION}

Partnerships between schools and the communities in which they reside are by nature complex propositions. While undoubtedly schools, parents, local educational associations, the business community and other actors may all care about student achievement, they may choose to address the topic in vastly different ways. Though it may seem intuitive that schools, parents and members of the community would create a cohesive network of support for children, historically this has not always been the case (Epstein \& Sanders, 2000; Epstein et al., 2002; Tyack \& Cuban, 1995). A closer examination of the nexus of school and community partnerships indicates that there is a wide and complex web of influences within a given community context that may either directly or indirectly impact the learning of students within schools (Bronfenbrenner, 1979; Leonard, 2011). The number of partners increases the complexity of the relationships and likelihood for disjointed relationships between the schools and community partners. The challenges inherent in school-community partnerships are not unique to the city of Cabot, Kentucky, the city's holistic response certainly has been.

In 2010, the city of Cabot embarked on a project called YouthPrint. The YouthPrint project convened a variety of stakeholders from both the public and nonprofit sectors with the goal of identifying and organizing the activities of youth development programs to support greater social-emotional outcomes for youth 
in the community. The leadership team met over several months, ultimately producing a report outlining local perspectives and best practices for creating such a system. The report put forth eight recommendations to guide the creation of an out-of-school time system of youth development in Cabot. The recommendations were:

1) Create a Coordinating Council comprised of Metro Government, Public Trust of Greater Cabot (PTGC) and Cabot Public Schools (CPS) to serve as a decision-making body/intermediary and a Community Advisory Coalition, including youth providers to advise the Coordinating Council;

2) Leverage and maximize existing financial resources;

3) Assist, promote and support quality standards across out-of-school time programs;

4) Promote the development and implementation of high quality training and professional development opportunities for youth development professionals;

5) Maintain a directory of services and create a system-wide means of collecting program results and outcome data by upgrading KidTrax (data tracking system);

6) Gather data and additional information to develop an initial implementation plan;

7) Provide opportunities for community input on priorities, strategies, services and policies and ensure effective communication and community engagement; 
8) In consultation with Ready by 21, conduct a process to develop a 10year strategic plan for youth that engages youth service providers, youth and community members to accomplish desired outcomes for youth (YouthPrint, 2010, p.2)

Despite an initial groundswell of enthusiasm and collaborative activity, the YouthPrint initiative ultimately did not gain the traction in the Cabot community to sustain its work for an extended period of time. Though the Cabot group did not achieve its initial goals, another opportunity for success was closer than they may have imagined.

In 2003, the Wallace Foundation sponsored an initiative to help five cities (Providence, New York, Boston, Chicago, and Washington D.C.) improve coordination among its afterschool providers, creating citywide systems that could support highquality programs and increase access. Since this time, the Wallace Foundation has commissioned a number of studies to examine and validate the efforts of the cities in facilitating this work. Prompted by the subsequent positive findings, the Wallace Foundation in conjunction with the National League of Cities (NLC), sought to identify other communities around the country that were also deeply involved in coming up with solutions about how to best coordinate out-of-school time activities with a variety of community stakeholders. In 2012, the Wallace Foundation provided an additional $\$ 7.8$ million in funding to nine cities (Baltimore, Denver, Fort Worth, Grand Rapids, Jacksonville, Cabot, Nashville, Philadelphia, and St. Paul) deemed "next generation cities" in order to further their work in developing coordinated systems of out-of-school time providers.

In a 2013 report entitled Is Citywide Afterschool Coordination Going Nationwide researchers commissioned by the Wallace Foundation sought to identify the components 
of coordinating systems that were being utilized in the original five Wallace Foundation funded cities as well as the "next generation" cities. A key finding of this report was the identification of three key components to community-wide out-of-school time system building. These components are the establishment of a coordinating entity to facilitate afterschool program coordination, a common data system to collect data about children's participation, and a common set of quality standards or a quality framework (Simkin et al., 2013). Additionally, researchers found that various cities were implementing different types of coordinating entities within their local communities. The three most selected types of coordinating entities identified were entities housed in intermediaries or other non-profit organizations, entities housed in a city agency, and entities that utilized a multi-organization partnership model. Other entities were housed in either the local school district or the city's office of the Mayor.

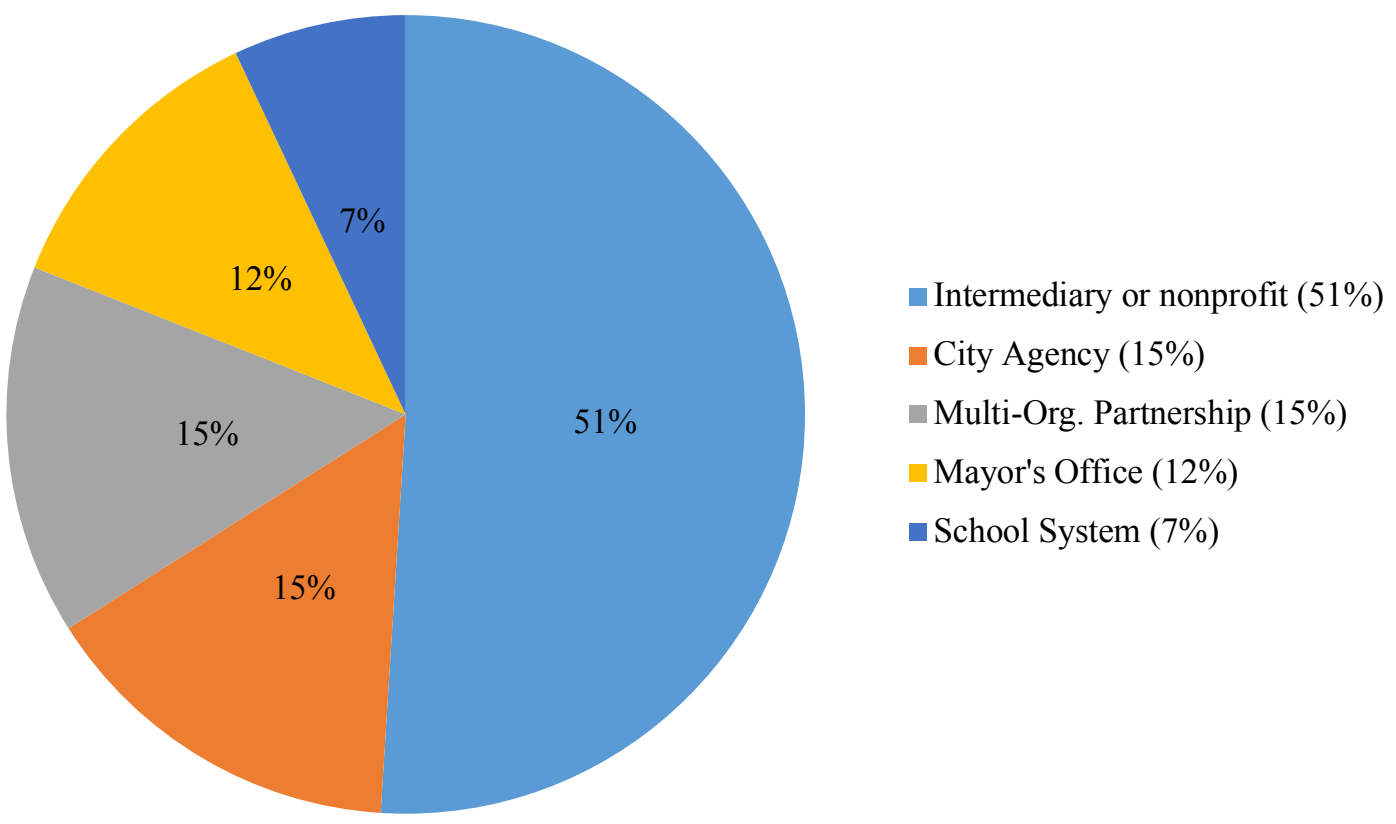

Figure 1: Organizational home of the Wallace Grantees' coordinating entity 
As a next generation city, Cabot was charged with the task of identifying their own data-system, coordinating entity, and quality standards. To accomplish the systembuilding work, Cabot chose the multi-organization partnership model. Cabot chose to operationalize the CASCADE data system developed and used by CPS as a studenttracking data system. In developing quality standards, Cabot utilized a three-pronged approach. To measure program quality, Cabot selected the Youth Program Quality Intervention (YPQI) tool developed by the David P. Weikart Center for Youth Program Quality. To capture the voice of youth participating in out-of-school time activities, Cabot selected the Survey of Academic and Youth Outcomes Youth Survey (SAYO-Y). Lastly, to gauge the organizational capacity of out-of-school time providers, Cabot developed its own Cabot Quality Standards.

The partnership model derived from foundational work in Cabot was named CARDS, an acronym which stands for Building Cabot's Out-of-School Time Coordinated System. The multi-organization partnership chosen by Cabot is governed by an executive committee which is comprised of CARDS' four founding partners: Cabot Metro Government, PTGC, CPS and The Partnership for Children. In addition to the executive committee, CARDS includes a Coordinating Council that is comprised of youth development agencies in the city of Cabot. To guide their work, CARDS has identified four focus areas: Data and Research, Participation and Capacity-Building, Communications and Program Quality ${ }^{1}$.

\section{Purpose of the Study}

As grant dollars provided by the Wallace Foundation to support systems building work are waning, the work of the CARDS partnership has pivoted from a concentration

\footnotetext{
${ }^{1}$ Citation is has been removed from text and bibliography to protect anonymity
} 
on system-building, to one of system sustainability. During the grant period much work has been undertaken by both the CARDS executive committee and coordinating council over the past several years, however, many questions persist as to how CARDS communicates its purpose and perceived value to not only partner organizations but the greater Cabot community. The purpose of this study then is to engage current and past stakeholders to understand the process of developing this partnership between local schools and the community.

\section{Research Questions}

To better understand the organizational mechanisms of the CARDS partnership, I explore three research questions:

1. Why did CARDS choose the multi-organizational partnership model as the coordinating structure for the initiative?

2. How does cross-sector collaboration theory explain the perceived benefits and/or challenges of the CARDS multi-organizational partnership model?

3. How do out-of-school time partner organizations make sense of the various components of the CARDS initiative?

A review of the literature, theory and practice associated with these three questions will

help to ground each of these inquiries within the context of the CARDS initiative and will also help to identify and rationalize an appropriate theoretical lens by which to inform this research study and its findings.

\section{Significance of Research}

As Chapter II will demonstrate, there is some agreement in the literature about the perceived benefits of school-community partnerships in the lives of young people. Though school-community partnerships theoretically are a boon for communities, in 
practice they are often challenging to both implement and evaluate. It is in this regard that the proposed research seeks to fill this gap in the literature. Sanders (2012) conducted a qualitative longitudinal study of the implementation and sustainability of reform efforts, namely school, family and community partnerships, in two separate districts. In offering recommendations for future practice, the author notes that future initiatives should consider the flexibility of reform efforts. Sanders finds that rigid reforms are less sustainable in the face of district changes, while reform efforts that are too flexible risk losing their core features and weaken their potential impact.

In their review of various types of school-community partnerships, Valli, Stefanski and Jacobson (2014b) recommended three key practices for collaborative efforts. The first recommendation is the strengthening and sustainability of partnerships. The authors warn that without strong partnerships, collective efforts can quickly unravel due to even a small amount of change within organizations. As the CARDS initiative at the executive level is a partnership between four separate entities, an examination into the strength of partnership ties between these groups will be a key area of investigation. The authors also state the need for ongoing and detailed evaluation of not only the partnerships themselves, but also the stated outcomes for youth and participants. The authors find that few partnership models do the work of creating comprehensive and rigorous systems of evaluation. As the creation of a coordinated system of out-of-school time (OST) programs is at the heart of the CARDS initiative, an investigation into the efficacy of said system is warranted. Finally, the authors call for the development of an integrated and comprehensive database to be shared by all partners and stakeholders.

Moving from theory to practice, a coordinated system of out-of-school time providers is a matter of particular importance to the district partner, CPS. With over 
101,000 students, CPS is the largest school district in the Commonwealth of Kentucky, and the $27^{\text {th }}$ largest school district in the United States (American School and University, 2014). Within CPS, the department of data and evaluation serves as not only the clearinghouse for achievement, attendance and discipline data but also a wide array of other tools. One such tool utilized by CPS is the Comprehensive School Survey (CSS). The CSS is designed to rate the overall satisfaction of students, parents and employees with their local school district (Rodosky, 2014). The survey is made up of a total of 52 questions that are broken into three categories; school relations, home/community support and school operation. Within the CSS, one question asks students whether they are involved in clubs or activities, besides sports, that are supported by their school. Data (Table 1) show that in the 2015 CSS survey less than $47 \%$ of students report being involved in a school club or activity at either the elementary, middle or high school level.

\section{Table 1}

CSS responses to "I am in clubs or activities (besides sports) supported by my school."

\begin{tabular}{|c|c|c|c|c|}
\hline & Yes & No & $\mathrm{N}$ & $\begin{array}{c}\text { Response } \\
\text { Rate }\end{array}$ \\
\hline Elementary & $46.3 \%$ & $53.7 \%$ & 14152 & $96.8 \%$ \\
\hline Middle & $41.3 \%$ & $58.7 \%$ & 19825 & $92 \%$ \\
\hline High & $42.5 \%$ & $57.5 \%$ & 23632 & $83.8 \%$ \\
\hline
\end{tabular}

When asked a similar question of involvement in clubs or activities sponsored by community organizations, the threshold for positive responses at either the elementary, middle or high school level drops to less than $35 \%$ (Table 2). 


\section{Table 2}

CSS responses to "I am in clubs or activities (besides sports) supported by community groups."

\begin{tabular}{lcccc}
\hline & Yes & No & N & $\begin{array}{c}\text { Response } \\
\text { Rate }\end{array}$ \\
\cline { 2 - 5 } Elementary & $34.3 \%$ & $65.7 \%$ & 14152 & $96.8 \%$ \\
Middle & $32.6 \%$ & $67.4 \%$ & 19825 & $92 \%$ \\
High & $33 \%$ & $67 \%$ & 23632 & $83.8 \%$ \\
& & & & \\
\hline
\end{tabular}

These data are of particular note when juxtaposed against literature on the potential benefits of quality out-of-school time programs for students of all ages. Vandell, Reisner, and Pierce (2007) found that for elementary students, participation in high-quality afterschool activities increased math scores, work habits, and also students' persistence in completing tasks. They also found an increase in elementary students' social skills and peer interactions and a decrease in disciplinary misconduct. The benefits were not just limited to younger students. The authors also found that middle school students who had access to high-quality afterschool programs demonstrated significant gains in math standardized scores compared to their peers who were routinely unsupervised afterschool. Middle school students who participated in afterschool activities also had reduction in disciplinary misconduct as well as reduced use of drugs and alcohol. Durlak, Weissberg, Dymnicki, Taylor and Schellinger (2011) also found that participation in afterschool programs that promote social and emotional learning held positive implications for students in kindergarten through high school. Compared to control groups, youth participants in these programs demonstrated improved social and emotional skills, attitudes, behavior and academic performance. 
The work of the CARDS initiative to coalesce an amalgamation of community stakeholders into a highly functioning coordinated system is a challenging task. The literature will show that a key impediment to the creation of such systems are the oftenunclear understandings of what each partner is expected to bring to the table and what they can expect in return. Current studies of out-of-school time systems tend to focus on either only the organizational structures of governing bodies or on the experiences of individual out-of-school time providers as they support students. Additionally, while studies tend to utilize case study methodology, they tend to only examine single cases. In this regard, the proposed research will provide a unique contribution to the literature in three specific ways.

First, this study will combine the perspectives of both the CARDS partner organizations as well as multiple partner organizations to uncover what coherence or dissonance may exist. As Bryson, Crosby and Stone note "few, if any research studies have gathered data on all of these [partners] in a way that could easily guide research or help policy makers... understand when cross-sector collaborations make sense, let alone how to design and implement them" (2006, p. 52). Previous research in this field tends to focus solely on either the antecedent conditions present in cross-sector collaborative efforts, or the processes of developing collaborations. As the proposed research features specific questions focused on both the initial conditions of the CARDS partnership as well as its processual dimensions, this research will serve as a timely contribution. Finally, as collaborative practice typically outpaces scholarship in this field, there is a call for research that collaboratively joins practitioners and scholars (Popp, MacKean, Casebeer, Milward, \& Lindstrom, 2014). As I am involved in the development of the CARDS partnership and am also utilizing the cross-sector collaboration and sensemaking 
theoretical frameworks to inform study, this research will provide a fresh lens to the field. By conducting this research, I seek to understand the challenges of this work and to provide clarity to spaces where little may have previously existed. As cities across the country seek to leverage community-wide resources to positively impact academic and social-emotional outcomes for young people, this timely research will ultimately make an important contribution to the existing literature and practice.

\section{Definition of Terms}

The following terms were used in the context of my study:

Cabot Afterschool Regional Partnership System (CARDS): Cabot Afterschool Regional Partnership System (CARDS) is a partnership between education, government and community organizations whose aim is to improve opportunities for youth in in Cabot, Kentucky.

Out-of-School Time (OST) Programs: Out-of-school time (OST) programs refers to youth development activities provided by organizations that operate outside of the typical school day. Such programs may occur before school, after school, weekends, or during seasonal holidays and breaks.

Cross-Sector Collaboration: "the linking or sharing of information, resources, activities and capabilities by organizations in two or more sectors to achieve jointly an outcome that could not be achieved by organizations in one sector separately" (Bryson et al., 2006, p. 44)

The Youth Program Quality Intervention (YPQI): The Youth Program Quality Intervention (YPQI) is an assessment tool created by the David P. Weikart Center for Youth Program Quality. The YPQI is designed to lead program staff at youth development organizations in a process that will provide support in assessing, planning 
for and improving activities to engage youth participants in out-of-school time programming.

The Survey of Academic and Youth Outcomes - Youth Survey (SAYO-Y): The Survey of Academic and Youth Outcomes - Youth Survey (SAYO-Y) is a survey instrument designed to capture the experiences of youth participants in OST programs. The SAYOY has three components which measure the experiences of youth experiences in OST programs; the youth's sense of competence; and the youth's future planning and expectations.

\section{Limitations of Study}

This qualitative study was based on interviews with both internal and external stakeholders of the CARDS initiative. While the work of developing the initiative has taken place over a number of years, most recently I have served as one of the school district's liaisons on the CARDS leadership team for the past 18 months. In this role I have developed a certain level of familiarity as well as cordial professional relationships with the individuals who will ultimately provide key perspectives to inform this study. It was of great import to explicitly articulate my position as "researcher" and not "colleague" to those individuals in settings where research was being conducted.

Another potential limitation inherent in case study methodology is the need for the researcher to select a case that is neither too broad (e.g., the state of cross-sector collaborations around the United States) nor too narrow (e.g., the procedures of developing a memorandum of understanding) in focus for a given study (Creswell, 2012). The justification for the selection of the CARDS initiative as the bound case for this study will be further elucidated in Chapter III of this dissertation. Conducting a case study of a cross-sector collaboration that is situated within the larger context of a 
nationwide initiative offers the potential to explore multiple lines of inquiry. For example, questions may arise about the antecedent conditions, processual dimensions and public value of other cross-sector collaborations vary in other communities, these questions cannot be answered within the scope of the current study. This study focused solely on answering the stated research questions as they relate to the CARDS initiative. Further investigation into cross-sector collaborations in other communities that are a part of this nationwide initiative may present itself in future research.

\section{Organization of Study}

The organization of this qualitative case study was designed to inform the three proposed research questions. Chapter II begins with a comprehensive review of the literature. This review begins with an overview of this historical context of school within local communities. This review also introduces the field of cross-sector collaboration which serves as the theoretical framework for this study. Lastly, the review of literature provides an overview of sense-making research and how it relates to the current study. Chapter III provides an in-depth description of the qualitative case study methodology that will be used to collect and analyze the data. Chapter IV presents the findings of the current study. The chapter is broken down into three broad topics which discuss the antecedent conditions of the CARDS cross-sector collaboration, the processual dimensions of the CARDS cross-sector collaboration and lastly the perceived public value of the CARDS cross-sector collaboration. An additional section provides additional findings discovered during the inductive coding conducted on my study's data. Finally, Chapter V discusses and summarizes the findings of my study, and offers recommendations for practices as well as implications for future research. 


\section{CHAPTER II}

\section{LITERATURE REVIEW}

This study seeks to examine the circumstances that led to the formation of the CARDS partnership as well as the seminal events that have shaped the collaborative's development. I examined the partnership's formation by investigating what factors led to the decision to form a multi-organizational partnership, the perceived benefits and challenges of this decision, and how partner organizations make sense of these efforts. These questions have been shaped by reviewing literature related to these topics, and

further informed by exploring proposed implications for future research to best contribute to the growing scholarship on cross-sector collaborations in the field of education.

This review of the literature is divided into three sections:

1. School-community partnerships

2. Cross-Sector Collaboration

3. Sensemaking

\section{Historical View of Schools Within Communities}

While there has been a proliferation of research on school community partnerships in recent years, (Cooper, Chavira, \& Mena, 2005; Joyce L Epstein \& Sanders, 2002; Griffin, 2010; Lin, 2010) the notion that schools and surrounding communities have a great impact on students is not at all new. Historically, the concept of school-community partnerships is best viewed through the lens of social welfare, in which various actors who have no formal relationship with a school attempt to provide support for a community's most vulnerable children. The structural aspects of schooling itself have been driven by the context of the communities in which they reside. Katz (1987) identifies four distinct organizational models of schools in the early part of the 
nineteenth century. Three of these models are relevant to this review of literature, notably paternalistic voluntarism, democratic localism, and incipient bureaucracy. Though unique, each of these models features distinct interactions between the schools themselves and the surrounding community.

Paternalistic voluntarism is exemplified in the establishment of the New York Free School Society in 1805. Under this paradigm, the society's main focus was to offer educational opportunities to poor children who did not have access to a formal education. (Katz, 1987). The society offered what would be considered a rudimentary education, with a strong focus on socializing its students in order to mitigate any social ills that were found in their communities. What is most notable about this educational model is that it assumed exclusive control of its students precluding parents or other community from having any involvement in decisions related to curriculum or staffing. In its attempt to provide a basic means of education and socialization, critics of the Free School Society argued that it failed to adequately include its constituents or adapt to the growing diversity of urban life.

To supplant the paternalistic voluntarism, model a new alternative of democratic localism was ushered in. Proponents of this model sought to bring desirable features of rural schools into the urban core. To remedy the perceived failings of the New York Free School Society, New York Secretary of State John C. Spencer advocated making each ward in the city an independent school district with powers comparable to districts in rural communities and overseen by a board of commissioners with limited influence (Katz, 1987). Advocates of democratic localism argued that the core functions schools should be carried out by the smallest possible unit and under control of a community made up of the families and children that attend each individual school. Democratic 
localism however flourished only briefly. While its proponents assumed that a more proximal relationship between schools and communities would allow for said school to be driven by that community's influence, what was not taken into account was the diversity of urban life; meaning that there was ultimately little to no agreement on how schools should function. The system that replaced democratic localism is what Katz identifies as incipient bureaucracy.

While the primary feature of democratic localism was its fragmented nature, the goals of incipient bureaucracy are quite opposite. The aim of this model of education was to standardize the structure and content of schooling. Supporters of these reforms based their arguments for a highly structured form of education on what they saw as the depravity of the urban condition. Quite different from advocates of local control, reformers such as Henry Barnard saw societal depravity as a detriment to the development of youth. Barnard states:

No one at all familiar with the deficient household arrangements and deranged machinery of domestic life, of the extreme poor, and ignorant, to say nothing of the intemperate, - of the examples of rude manners, impure and profane language, and all the vicious habits of low-bred idleness, which abound in certain sections of all populous districts — can doubt, that it is better for children to be removed as early and as long as possible from such scenes and examples (Barnard, 1856, p. 458)

Barnard along with Horace Mann, were the chief architects of the common school movement. Schools then would be charged with what Barnard and others felt communities and families were ultimately unable to do; produce citizens with the knowledge and skills to maintain a republic (Labaree, 2012). To accomplish this task, 
schools would provide female teachers as a surrogate mother to instill virtues such as “cleanliness, delicacy, refinement, good temper, gentleness, kindness, justice and truth" (Katz, 1987). Common schools were able to transform into one of the most enduring educational reforms in the history of the United States of America. In his Twelfth Annual Report of 1848, Mann argues why he felt the approach that he and other common school reformers adopted was so necessary. He states:

Education, then, beyond all other devices of human origin, is the great equalizer of the conditions of men - the balance-wheel of the social machinery... The spread of education, by enlarging the cultivated class or caste will open a wider area over which the social feelings will expand; and, if this education should be universal and complete, it would do more than all things to obliterate factitious distinctions in society (Mann, 1848).

Progressive Era luminary John Dewey had quite a different view of the role of community in the educational discourse. Dewey contends that, since their beginnings, school have played an integral role in society; that schools were never separate institutions, as educative processes were naturally conducted in the natural discourse of family and community life (Dewey, 1902). As education came under state control however, there was a split between what features of government institutions fell under state control and what fell under the auspices of society. Dewey raises several considerations when assessing school's role as a social center.

The first consideration is "the much-increased efficiency and ease of all the agencies that have to do with bringing people into contact with one another" (Dewey, 1902, p. 77). This consideration relates much to the challenges of diversity in education previously discussed. As the United States of America evolved into an increasingly more 
diverse society, urbanization and technological progress eroded the factors that once separated divergent groups. Other aspects such as magazines, newspapers, and longdistance transportation have served to propagate more diverse views than had previously been accounted for. Dewey does however lament that while public education has the ability to rapidly assimilate many cultures into one, it may do so at the detriment of native traditions such as music, art literature and language.

Building off of the first consideration, Dewey (1902) finds that with increasing interaction between cultures, the bonds of social discipline and control are more lax. He found an increasing level of dissonance between the traditional power of religion and societal customs unique to each group as younger generations assimilated more and more into the dominant culture. While Dewey as a pragmatist had no problem with the decreased role of dogmatism and other measures of social control, he acknowledged that there is a temporary loss experienced in this regard. Given the relatively short time that the average child spends in school, Dewey held that society must supplement these losses by searching "for other agencies with which it may repair the loss, and which may produce the results the former methods are failing to secure" (Dewey, 1902, p. 79). Dewey also suggested that as the intellectual knowledge base becomes more intertwined with daily life than ever before, a purely intellectual education becomes increasingly obsolete. While at one point in history, formalized schooling was only relegated to a small and clearly defined class of the community, it was now both accessible and of practical use to all. According to Dewey, society must ensure that there are intentional efforts to connect what students are learning in school with the changing world around them. 
While Dewey acknowledged the place of larger society in formalized education, Bronfenbrenner developed the ecological systems theory as a way to formally explain these interactions. Ecological systems theory posits that human development is not simply a function of self, but is directly informed by the various environments, or systems, that exist around each individual. (Bronfenbrenner, 1979) Furthermore, each of these systems not only interacts with an individual, but may interact with other systems of influence concurrently. Each of these systems may have differing effects based on proximity to an individual. In his initial theory, Bronfenbrenner put forth a typology of these systems to best explain and examine such interactions: The microsystem; the mesosystem; the exosystem; and the macrosystem.

The microsystem deals with settings with which an individual has direct contact. There is a vast array of microsystems that students interact with on a daily basis. Some examples of microsystems include but are not limited to a student's school, a student's neighborhood, a student's family and home life, a student's peer group, a student's faith institution and a sports team or other club where a student may be a participant. The mesosystem is comprised of the interactions between one or more microsystems. Just as the number of microsystem interactions with a student can be widely varied, so too can the creation of mesosystems. For example, a student's development may be influenced based on the mesosystem relationship between that student's parents and peer group. Likewise, a student's academic development may be impacted by the mesosystem relationship between a student's parents and school.

The final two systems in Bronfenbrenner's model tend to be more distally located from the student. The exosystem is comprised of organizations and entities that may have an effect on a student's development, but with which the student has no direct contact. 
An example of an exosystem is the employer of a student's parent. The student does not work at their parent's work place but is impacted by the workplace in a variety of ways. If the parents' work place does not have flexible hours, the parent may not always be able to participate in school activities such as parent-teacher conferences. A parent's workplace may not offer health insurance to their workers which may adversely impact a student's ability to receive treatment for common childhood illnesses. Finally, the macrosystem accounts for social mores and prevailing societal attitudes. An example of a macrosystem is the national debates regarding academic standards, standardized testing, teacher quality and accountability. While an individual student is not necessarily an actor in these various discourses, the outcomes of such debates can have direct impacts on the academic development of students.

The ecological systems theory has provided a framework for many researchers to examine how both internal and external factors affect student development and student achievement. It has been found to be particularly useful in this regard as it provides a duality of focus; one accounting for the complexities of school, family and community relationships while the other accounting for individual student development (Leonard, 2011). Building upon the work of Bronfenbrenner, Epstein further explores the interactive nature of various influences. Her work is based in the premise she puts forth that "there is a growing recognition that families, schools and communities will be able to do more to help children reach important educational goals if they work together, combine resources, communicate effectively, and let students know about their collaborations (Joyce L Epstein \& Sanders, 2002, p. 410) Epstein's (1987) theory of overlapping spheres of influence features a model of external and internal structures. 
External structures deal primarily with the interactions of students' lives at home, at school and in their community. Various factors such as time, stages of child development, and contrasting philosophies and practices all play a role in the students' external surroundings. Internal structures of Epstein's model deal with the interpersonal relationships between various actors in a student's life. These various role groups may include parents, other children educators and members of the community. In these internal spheres of influence information is shared and various actors interface with one another, all either positively or negatively impacting the development of the student. Epstein's full model recognizes the interlocking histories of institutions that motivate, socialize and educate children while also representing changes over time in the skills and collaborative activities of parents, teachers community partners and students (Joyce L Epstein \& Sanders, 2002, p. 412).

The work of Dewey, Bronfenbrenner and Epstein explicate the idea that schools are very much connected to their surrounding communities in several ways. For example the proximity of settings with which children interact greatly impacts their influence. Other considerations that must be accounted for are the interactions between various settings in a child's life. While there has been general agreement on the importance of considering community contexts in schooling, there has been little agreement on how to classify the efforts to develop robust partnerships between schools and the communities in which they reside.

\section{Typology of School-Community Partnerships}

Part of the challenge in understanding the workings of school-community partnerships is the lack of agreement regarding the nomenclature of the field. Valli, Stefanski and Jacobson (2014b) have found similar challenges, while attempting to 
review literature that clearly identified conditions that allowed for positive outcomes as they relate to school and community partnerships. In the course of their review of literature, the authors became increasingly aware that different terminology was often used to describe the same phenomena - or the same terminology to describe quite different phenomena. These occurrences led Valli et al. to create a typology of school community partnerships to use as a framework to organize the literature.

The typology is comprised of four categories: Family and Interagency Collaboration, Full-Service Schools, Full-Service Community Schools and the Community Development model. Family and Interagency Collaboration is the simplest model to understand in the typology. In this model, partners coordinate services to help promote student learning and development (Valli, Stefanski, \& Jacobson, 2014a). The goals in this model are specific, however are limited due to the lack of a comprehensive set of programming available. The Full-Service School model goes a step further than the Family and Interagency Collaboration model as it seeks not only to positively impact academic outcomes, but also addresses the health and other social needs of a student's entire family. These more comprehensive services are often called "wrap-around" services. This is because the assortment of services is intended to wrap a web of supports around students attending a given school and their families. The Full-Service Community School model also features the wrap-around services provided in the previous model, but goes further in that schools and families are not the only stakeholders involved in their operation. Included in the design and functionality of Full-Service Community Schools are a collection of external stakeholders which potentially include local businesses, college faculty members and students, youth workers and neighborhood residents (Dryfoos, 2002). The final and most comprehensive model in the typology is 
the Community Development model. Mirroring Bronfenbrenner's Ecological Systems Theory (1986), the Community Development model recognizes that while schools maintain a certain locus of control in regard to affecting student outcomes, many of the challenges within schools are simply a microcosm of the communities in which they reside. The Community Development model then calls for participants to work together to strengthen social networks, physical infrastructure and the community's economic viability through the conduit of improving local educational outcomes (Samberg \& Sheeran, 2000).

In addition to the stated problems of understanding the types of schoolcommunity partnership efforts, there are additional challenges in this field. Some of the challenges encountered are a lack of centralized decision making, nebulous role specifications of partners, absence of Memoranda of Understanding, staffing turnover of key partners and positions, lack of continuity between partner organizations and school staff and inadequate funding (Leone, Lane, Arllen, \& Arllen, 1996; Quane \& Wilson, 2011; Schutz, 2006). The far-reaching goals of the CARDS partnership most closely resemble the Community Development model in the presented typology as evidenced by both the diversity of external school stakeholders and the far-reaching nature of collaboration. While this a model would do much to assist in understanding the partnership, the noted challenges are by no means insignificant. To provide an alternative view of partnerships between communities and schools, I look to the research area of cross-sector collaboration. 


\section{Table 3}

\section{Defining Local Cross-Sector Collaborations for Education}

1. Locally Organized: The locus of collaboration and key decision making is at the school district, city, metropolitan, or county level.

2. Large Scale: The initiative encompasses multiple schools.

3. Cross Sector: Initiatives are cross sector in two distinct senses of the term: they involve meaningful and regularized collaboration across two or more agencies of government, and they involve meaningful and regularized collaboration of both formal government and key organizations within the civic sector (such as business associations, philanthropies, parent groups, community-based organizations and/or private social-service providers.

4. Inclusive of School District: The K-12 public school district is among the major partners.

5. Education-Outcomes Focused: There is central and sustained attention to educational outcomes.

6. Formal: Collaboration is not ad hoc but formally structured to at least some degree, for example, including an agreed-upon name, a roster of partners, some degree of internal organizational structure, a website.

Henig, Riehl, Rebell, and Wolff (2015)

While its roots are in public administration, there are many lessons to be learned in better understanding school-community partnerships. Henig et al. (2015) frame a set of parameters (Table 3) to identify the uniqueness of cross-sector collaborations for education. The next section of this literature review will further explore cross-sector collaborations and present frameworks to better understand their utility in observing partnership activities. 


\section{$\underline{\text { Cross-Sector Collaboration }}$}

The concept of cross-sector collaborations like school-community partnerships has faced scrutiny in the past as there had not been methods to empirically study the theoretical concepts contained within. Over the past decade however, a groundswell of new research has focused on the development of frameworks with the goal of observing and testing the usefulness of cross-sector collaboration theory. While each of the frameworks to be discussed highlight various aspects of cross-sector collaborations, there are three salient themes that emerge from the literature. The first theme is the importance of antecedent conditions. The second theme is a focus on the processual dimensions of cross-sector collaborations. The final theme is focused on the interpretation of crosssector collaboration outcomes. In the following section, I will summarize the prominent frameworks from the literature on cross-sector collaborations.

\section{Cross-Sector Collaboration Organizing Framework}

Like the concept of school-community partnerships, research around cross-sector collaborations has suffered from a lack of structured ways to observe and evaluate their effectiveness. Part of this challenge has been due to the overall challenging nature of partnerships, while other challenges have been due to the interdisciplinary nature of the field of study. Bryson, Crosby and Stone (2006) presented the first attempt to develop a framework by which to understand partnerships involving multiple actors from multiple sectors. The authors define cross-sector collaboration as "the linking or sharing of information, resources, activities and capabilities by organizations in two or more sectors to achieve jointly an outcome that could not be achieved by organizations in one sector separately" (Bryson et al., 2006). This organizing framework features a comprehensive view of cross-sector collaborations which takes into account the salient features of these 
partnerships such as the initial conditions, processes such as structures and governance, contingencies, constraints as well as outcomes and accountabilities. Each of these five framework levels can be seated in the identified themes of antecedent conditions, processual dimensions and outcomes.

The initial conditions proposed within the framework take into account a number of factors. The environmental context of a community plays a key role. As mentioned within the authors' definition of cross-sector collaboration, the driver of such partnerships is often a result of a contextualized problem of interest that impacts multiple stakeholders. Another way to think of this concept is through what the authors call sector failure. Bozeman (2002) states that dealing with such a failure can be addressed in one of three ways: communities can live with the problem, engage in symbolic actions that only provide superficial solutions to the problem, or create cross-sector partnerships to provide solutions in order to transform sector failures into public value. Other initial conditions take into account the sponsors of such partnerships and a general agreement on the particular problem of interest.

The processual themes of this framework provide the most robust set of factors contributing to cross-sector collaborations. As one of the initial conditions calls for stakeholders to agree on the problem of interest, the process of formalizing those agreements is an important one. The creation of formalized agreements helps contribute to and strengthen other processual components such as building leadership, legitimacy and trust (Ostrom, 1990). Formalized agreements also help provide structure to what are often very loosely-coupled relationships. Glassman (1973) argues that the degree to which systems are coupled, depends upon how many variables they share. Systems that have few variables in common experience loose-coupling while systems that have many 
variables in common experience tighter coupling. The authors suggest that firm structures and governance structures may help allay the constraints of cross-sector collaborations which may impede progress such as power imbalances and competing institutional logics (Bryson et al., 2006).

Lastly, the framework discusses the outcomes of cross-sector collaboration. The most important outcome identified is the creation of public value. Through the lens of this framework, such value is created by maximizing the strengths of each sector while mitigating each sector's weaknesses. Donahue (2004) identifies three general criteria by which to judge the success of cross-sector collaboration: (1) by simply existing, (2) by meeting the goals of each partner in the collaboration and (3) outperforming the alternative to such a collaboration i.e. creating a greater public value that any of the sectors could have accomplished by themselves.

\section{Ansell and Gash's Collaborative Governance Model}

The Collaborative Governance Model posed by Ansell and Gash acknowledges the presence of all three of the themes found in the cross-sector collaboration literature. However, the greatest attention is given to the notion of the antecedent or starting conditions. As the authors note, conditions present at the beginning of a collaborative play a key role in informing the willingness of key stakeholders in partnership efforts (Ansell \& Gash, 2008). The authors distill their collaborative governance model's starting conditions into three key areas: resource and power imbalances, incentives for stakeholders to collaborate and past histories of conflict and/or collaboration between stakeholders.

Imbalances in power may occur when it is perceived that all partners or stakeholders do not come into collaborations with equal resources. Resources may be 
characterized as either human or fiscal. Power imbalance in collaboration leads to the notion that those actors with greater status or organizational infrastructure may be prone to disproportionately affect the outcomes of collaboration in their favor. (Ansell \& Gash, 2008). To address, the authors suggest intentional efforts to empower weaker or disadvantaged partners in order to have equitable representation in collaborative efforts.

Research also shows that power imbalances may inform the incentives of groups to participate in collaborative efforts (Imperial, 2005). As stated by Ansell and Gash, "incentives to participate depend in part upon stakeholder expectations about whether the collaborative processes will yield meaningful results, particularly against the balance of time and energy that collaboration requires" (Ansell \& Gash, 2008, p. 552). Brown (2002) states that the incentives for stakeholders to collaborate increase as the relationship between their participation and the achievement of their goals becomes clearer. This is a common theme reflected in the cross-sector collaboration literature (Bryson, Crosby, \& Stone, 2015) as one of the reasons for engaging in partnerships is that the problems interest are generally not able to be solved by one organizational actor alone.

Finally, the past relationships between partners in a collaboration may greatly impact the success of a partnership. A history of antagonism may create an adverse culture that even the most willing partners cannot overcome. The pre-existence of conflict may express itself in the low levels of trust, which will reduce levels of commitment and negatively impact communication between partners (Ansell \& Gash, 2008). Conversely, a track record of positive relationships may help to create an environment of corporation. 


\section{Black Box of Collaboration Processes}

The framework of Thompson and Perry (2006) acknowledges that collaboration can be a useful tool in a variety of settings. Their framework draws on fields such as organizational theory, public administration theory and strategic management theory. The authors argue however, that despite its usefulness in order to effectively manage collaborations, practitioners need to know what in fact collaboration is. And so their research aims to peer inside what they coin the "black box", to elucidate the five dimensions of collaboration. Thomson (2001) defines collaboration as:

A process in which autonomous actors interact through formal and informal negotiation, jointly creating rules and structures governing their relationships and ways to act or decide on the issues that brought them together; it is a process involving shared norms and mutually beneficial interactions (p. 23)

Using this definition as a starting point, the authors begin to unpack their black box of collaboration to reveal its components.

The first dimension is that of governance. The authors posit that for collaboration to occur, there must be a willingness by partners to jointly agree to rules and structures that both govern behavior and provide for decision making strategies. The process of governing implies that partner organizations are willing to hold both themselves and other partners accountable to the agreed upon standards of operation. This willingness as suggested by Ostrom (1990) is undergirded by the principles of trust, trustworthiness and reciprocity. While a key process, the authors concede that there is no universally suggested collaboration model, and is highly determined by the context of the collaboration itself. 
The second dimension of collaboration is a determination of the administrative structure. Like the potential looseness of governance structure, the authors do not advocate for any particular form of administration. This is due to the fact that in collaborations, there is less dependence on traditional mechanisms of administration such as bureaucracy and standardized routines and more emphasis placed on effective communication and interdependent relationships (Thomson \& Perry, 2006). The call then is for partners to be able to lead in a variety of capacities to contribute to the collaboration's success; even though such roles may span a variety of functions not germane to the originally agreed upon role.

The third dimension of the black box framework is also what Thomson and Perry identify as the most problematic one; the autonomy dimension, which includes the process of reconciling individual and collective interests. As the authors note, partners in collaboration play dual roles. In one capacity the partner is advocating for the propagation of its organization's goals and interests. In the other role the partner is acquiescing to the will of the larger collaborative effort. It is in this dimension the authors note that collaborations quite often fail. As one researcher notes, although greater collaboration is not a very new idea in public administration, it has never fulfilled its promising potential (Vigoda-Gadot, 2003). The mutuality dimension states that for a collaboration to be ultimately sustained, all partners must find the effort mutually beneficial. Much in the vein of the previous dimension, collaboration may successfully occur when partners can satisfy each other's goals without detriment to their own (Wood $\&$ Gray, 1991). Colloquially, the mutuality dimension calls for a collaboration to ensure that its participants are able to secure a win-win situation for the particular entity that they represent. 
The final dimension within the black box of collaboration framework entails the process of establishing the norms of reciprocity and trust. The reciprocity component of this dimension states that partners are more likely to be willing to participate in collaboration if other partners demonstrate the same level of commitment. Ensuring that all partners have an equitable stake in a partnership eases apprehensions that some partners may be hold. Closely related to reciprocity is the level of trust that partners have in one another. The authors suggest that increased levels of trust among partners to act with honesty and integrity may help to mitigate the complexity that is inherent in collaborations. The authors also suggest that by focusing on antecedent conditions of collaborations instead of focusing on the preceding processual dimensions means that researchers are missing an important piece of the puzzle (Thomson \& Perry, 2006). By focusing on these systematic processes contained within collaborative efforts, the authors hope that future researchers might further this field of study.

\section{Collaborative Governance Regime}

The collaborative governance regime (CGR) framework of Emerson, Nabatchi and Balogh (2012) is interdisciplinary in nature, drawing from the fields of organization theory, public administration as well as planning and environmental management studies. The term regime is used to "encompass the particular mode of, or system for, public decision making in which cross-boundary collaboration represents the prevailing pattern of activity" (Emerson et al., 2012, p. 3) The greatest attention however is reserved for the collaborative dynamics of CGR, which fall within the processual dimensions theme of cross-sector collaborations. These dynamics are principled engagement, shared motivation and a capacity for joint action. In CGR, principled engagement is highly interactive requiring partners to engage in processes of discovering shared interests, 
deliberating upon and defining objectives of the CGR and lastly determining what the initial agenda for the partnership will be (Emerson et al., 2012). In addition to the process of engagement, the authors note that shared motivation amongst partners is of equal import. In CGR, shared motivation begins by developing mutual trust between partners. Mutual trust is not typically present at the beginning of partnerships but proves to be essential in building rapport within the CGR by partners proving to one another that they are reasonable and dependable. Establishing trust helps to strengthen mutual understanding between partners, the second component of shared motivation.

Establishing baselines of trust and understanding among partners ultimately builds the partnership's legitimacy and shared commitment of partners to the CGR's success. The final component of CGR's collaborative dynamics is determining the partnership's capacity for joint action. This capacity can be enhanced through the facilitation of procedural and institutional arrangements. The authors note that these arrangements must be defined at both the intraorganizational (partners' internal CGR management) as well as the interorganizational (how partners share decision making authority) levels (Emerson et al., 2012). These agreements directly inform the leadership considerations of CGR. It is imperative for a CGR to establish a method of governance in order to ultimately take advantage of the benefits of collaboration, most notably shared knowledge and the leveraging of resources.

\section{Communicative Framework of Value in Cross-Sector Partnerships}

The main purpose of the framework developed by Koschmann, Kuhn and Pfarrer (2012) is to address one of the key challenges of cross-sector collaborations; the communication of their value. As previously mentioned, one of the main drivers for collaborative efforts is that the value produced in such partnerships cannot be created by 
single sectors alone. The authors argue that communication is not just used for the transmission of information. Rooted in communication theory, this framework suggests that communication not only increases the potential value of cross-sector partnerships, but also provides a method of assessing the value of cross-sector partnerships.

Koschmann et al. identify two specific communicative practices that can aid in assessing the value of cross-sector partnerships. The first practice calls for the examination of external intertextual influence. A cross-sector partnership is more likely to be assessed as valuable if its authoritative texts are able to influence public perceptions of relevant issues. This external influence may also be seen as being valuable to the extent that it influences the authoritative texts, policies and practices of both internal and external stakeholders (Koschmann et al., 2012). The second communicative practice to assess the value of cross-sector partnerships deals examines how such collaborations are able to justify their own existence through the creation of capital. Cross-sector collaborations that are able to engage individuals in the idea of creating positive narratives around the value of such partnerships are ultimately deemed more successful and thereby more valuable. Of all the examined frameworks, that of Koschmann et al. is unique in both its reliance on communication theory and its focus on articulating the public value of cross-sector partnerships. The framework however is cumbersome in that the only way to observe the entire partnership is through the lens of authoritative texts. This may prove difficult to operationalize, particularly in the current study. To capture the principles contained within the creation and communication of cross-sector partnership narratives, the authors point to the role that sensemaking plays in these processes which may prove to be a more appropriate vehicle for understanding the public value of these partnerships. 


\section{Sensemaking}

Sensemaking refers to those processes of interpretation and meaning production whereby people interpret phenomenon and produce intersubjective accounts (A. D. Brown \& Humphreys, 2003). That is to say that sensemaking is not simply about understanding an event or phenomena, but it is the operationalizing of those feelings into tangible actions and responses. The process of creating the governance structure of the CARDS initiative has primarily been driven by the CARDS Executive Committee. The policies and procedures developed at the executive level, however, are ultimately executed by the youth development agencies that comprise the CARDS Coordinating Council. The CARDS Executive Committee and Coordinating Council meet together monthly to share updates regarding both the governance and programmatic activities of each group. As the concept of creating a coordinated system of out-of-school time

providers has taken many forms over the past decade, questions still arise as to how youth development agencies make sense of the CARDS initiative and its overall benefit to their respective organizations. In this study, sensemaking is an appropriate lens by which to understand partner organizations' responses to CARDS, as they must not only interpret the activities of the initiative, but they ultimately must weave said activities into the daily practices of their organization.

Weick (1995) proposed a framework consisting of seven propositions by which he explained the processes by which individuals and organizations make sense of their environments. The first tenet of sensemaking has to do with identity. The views of individuals and organizations do not exist in vacuum, but instead are shaped by an array of experiences that inform how various situations are interpreted. A second characteristic of sensemaking is retrospective in nature. Retrospection posits that present events are 
compared to prior events in order to make sense. Extraction of cues, another tenet of sensemaking, requires an actor to focus on what they feel are the most important elements of an event. As sensemaking is retrospective in nature, the process of extracting cues is often informed by prior experiences. This extraction of clues will lead an actor to determine whether or not an event is plausible. The emphasis on plausibility over accuracy in sensemaking may lead to a variety of interpretations of events dependent on the interpretation of individual actors. Complicating the concept of plausibility is that sensemaking is social in nature. Individuals within an organization may share interpretations with one another, even as the interpretations of the same event may vary. Just as sense making contains a social aspect, it also enactive of the environment. The narratives built around an event force actors to develop a socially constructed reality in order to further make sense of an event. The final characteristic states that sense making is an ongoing activity. While a singular event may spur the sensemaking process, Weick suggests that "the basic idea of sensemaking is that reality is an ongoing accomplishment that emerges from efforts to create order and make retrospective sense of what occurs (Weick, 1993). Weick operationalized sensemaking in his analysis of the Mann Gulch fire. The Mann Gulch fire of 1949 was a large wildfire in Montana in which thirteen firefighters ultimately lost their lives. This incident was pivotal in that the United States Forest Service developed new safety measures and training to address the suppression of wildfires in the future. In examining the incident, Weick determined that because firefighters on the ground were dealing with a new phenomenon, namely a raging wildfire the likes of which they had not seen before, they were not able to make sense of the event. Therefore, a breakdown in sensemaking ability in a vulnerable situation contributed to the loss of life in a major disaster. 
Sensemaking has been utilized in the both the fields of education as well as community partnerships as a way to understand the mechanisms of building trust and the challenges inherent in school and organizational governance (Adobor, 2005; Ang, Killen, \& Sankaran, 2015; Golob, Johansen, Nielsen, \& Podnar, 2014; Termeer, 2009) . In community partnerships, Fawcett, Boothroyd, Schultz, Francisco, Carson and Bremby (2003) utilized sensemaking to examine a community's efforts in building a participatory evaluation system for community initiatives. Some of the challenges that led to this research were attempting to understand problems and goals, developing appropriate research questions and methods, and establishing metrics to determine whether various initiatives were successful. The authors noted several challenges in establishing the system of participatory evaluation. First, some participants lacked the necessary knowledge or skills to effectively document and interpret findings. Next there was a large commitment of time and effort that not all participants were able to commit to. Additionally, communication gaps coupled with other past experiences diminished the trust that community members had with researchers. Despite these and other challenges however, Fawcett et al. found that a participatory paradigm was beneficial overall. The authors state that having a contextualized understanding of communities and initiatives better informs researchers as they attempt to make meaning of the hard data points which they received.

Warren (2005) sought to investigate the processes and methods used to build collaborations between schools and community organizations by identifying three models; the service model, the development model and the organizing model. The author notes that the creation of such typologies can lead to the reduction of the disconnection between educational organizations and the community organizations that surround them 
by helping all stakeholders to make sense of their roles in achieving comprehensive school and community reform.

In education, sensemaking has been used by researchers to understand how various actors operationalize external mandates and accountabilities. Koyama (2014) analyzed the role of principals in negotiating accountability measures introuduced by school districts by virtue of the No Child Left Behind (NCLB) legislation. Koyama conducted an ethnography using a sample of 45 principals in New York City. Findings indicate that principals made decisions to selectively implement NCLB measures within their schools. They made these decisions even at the risk of being out of compliance and facing disciplinary action up to and including the loss of their jobs. Koyama surmised that principals used sensemaking to inform their actions and roles as informal policymakers within their school contexts.

While Koyama found sensemaking to be an output of her research, Louis and Robinson (2012) utilized sensemaking as a theoretical lens. The authors frame their research by examining the theoretical concepts of sensemaking, crafting coherence, and instructional leadership. The authors utilized a random sampling of existing teacher and principal surveys conducted in nine states, 45 districts within these states, and about 175 schools within the chosen districts. The findings showed external accountability policies had a positive impact in cases where principals found congruency between their own personal beliefs, district supports, and the policies themselves. In cases of positive impact, school leaders shaped policies to fit the particular needs of their own schools. Conversely, in instances where one or more of these factors was missing, principals demonstrated more negative attitudes toward both external policies and instructional 
leadership. Louis and Robinson's findings point toward the efficacy of principals in relation to their sensemaking and instructional leadership abilities.

\section{Summary of Literature Review Findings}

The research presented in the review of literature points to a strong relationship between local communities and the positive development of youth. The literature also shows that relationships between adults and youth happen not only in the confines of school buildings, but quite often occur within youth development organizations that are located in surrounding communities. As partnerships between youth development organizations and schools are developed on many different levels and may often be distally located from one another, the literature indicates that the intentionality of crosssector partnerships may have an impact on the effectiveness of any proposed partnership and organizational relationships. Finally, after other structural features of a partnership are accounted for, there still remains the need for all actors within a partnership understand their roles. Acknowledging the role sensemaking plays in developing partnerships may play a key role in ensuring all parties of their role in an initiative's ultimate success. The next chapter will provide detailed information regarding the methods by which I seek to explore these topics. 


\section{CHAPTER III}

\section{METHODOLOGY}

The purpose of this qualitative research study was to explore the conditions that led to the development of the CARDS partnership. To guide this exploration I sought to answer three research questions: Why did CARDS choose the multi-organizational partnership model as the coordinating structure for the initiative? How does cross-sector collaboration theory explain the perceived benefits and/or challenges of the CARDS multi-organizational partnership model? Finally, how do out-of-school time partner organizations make sense of the various components of the CARDS initiative? In this chapter, the methodological features of my study will be discussed including the rationale for the selection of a qualitative research design; more specifically a case study, employing a multiple-case embedded design. This will be followed by discussion of my study's context, sampling strategy, data collection, and data analysis. I justified the delimitations that were made and acknowledged the limitations of my study. Also discussed are the processes for ensuring data verification; specifically the assessment of credibility, transferability, dependability, and confirmability. Given that the means of reporting findings varies from study to study, this chapter will also foreshadow how the findings will be reported in Chapter IV. Furthermore, this chapter includes discussions of the ethical considerations of my study and the steps by which the rights and wishes of the informants were be protected. A feature of qualitative research is that the researcher is an actual instrument of data collection. As such, this necessitates a discussion of how the my positionality was be explored, thus acknowledging any potential biases. Finally, the chapter closes with a summary. 


\section{Research Design}

To conduct this study, I utilized a qualitative research methodological approach. The methodology I chose was a case study, employing a multiple-case embedded design. In a multiple case study, several cases are used to illustrate a particular issue (Creswell, 2012). The goal of using multiple cases is to further strengthen any findings that may arise from the research. Using a multiple-case design is also beneficial in that it adds to the construct validity of this research (Yin, 2009). Yin and Davis (2007) note that utilizing a case study to conduct this research is appropriate, as the goal is to understand a real-life phenomenon in depth, while highlighting important and highly pertinent contextual conditions that exist. The context of this research is the community-wide effort to create a system by which to coordinate the out-of-school time programs and activities of youth development agencies. The phenomena being examined are the decision-making process of past and current CARDS executive leadership as well as experiences of youth development agencies as they attempt make sense of this initiative while becoming active participants. In this research study, the larger case being examined is that of the CARDS initiative. Within this larger case are smaller embedded cases which serve to provide greater insight into the workings of the larger initiative.

Bengtsson (1999) notes that an embedded case study draws conclusions about a particular phenomenon by investigating the sub-units of the study's object. To achieve this goal conclusions from one case should be compared and contrasted with the results from other cases. Due to the sampling strategy of the present study which will be discussed in the next section, an embedded case study design presents the opportunity to more deeply explore how sub-units inform the larger case (Gustafsson, 2017). Baxter and Jack go further in explaining the opportunities present in an embedded design: 
The ability to look at sub-units that are situated within a larger case is powerful when you consider that data can be analyzed within the subunits separately (within case analysis), between the different subunits (between case analysis), or across all of the subunits (cross-case analysis). The ability to engage in such rich analysis only serves to better illuminate the case. (Baxter \& Jack, 2008, p. 550)

For this study then, it was determined that a multiple-case embedded design provides the greatest opportunity to weave strands of perspectives into a cogent tapestry.

\section{Sampling}

The primary unit of analysis for this qualitative study was the CARDS initiative. Within this overarching unit, I identified three embedded cases (Table 4) to conduct my study: CARDS Executive Committee members who were at one time affiliated with CARDS but are no longer involved in the day to day operations of the initiative; CARDS Executive Committee members who are both currently affiliated with CARDS and involved in the day to day operations of the initiative; and youth development providers who serve as partner organization in the CARDS initiative. Each of these embedded cases played distinctive roles in the formation of CARDS and may be able to provide unique perspectives to inform my study's research questions. 


\section{Table 4}

$\underline{\text { Composition of embedded cases within current study }}$

\begin{tabular}{|c|c|c|}
\hline $\begin{array}{c}\text { Embedded Case \#1 } \\
\text { Previous CARDS } \\
\text { Executive Committee } \\
\text { Members } \\
\end{array}$ & $\begin{array}{c}\text { Embedded Case \#2 } \\
\text { Current CARDS Executive } \\
\text { Committee Members }\end{array}$ & $\begin{array}{c}\text { Embedded Case \#3 } \\
\text { CARDS Partner } \\
\text { Organizations }\end{array}$ \\
\hline CPS Representative & CPS Representative & $\begin{array}{l}\text { CARDS Partner } \\
\text { Organization } \\
\text { Large \& Old }\end{array}$ \\
\hline PTGC Representative & PTGC Representative & $\begin{array}{l}\text { CARDS Partner } \\
\text { Organization } \\
\text { Large \& New }\end{array}$ \\
\hline CMG Representative & CMG Representative & $\begin{array}{l}\text { CARDS Partner } \\
\text { Organization } \\
\text { Small \& Old }\end{array}$ \\
\hline $\begin{array}{l}\text { Partnership for Children } \\
\text { Representative }\end{array}$ & $\begin{array}{l}\text { Partnership for Children } \\
\text { Representative }\end{array}$ & $\begin{array}{l}\text { CARDS Partner } \\
\text { Organization } \\
\text { Small \& New }\end{array}$ \\
\hline
\end{tabular}

To identify informants within the first two embedded cases of this study, I used a purposive sample technique. Ishak and Bakar (2014) note that purposive sampling in case study research is appropriate in three situations: To select unique cases that are particularly informative, to reach select members of a specialized population that is difficult to reach or to identify particular types of cases for more in-depth study. The ability to choose informative cases as well as particular types of cases was of particular benefit in this case study. As qualitative study is not concerned with the generalizability of a randomized sample, this sampling technique allowed for the selection of multiple cases to add to the richness of the data. To identify focus group participants within the third embedded case, I utilized critical case sampling. Critical case sampling is 
appropriate for this study as its use will provide key insight into how various types of organizations who are affiliated with the CARDS initiative (i.e. size of organization, length of engagement) may respond to the questions posed (Patton, 1990). To assist in determining appropriate agencies for participation in focus group, I relied on document analysis of the CARDS partner organization roster.

\section{Data Collection}

To conduct this research, I utilized multiple sources of data. The use of multiple data sources provides a means of triangulation (which will be discussed in greater detail later in this chapter). Data collection strategies will include semi-structured interviews, focus groups and documents.

\section{$\underline{\text { Semi-Structured Interviews }}$}

Semi-structured interviews were conducted with current and past members of the CARDS executive committee who comprise the first two embedded cases of the proposed study. The purpose of these interviews with CARDS executive team members was to explore the decision making processes which led to the CARDS initiative in Cabot to choose a partnership governance model. Past executive team members were able to provide perspective on any perceived challenges or benefits of the partnership model in CARDS' past, while current CARDS executive team members provided real-time feedback on how the partnership model is working. Each interview question was directly linked to one or more of the research questions. Additionally, each interview question was directly linked to one or more of the propositions posited by Bryson et al.'s (2015) cross-sector collaboration theoretical framework (Table 5). Interviews were recorded and transcribed verbatim, and the resulting data was analyzed. All interviews lasted approximately one hour each and were captured using a digital voice recorder. 
Participants were sent a recruitment letter via e-mail (Appendix B) to gauge their interest in taking part in this research study. To accommodate the schedule of participants, I allowed those being recruited to select a date, time and location that was most convenient for them. Upon agreement of participation, a consent form (Appendix A) was sent to the participant a minimum of 48 hours prior to the interview for their review. During this 48 hour period of time, the participant had the opportunity to ask any questions about the form. On the day of the interview, I once again reviewed the consent form with the participant and asked if they had any questions. If there were no further questions, I had the participant sign the consent form which was stored in the case study database. The participant was also sent a copy of the signed consent form for their own personal files.

Focus Group Interviews

To procure data from selected out-of-school time providers, I conducted focus groups with the leadership team from each selected organization that have been responsible for the implementation of the CARDS initiative. 
Table 5

Cross-sector collaboration propositions with associated interview protocol questions

Associated

Interview

Cross-Sector Collaboration Proposition

Question

\section{Address Initial Conditions}

Proposition 1: Similar to all interorganizational relationships, cross-sector collaborations are more likely to form in turbulent environments. In particular, the formation and sustainability of cross-sector collaborations will be affected by driving and constraining forces in their competitive and institutional environments, including political forces and the availability of relevant technology.

Proposition 2: Public policy makers are most likely to try cross-sector collaboration if they believe that separate efforts by several sectors to address a public problem have failed, or are likely to fail, and the actual failures cannot be fixed by a separate sector alone, or, less dramatically, that no sector can address the presenting problem effectively on its own.

Proposition 3: Cross-sector collaborations are more likely to succeed when one or more linking mechanisms - such as powerful leaders and sponsors; general agreement on the problem; existing networks; neutral conveners; requests for proposals, plans, projects or technologies requiring collaboration; and consequential incentives favoring collaboration-are in place at the time of their initial formation.

Proposition 4: The form and content of a collaboration's initial agreements, as well as the processes used to formulate them, will affect the outcomes of the collaboration's work. A sequence of increasingly operational agreements involving key decision makers, a certain degree of flexibility, and re-negotiability are likely to be important elements of the agreement process.

Proposition 5: Cross-sector collaborations are more likely to succeed if they have committed, able sponsors and effective, persistent champions at many levels who provide formal and informal leadership. Proposition 6: Cross-sector collaborations are more likely to succeed if they establish with both internal and external stakeholders the legitimacy of collaboration as a necessary form of organizing, as a separate entity, and as a source of trusted interaction among members.

Proposition 7: Cross-sector collaborations are more likely to succeed if a continuing virtuous circle of trust-building activities (including nurturing of cross-sectoral and cross-cultural understanding) can be established and maintained. 
Proposition 8: Because conflict is common in partnerships, cross-sector collaborations are more likely to succeed if partners use resources and tactics to help equalize power and manage conflict, particularly in the early phases of planning and organizing the work to be done.

Proposition 9: Cross-sector collaborations are more likely to succeed if they use a combination of deliberate and emergent planning, with deliberate planning emphasized more in mandated collaborations and emergent planning emphasized more in non-mandated collaborations. At some point, however, emergent planning needs to be followed by formalization; too much emergent planning can undermine collaboration success.

Proposition 10: Cross-sector collaborations are more likely to succeed if their planning makes use of stakeholder analyses, emphasizes responsiveness to key stakeholders, uses the process to build trust and the capacity to manage conflict, and builds on the competencies and distinctive competencies of the collaborators.

Proposition 11: Inclusive processes are needed to produce inclusive structures that, in turn, foster inclusive practices. Both inclusive processes and structures facilitate effective collaboration.

\section{Create Effective Structural and Governance Arrangements}

Proposition 13: Collaborative structure is influenced by environmental factors, such as system stability and the collaboration's strategic purpose; structures must be able to handle changes in the environment and strategic purpose.

Proposition 14: Collaborative structure is also likely to change over time due to ambiguity of membership and complexity in local environments.

Proposition 15: Collaboration structure and the nature of the tasks to be performed at various levels, including the client or street level, are likely to influence a collaboration's overall effectiveness; a measure of structural ambidexterity is likely to be necessary to manage the array of tasks.

Proposition 16: Governing arrangements, including those that operate at both informal and formal levels, must be able to respond effectively to strategic, operational, and mixed issues and the extent to which they do is likely to influence collaboration effectiveness. This responsiveness is needed in part to decide who gets to decide and to be able to manage spatial and temporal ambidexterity.

\section{Manage Contingencies and Constraints Affecting Process and Structure}

Proposition 17: Collaborations that are prepared to take advantage of a window of opportunity are far more likely to succeed than those that are not. 
Proposition 18: In order to be effective, collaborations must manage the many roles of technology as a facilitator of collaboration and as a nonhuman actor capable of providing solutions, affecting policies and politics, altering public perceptions, and, stimulating internal organizational changes.

Proposition 12: Collaborations involving system-level planning activities are likely to involve the most negotiation, followed by collaborations focused on administrative level partnerships, followed by service delivery partnerships.

Proposition 19: Needed competencies must be available or developed or cross-sector collaboration goals will not be achieved.

Proposition 20: Cross-sector collaborations are more likely to succeed if the collaborations build in resources and tactics for dealing with power imbalances and shocks. Shocks need to be expected and can be positive, for example, a window of opportunity.

Proposition 21: Competing institutional logics are likely within cross-sector collaborations and may significantly influence the extent to which collaborations can agree on essential elements of process and structure as well as outcomes. Competing logics must be managed effectively.

\section{Manage Outcomes and Accountabilities}

Proposition 22: Cross-sector collaborations are most likely to create public value if they build on individuals' and organizations' self-interests along each sector's characteristic strengths, while finding ways to minimize, overcome, or compensate for each sector's characteristic weaknesses.

Proposition 23: Cross-sector collaborations are most likely to create public value if they produce positive first-, second-, and third-order effects far in excess of negative effects.

Proposition 24: Cross-sector collaborations are most likely to create public value if they are long-lived, resilient, and engage in regular reassessments.

Proposition 25: Cross-sector collaborations are more likely to be successful if they have an accountability system in place that tracks inputs, processes, and outcomes; use a variety of methods for gathering, interpreting, and using data; and have in place a results management system built on strong relationships with key political and professional constituencies.

Proposition 26: The normal expectation ought to be that success will be very difficult to achieve in crosssector collaborations. 
The purpose of these focus groups was to understand how out-of-school time providers understand both the overall workings and the articulated benefits of their participation in the CARDS initiative. As Lambart and Loiselle (2008) note:

[t]he primary goal of this method is to use interaction data resulting from discussion among participants (e.g. questioning one another, commenting on each others' experiences) to increase the depth of the inquiry and unveil aspects of the phenomenon assumed to be otherwise less accessible. Group interactions may accentuate members' similarities and differences and give rich information about the range of perspectives and experiences. (p. 229)

Depending on the size of the partner organization, the composition and number

the leadership team members responsible for the facilitation of the various components of CARDS relationship may vary widely. By using focus groups, I was able to fully capture the understanding of CARDS from all applicable stakeholders at a given organization.

\section{Document Analysis}

I also reviewed documents including data reports, meeting minutes, grant proposals and other documents utilized in strategic planning or training modules. These documents served not only to support statements and themes found in individual interviews and focus group data, but also served as primary resources to provide important information about the history, process and overall context of the CARDS initiative that may not be found in other collected data.

\section{Data Analysis}

Interviews with executive committee participants were audio recorded and transcribed verbatim using the Rev voice recording and transcription service. The service allows the researcher to record interviews and then immediately provide them to Rev 
transcribers, who will provide a transcript of the conversation within 24-48 hours. After receiving transcribed documents, I listened to and compared voice recordings of individual interviews and focus groups to the transcript documents in order to ensure accuracy. To code interview and focus group transcripts, NVivo qualitative analysis software was used to facilitate the coding of interview and focus group transcripts. I used a two-pronged approach in coding individual interviews. I first utilized deductive coding to identify statements from informants that discretely align with one of the propositions of the cross-sector collaboration theoretical framework. Codes utilized in the deductive coding analysis (Table 5) were derived from the propositions specified within the Bryson et al. (2015) cross-sector collaboration theoretical framework. I subsequently coded each individual interview a second time utilizing an inductive coding approach. With the inductive coding approach, I assigned codes to significant statements found within transcripts and that assisted in the development of emerging themes. The purpose of using a secondary coding strategy was to determine if themes do in fact emerge that may either bolster or challenge the propositions laid forth in the cross-sector collaboration theoretical framework. Interviews with the executive committee were used to inform my study's first two research questions which seek to understand the reasons behind choosing the network partnership governance model and to identify the degree to which cross-sector collaboration theory explains any perceived benefits or challenges of said model.

To analyze focus group data, I employed Yin’s (2009) explanation building technique. Explanation building is a special type of pattern matching, where the goal is to analyze the data by building an explanation about the case. An iterative process, this analysis calls for the continuous comparison of data in order to develop a general 
explanation that can be applied to the overarching case(s) being studied. One of the cautions regarding case study data analysis is that data may be treated independently rather than as part of the entire case. To address this concern, special attention was given to ensuring that the analysis or inclusion of data outside of the scope of the research questions did not occur (Baxter \& Jack, 2008).

\section{Presentation of Findings}

To report the findings of the case study, I use Yin's (2009) multiple case study reporting format. In this format, I provide abbreviated narratives of each embedded case presented in separate sections followed by an additional section which provide analysis and findings. For the purposes of this study, Chapter IV provides narrative descriptions of each of the three aforementioned embedded cases, namely Executive Committee members who were present during the formation of the CARDS initiative, Executive Committee members who currently work on the CARDS initiative, and youth development organizations who are partners in the CARDS initiative. For example, the first embedded case will provide a narrative description of both the precursors to the formation of the CARDS initiative and also the initial circumstances surrounding its establishment. The richness of this narrative description is buttressed by the varying perspectives of the individuals who will ideally view this topic from the respective CPS, PTGC, CMG and Partnership for Children points of view. 


\section{Table 6}

Deductive codes related to cross-sector collaboration theoretical framework

Dimensions of Cross-Sector Collaboration

Address Initial Conditions

Design Effective Processes

Create Effective Structural and

Governance Arrangements

Manage Contingencies and Constraints Affecting Process and Structure

Manage Outcomes and Accountabilities
Associated Codes

Context of Collaboration, Public Failure, Linking Mechanisms

Collaborative Agreements, Sponsors and Champions, Internal and External Stakeholders, Trust, Conflict, Collaborative Planning Processes, Collaborative Planning Processes with Stakeholders, Inclusive Processes

Collaborative Structures influence by environmental factors, Collaborative structures influenced by ambiguity and complexity, Collaborative Structures influence on success, Formal/Informal Governance

Windows of opportunity, technology, systems level planning activities, administrative level planning activities, service delivery level planning activities, needed competencies, power imbalances and shocks, institutional logics

Organizational partner interests, firstorder effects, second-order effects, thirdorder effects, resiliency, accountability

Though each embedded case was informed by several individual interviews or focus groups, these individual cases will primarily serve as the evidentiary base for the larger case with the aim of answering the identified research questions (Yin, 2009).

\section{Limitations and Delimitations of Study}

The proposed qualitative study is based on interviews with both internal and external stakeholders of the CARDS initiative. While the work of developing the 
initiative has taken place over a number of years, most recently I have served as one of the school district's liaisons on the CARDS leadership team for the past 18 months. In this role I have developed a certain level of familiarity as well as cordial professional relationships with the individuals who ultimately provided key perspectives to inform this study. As I embarked on this study, it was of great import to explicitly articulate my position as "researcher" and not "colleague" to those individuals in settings where research was being conducted.

Another potential limitation inherent in case study methodology is the need for the researcher to select a case that is neither too broad (e.g., the state of cross-sector collaborations around the United States) nor too narrow (e.g., the procedures of developing a memorandum of understanding) in focus for a given study (Creswell, 2012). The justification for the selection of the CARDS initiative as the bound case for this study is further elucidated in Chapter III of this dissertation. Conducting a case study of a cross-sector collaboration that is situated within the larger context of a nationwide initiative offers the potential to explore multiple lines of inquiry. For example, questions may have arisen as to how the antecedent conditions, processual dimensions and public value of other cross-sector collaborations vary in other communities, these questions cannot be answered within the scope of the current study. While in the end document analysis may lend itself to comparing the unit of analysis to other community contexts, this study will be delimited accordingly. The current study focuses solely on answering the proposed research questions as they relate to the CARDS initiative. Further investigation into cross-sector collaborations in other communities that are a part of this nationwide initiative may warrant further research in the future. 


\section{Researcher Positionality}

Milner (2007) provides a methodological framework by which researchers can examine their own positionality. The framework is comprised of four components; researching the self, researching the self in relation to others, engaged reflection and representation and shifting from self to system. Researching the self requires researchers to critically examine their own racial and cultural vantage points. Researching the self in relation to others challenges researchers to juxtapose the aforementioned vantage points with those of others. Engaged reflection and representation calls for researchers to think critically about interactions with others; acknowledging that a diversity of life experiences may inform the way various actors interpret a variety of situations. Finally, shifting from self to system requires researchers to ground from an examination of their own personal perspectives to focus how larger societal contexts. In Appendix F, I undertook the process of examining my own positionality as a researcher within the context of the current study.

Qualitative "Validity"

Not all qualitative researchers accept the applicability of validity commonly associated with quantitative research in the social sciences (e.g., Altheide \& Johnson, 1998). However, assessing the soundness of qualitative research methods and data is a worthwhile undertaking. In pursuit of this, Guba and Lincoln (1985) proposed four criteria for assessing the soundness and methodological rigor of qualitative research, offering alternatives to traditional quantitatively-oriented criteria of internal validity, external validity, reliability, and objectivity. Respectively, these are: credibility, transferability, dependability, and confirmability. Credibility 
Triangulation is an appropriate strategy by which to bolster the credibility of a study. Shenton (2004) states that "triangulation may involve the use of different methods, especially observation, focus groups and individual interviews" (p.65). Triangulation of data sources is inherent in the proposed multiple case study design. The three embedded cases will allow the continual comparison of viewpoints to elicit the most salient perspectives. To further establish credibility, I utilized member checking. After transcription, interview and focus group participants will be provided with electronic copies of their transcripts to ensure that information was communicated accurately.

\section{Transferability}

Transferability refers to the degree to which the results of qualitative research might be generalized to other contexts, populations or settings. Shenton (2004) notes that to inform the transferability of a study, the researcher should explicitly communicate descriptive information including but not limited to the number of participants taking part in a study, the location of the study, data collection methods that were employed and the time period over which the data were collected. Inherent within case study methodology is the need to specifically bound the case, in order to communicate the unit of analysis. Confirmability

Confirmability seeks to mitigate researcher bias to ensure that data collected are analyzed in a balanced fashion (Shenton, 2004). The use of triangulation again plays a key role in promoting confirmability, and ensuring that the perspectives of the researcher do not unduly shape the research to be conducted. 


\section{Dependability}

A key component in contributing to the dependability of my study will be the use of an electronic case study database that will be maintained throughout the duration of this research. The case study database will be comprised of any notes, narratives or documents that will be utilized during the analysis. This database not only will serve as a reference for other researchers to review evidence directly related to the case study findings, but will also increase the reliability of the case study itself (Yin, 2009).

\section{Summary of Methodology}

In the preceding chapter, I articulated the methods by which I conducted this qualitative study. I discussed in depth the rationale behind the decision to utilize a multiple case-embedded study design and how it informed the research questions that this study seeks to answer. I also discussed the techniques of both data collection and data analysis that were used to inform the findings that will be presented in Chapter IV. The use of the previously outlined methodological procedures ensures that the present study aligns with the criteria of trustworthiness (i.e. credibility, transferability, dependability and confirmability) that are set forth by the field of qualitative research. 


\section{CHAPTER IV}

\section{FINDINGS}

The current study sought to utilize the Cross-Sector Collaboration Theoretical Framework of Bryson et al. (2015) to conduct a qualitative multiple case embedded study of a community-wide partnership for school age youth named CARDS. Chapter IV presents the major findings of the current study. To understand the mechanisms of CARDS my study posed three research questions that asked why did CARDS choose the multi-organizational partnership model as the coordinating structure of its initiative, what are the ways that cross-sector collaboration theory explain the perceived benefits and/or challenges of the multi-organizational partnership model and lastly how do out-of-school time partner organizations make sense of the various components of the CARDS initiative.

\section{Organization of the Chapter}

In Chapter III, I indicated that I would utilize Yin's (2009) multiple case study reporting format. In this chapter, I will first provide abbreviated narratives of each of three embedded cases. The embedded cases are of CARDS Executive Committee members who were present during the formation of the initiative, CARDS Executive Committee members who are currently active with the CARDS initiative and lastly youth development organizations who participate in the CARDS initiative. As each case is comprised of several individuals and organizations, I will provide tables that identify demographic information as well as brief descriptions of the roles that they have played in the CARDS initiative. 
Next, I will provide analysis of the data collected while conducting this study. The research questions which guide the current study have been closely aligned with the Cross-Sector Collaboration Theoretical Framework. In interpreting this framework, three themes emerged from the framework and the propositions therein, namely; antecedent conditions, processual dimensions and perceived public value. Two rounds of coding were conducted on the data collected. The first round of deductive coding analysis that will be presented was used to identify statements from interviews, focus groups and document analysis that closely align to the propositions laid forth in the Cross-Sector Collaboration Theoretical framework. Though there are twenty-six propositions that comprise the cross-sector collaboration theoretical framework, I will only discuss the most pertinent thematic elements which arose from the data. The second round of inductive coding analysis which will be presented was used to present any themes that emerged from the data that either support or challenge the propositions of the CrossSector Collaboration Theoretical framework. To conclude the chapter, I will provide a summary of the findings presented, and once again align them to the research questions presented at the beginning of my study.

\section{Profiles of Case \#1 Informants}

Case \#1 was comprised of individuals who were at one time members of the CARDS Executive Committee, but are no longer involved in the day-to-day operations of the initiative. I initially sought to conduct semi-structured interviews with four individuals, each who would represent each respective founding partner of the CARDS initiative. Throughout the interview process however, several informants suggested additional individuals with whom I should speak with to offer perspective. In the end, a total of seven interviews were conducted which comprise the first case. Table 7 provides 
demographic information collected from each of the informants in Case \#1. Of note, $86 \%$ of informants identify their race as White, while $86 \%$ identify their gender as female. All informants earned at least a master's degree.

Table 7

Demographic Information of Case \#1 Informants

\begin{tabular}{|c|c|c|c|c|c|}
\hline & $\begin{array}{c}\text { Identified } \\
\text { Gender }\end{array}$ & $\begin{array}{l}\text { Identified } \\
\text { Race }\end{array}$ & $\begin{array}{l}\text { Educational } \\
\text { Attainment }\end{array}$ & $\begin{array}{c}\text { Organizational } \\
\text { Affiliation }\end{array}$ & $\begin{array}{c}\text { Number of } \\
\text { Years } \\
\text { Affiliated }\end{array}$ \\
\hline Lois & Female & White & $\begin{array}{l}\text { Master's } \\
\text { Degree }\end{array}$ & $\begin{array}{l}\text { Partnership for } \\
\text { Children }\end{array}$ & 5 \\
\hline Cheryl & Female & White & $\begin{array}{l}\text { Master's } \\
\text { Degree }\end{array}$ & $\mathrm{CMG}$ & 3 \\
\hline Joyce & Female & White & $\begin{array}{l}\text { Master's } \\
\text { Degree }\end{array}$ & $\mathrm{CMG}$ & 4 \\
\hline Suzanne & Female & $\begin{array}{l}\text { African- } \\
\text { American }\end{array}$ & Doctorate & CPS & 5 \\
\hline Ann & Female & White & $\begin{array}{l}\text { Master's } \\
\text { Degree }\end{array}$ & PTGC & 4 \\
\hline Warren & Male & White & $\begin{array}{l}\text { Master's } \\
\text { Degree }\end{array}$ & PTGC & 5 \\
\hline Ronald & Male & White & $\begin{array}{l}\text { Master's } \\
\text { Degree }\end{array}$ & $\mathrm{CMG}$ & 3 \\
\hline
\end{tabular}

\section{$\underline{\text { Lois }}$}

The interview with Lois was conducted on June 26, 2017. Lois is a White female who is a retiree from a large local human services agency. Lois played two roles in the formation of the CARDS initiative. First, she served as the co-chair of the committee that produced the YouthPrint document that informed the CARDS initiative strategy. Lois also served as the co-chair of the Partnership for Children, an organization which is considered a founding partner of the CARDS initiative and actively advocates for OST programs. 


\section{Cheryl}

The interview with Cheryl was conducted on July 10, 2017. Cheryl is a White female who is a retiree from Cabot Metro Government. Though she was not on my original list of potential interviewees, her name came up in several interviews as someone who could provide an additional perspective. Cheryl served as the grant writer for the original Wallace Foundation Grant that was submitted on behalf of the Cabot community. Joyce

The interview with Joyce was conducted on August 16, 2017. Joyce is a White female who currently serves as the Executive Director of The Cabot Grad Project, an organization that seeks to increase educational attainment in the Cabot community. Like Cheryl, Joyce was not an original interviewee, but was repeatedly mentioned as someone who could inform the present study. Joyce role in the formation of CARDS was as the chief advisor on education for CMG. During this time, the partnership discussions and responsibilities were generated from her office.

\section{$\underline{\text { Suzanne }}$}

The interview with Suzanne was conducted on June 30, 2017. Suzanne is an African-American female retiree from CPS. Suzanne formerly served on the CARDS Executive Committee as the representative from the local school district. During this time, she was responsible for assisting with volunteer recruitment and providing support to youth service organizations that had prior relationships with CPS in the transition to CARDS.

$\underline{\text { Ann }}$

The interview with Ann was conducted on June 30, 2017. Ann is a White female who was formerly employed by PTGC. Ann's role in the formation of CARDS was as 
the PTGC representative on the CARDS Executive Committee. Later, Ann became the project manager for the subsequent grant from the Wallace Foundation.

Warren

The interview with Warren was conducted on June 26, 2017. Warren is a White male who is currently employed by PTGC. Warren's role in the formation of CARDS was as one of the coordinators of the dropout prevention summit that served as the catalyst for the creation of the YouthPrint document.

\section{$\underline{\text { Ronald }}$}

The interview with Ronald was conducted on June 29, 2017. Ronald is a White male who currently serves as a program officer at a local foundation. Ronald's role during the formation of CARDS was as the chief educational advisor for the CMG mayoral administration once Joyce departed. In this role, Ronald helped to create the original charter document under which the CARDS initiative would be governed.

\section{Profiles of Case \#2 Informants}

Case \#2 of my study was comprised of individuals who currently serve on the CARDS Executive Committee. A total of four semi-structured interviews were conducted with individuals who represent each respective founding partner of the CARDS initiative. Table 8 provides demographic information collected from each of the informants in Case $\# 2$. Of note, all Case $\# 2$ informants identify their race as White, their gender as female and have obtained at least a master's degree. One informant earned their doctorate. 


\section{Table 8}

Demographic Information of Case \#2 Informants

\begin{tabular}{lccccc}
\hline & $\begin{array}{c}\text { Identified } \\
\text { Gender }\end{array}$ & $\begin{array}{c}\text { Identified } \\
\text { Race }\end{array}$ & $\begin{array}{c}\text { Educational } \\
\text { Attainment }\end{array}$ & $\begin{array}{c}\text { Organizational } \\
\text { Affiliation }\end{array}$ & $\begin{array}{c}\text { Number of } \\
\text { Years Affiliated }\end{array}$ \\
\cline { 2 - 6 } Lois & Female & White & Master's Degree & $\begin{array}{c}\text { Partnership for } \\
\text { Children }\end{array}$ & 5 \\
Candace & Female & White & Master's Degree & PTGC & 3 \\
Margie & Female & White & Doctorate & CPS & 1 \\
Tammy & Female & White & Master's Degree & CMG & 5 \\
\hline
\end{tabular}

$\underline{\text { Lois }}$

The interview of Lois was conducted on June 26, 2017. Lois is a white female who is a retiree from a large local human services agency. Lois is the same individual who served as the Partnership for Children representative in Case \#1. Though she played a role in the formation of CARDS, she still serves as the Partnership for Children's representative on the CARDS Executive Committee. I unsuccessfully attempted to procure another representative from the Partnership for Children. Lois however was and continues to be the organization's chief representative and advocate in the CARDS initiative.

\section{Candace}

The interview with Candace was conducted on June 26, 2017. Candace is a white female who is a current employee of PTGC. In her current role, Candace served as the project manager for the grant from the Wallace Foundation. Though the grant has since expired, Candace continues to serve as the project manager for the CARDS initiative, as her job entails the day-to-day responsibilities of maintaining the partnership. 


\section{$\underline{\text { Margie }}$}

The interview with Margie was conducted on June 22, 2017. Margie is a white female who is currently employed by CPS. In her current role, Margie assists the CARDS partnership in coordinating student level data contained within the CPS CASCADE database. Margie has been with the CARDS initiative for the shortest period of any informant interviewed.

\section{Tammy}

The interview with Tammy was conducted on June $29^{\text {th }}$, 2017. Tammy is a white female who is currently employed by CMG. The current CMG Executive Committee representative was not available to be interviewed. I was directed to Tammy as she has been affiliated with the CARDS initiative for many years. In her current role, Tammy coordinates the training opportunities for CARDS initiative affiliated youth service organizations. She also oversees the Youth Development Certificate that has been offered as a credential to employees of CARDS affiliated youth service organizations.

\section{Profiles of Case \#3 Focus Group Participants}

Case \#3 was comprised of four youth service organizations who currently participate in the CARDS initiative. A total of three focus groups were conducted with individuals at each organization who are directly responsible for implementing the CARDS programmatic requirements at their respective organizations. Initially the sampling strategy of the present study called for four focus groups to be conducted. I was however only able to identify three youth service non-profit organizations that fit specific criterion identified in the sampling strategy of the present study. Table 9 provides demographic information of each individual participant in the focus group. 
Subsequently I will provide a brief narrative of each participating organization including their relationship to CARDS and the present study.

\section{Table 9}

Demographic Information of Case \#3 Informants

\begin{tabular}{|c|c|c|c|c|c|}
\hline & $\begin{array}{l}\text { Identified } \\
\text { Gender }\end{array}$ & $\begin{array}{l}\text { Identified } \\
\text { Race }\end{array}$ & $\begin{array}{l}\text { Educational } \\
\text { Attainment }\end{array}$ & $\begin{array}{l}\text { Organizational } \\
\text { Affiliation }\end{array}$ & $\begin{array}{c}\text { Number of Years } \\
\text { Affiliated }\end{array}$ \\
\hline Corey & Male & White & Bachelor's Degree & HYPE & 1 \\
\hline Hazel & Female & Black & Bachelor's Degree & HYPE & 1 \\
\hline Eric & Male & Black & Some College & HYPE & 3 \\
\hline Kevin & Male & Black & Master's Degree & IFC & 4 \\
\hline Bianca & & & Bachelor's Degree & IFC & 2 \\
\hline Jamir & Male & White & Master's Degree & KID'S INC. & 2.5 \\
\hline Clyde & Male & White & Some College & KID'S INC. & 4 \\
\hline Rochelle & Female & White & Bachelor's Degree & KID'S INC. & 2.5 \\
\hline Andy & Male & White & Bachelor's Degree & YAGC & 4 \\
\hline Tracey & Female & White & Bachelor's Degree & YAGC & 4 \\
\hline Hannah & Female & White & Bachelor's Degree & YAGC & 3 \\
\hline Michelle & Female & Black & $\begin{array}{l}\text { High School } \\
\text { Diploma }\end{array}$ & YAGC & 2 \\
\hline
\end{tabular}

\section{$\underline{\text { HYPE }}$}

The focus group with HYPE took place on September 27, 2017. The focus group was conducted at the HYPE office building. The focus group was comprised of three individuals; Corey, Hazel and Eric. HYPE is a non-profit youth serving organization whose main programmatic offerings deal with music production and digital arts. HYPE has fewer than 60 youth participants on its roster, and has been affiliated with the CARDS initiative for just over a year. For the purposes of this study's sampling strategy, HYPE is considered a new, low-capacity organization.

Institute for Change 
The focus group interview with the Institute for Change (IFC) took place on September 27, 2017. The focus group was conducted at the IFC office building. The focus group was comprised of two individuals; Kevin and Bianca. IFC is an established non-profit organization with an over ninety-year history in the Cabot community. While youth services and education are a part of the organization's programmatic portfolio, it is not its sole focus. IFC also has departments who focus on other areas such as employment and housing assistance. IFC has fewer than 60 youth participants on its roster, and has been affiliated with the CARDS initiative for just over four years. For the purpose of this study's sampling strategy, IFC is considered an old, low-capacity organization.

\section{KID'S INC.}

The focus group interview with KID'S INC. took place on October 5, 2017. The focus group was comprised of 3 individuals; Jamir, Clyde and Rochelle. KID'S INC. is a youth service organization with an over 60 year history in the Cabot community. The programmatic focus of KID'S INC. is to provide youth with access to OST opportunities in their communities. KID'S INC. services over 3500 youth each year, and has been affiliated with the CARDS initiative for four years. For the purposes of this study's sampling strategy, KID'S INC. is considered an old, high-capacity organization.

\section{Youth Association of Greater Cabot}

The focus group with the Youth Association of Cabot (YAGC) took place on October 16, 2017. The focus group was comprised of 4 individuals; Andy, Tracey, Hannah and Michelle. With an over 160 year history, the YAGC is the largest youth service organization in the Cabot community. The programmatic focus of the YAGC is primarily as a health and wellness provider, but over the years has also included a youth 
development focus in its portfolio. For the purposes of this study's sampling strategy, the YAGC is considered an old, high-capacity organization.

\section{$\underline{\text { Antecedent Conditions }}$}

This study utilized the Cross-Sector Collaboration theoretical framework as a tool to understand the mechanisms which inform partnerships. The framework calls for the intentional identification of what this study recognizes as the antecedent conditions of cross-sector collaborations to clearly identify why partnership occurs at all (Bryson et al., 2006, 2015). The antecedent conditions and its stated propositions include but are not limited to understanding the environmental context around a collaborative effort, a general agreement on the problem of interest the partnership seeks to solve, as well as an examination of the historical relationships between partners, which may either positively or negatively affect the collaborative climate.

The YouthPrint report planted the seeds of collaborative youth development in the Cabot community, which then germinated into what is currently known as the CARDS partnership. However, the data collected from interviews, focus groups, and document analysis presents a different picture. Evidence suggests that YouthPrint was not the beginning of CARDS; rather it was just a step in its evolutionary process. The antecedent conditions that ultimately led to the CARDS partnership in its current form stretch much further into the past.

One of the antecedent conditions identified in the cross-sector collaboration framework is the identification of sector failure. Bryson et al. (2006) defines sector failure as the circumstance in which single efforts to solve a public problem by any one sector alone have failed. The authors elaborate by stating that "as a society, we rely on the differential strengths of the for-profit, public, and non-profit sectors to overcome the 
weaknesses or failures of the other sectors and to contribute to the creation of public value" (Bryson et al., 2006, p. 46). In the case of CARDS, the sector failure that framed the context for collaboration was educational attainment. As early as 2002 , leaders in the Cabot community were beginning to have substantive conversations around educational attainment, as they viewed the issue as having an impact on the entire city. As Cheryl recalled:

They said "We've got to do something about educational attainment in Cabot, because the community's losing out because our kids in public schools aren't doing well enough."

This recollection is corroborated by a 2002 report by The Brookings Institution Center on Urban and Metropolitan Policy titled, Beyond Merger: A Competitive Vision for the Regional City of Cabot. During that time, the city of Cabot and the surrounding County overnment had merged into what would come to be known as a Metropolitan Government. The report stated that Cabot "must strengthen educational attainment among students at all levels and apply unprecedented commitment to pulling up the lowest-achieving students" (Brookings Institution, 2002, p. 56). ${ }^{2}$

Shortly thereafter, Greater Cabot Inc. (GCI), the Chamber of Commerce for Metropolitan Cabot, formed a task force to explore educational attainment in Cabot Public Schools and to determine what part GCI could play in the process of raising achievement. In its 2003 report, Everyone Reads, GCI laid out a list of four recommendations for improving academic achievement; Accountability, Assessment, Professional Development and "All Students". Accountability called for an increase in the authority of the Superintendent in driving the goal of having every child reading at

\footnotetext{
${ }^{2}$ Citation is has been removed from bibliography to protect anonymity
} 
grade level. Assessment suggested that CPS should increase the frequency of evaluations to assess students' ability to read and write. The Professional Development goal called for tying professional development for teachers to the suggested reading goals. Finally, "All Students" states that these goals should be adopted for every student within CPS. Further, this goal indicates that additional resources should be targeted towards early childhood education and dropout prevention programs ${ }^{3}$. In the fourth recommendation's narrative, GCI notes that while CPS had made progress in reducing the number of dropouts over the past four years, it remained greater than the state average. To that end, GCI laid out a goal for the CPS Board of Education to reduce the CPS dropout rate to less than the rate for the rest of Kentucky over the next four years.

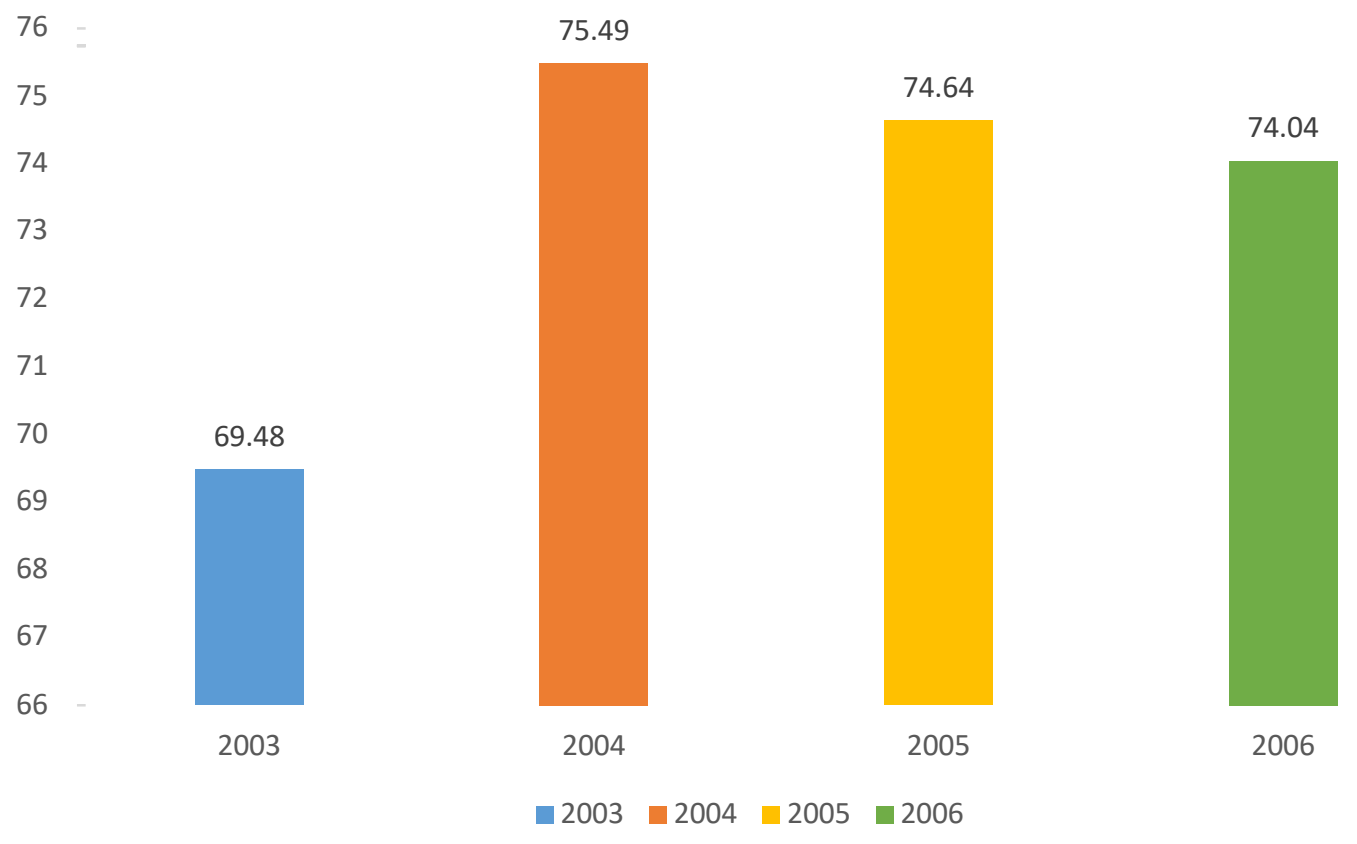

Figure 2: 2003-2006 CPS Graduation Rates

CPS data indicate (Figure 2) that in 2003 at the time of the GCI report, the CPS graduation rate was $69.48 \%$. Data suggest that a renewed community-wide focus had

\footnotetext{
${ }^{3}$ Citation is has been removed from text and bibliography to protect anonymity
} 
some impact, as CPS realized a a 6\% increase in graduation rates between 2003 and 2004. The graduation rate however decreased slightly over the next two years, with a reported rate of $74.04 \%$ in 2006.

\section{America's Promise Grad Nation Dropout Summit}

Between October 2007 and December 2010 the America's Promise Alliance, through its Grad Nation initiative, hosted 105 Dropout Prevention Summits across the country. In total, the summits attracted more than 33,000 participants including educators, business leaders, non-profit professionals, families and other policy makers. In a subsequent evaluation of the Dropout Prevention Summits conducted by Duke University's Center for Child and Family Policy it states that the summits were designed "as action forcing events to raise awareness and bring together cross sector coalitions for greater action in communities... They also led to the creation of new awareness efforts, follow-up activities and fundraising (Gifford \& Evans, 2011, p. 3)

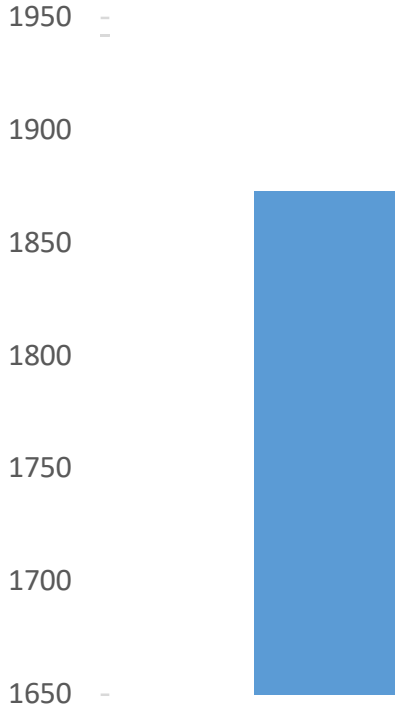

2004-05

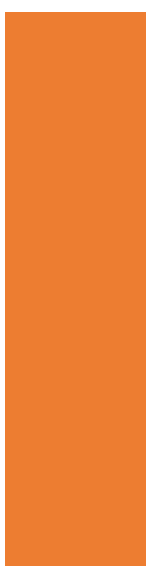

2005-06

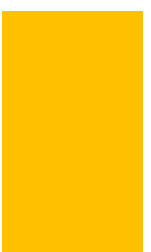

2006-07

[2004-05 -2005-06 - 2006-07

Figure 3: 2004-2007 CPS Number of Dropouts 
Cabot was chosen as one of the first communities to host a Dropout Prevention Summit in 2008. Figure 3 shows that despite a significant amount of attention given to the subject of educational attainment, there was still a sizable number of students who were dropping out-of-school before obtaining a high school diploma. In the evaluation, a number of qualitative and quantitative data points were collected to examine the effectiveness of the summits around the United States. Quotes from Cabot participants were featured several times in the evaluation with the most robust responses detailing the outcomes of Cabot's participation in the Dropout Prevention Summit. It states that:

Cabot was named an America's Promise Featured Community following the summit. Our partnership with AP has opened the doors to several other opportunities. Through the state, Cabot was a site for the Forum for Youth Investment's Quality Counts Initiative, and a Cabot Metro Office of Youth Development staff member also was a trainer for High Scope's Youth Quality Assessment (YQA) and Advancing Youth Development (AYD). Having worked with AP to put together a collaboration of technical assistance experts, the Forum for Youth Investment/Ready by 21 chose Cabot as one of six cities for its Southeast Challenge. FYI is working with us to assess our outstanding needs to create Youth Print, and will link us with much needed TA in areas of financial asset mapping, market research, and how to work with or form an intermediary organization. (Gifford \& Evans, 2011, p. 11)

This quote illuminates three key points related to the present study. The first is that the quote elucidates the groundswell of support that was previously discussed in Chapter I. Secondly, this quote also provides the first mention of the YouthPrint report, previously assumed was the foundation of the CARDS Partnership. Finally, the quote indicates that 
the Cabot collaborative would be exploring the concept of forming an intermediary organization. This final point is contradictory to not only the very existence of the CARDS partnership, but also to the perspectives of this study's informants, which will be discussed in the next section.

\section{YouthPrint}

Shortly after the 2008 Dropout Prevention Summit, Public Trust of Greater Cabot convened a meeting of actively engaged community stakeholders in 2009 to create a comprehensive plan for youth that would be called YouthPrint. Building upon outcomes of the Dropout Prevention Summit and the findings of a report produced for the summit titled, Youth Voice: In Their Own Words, the YouthPrint report found that "Too many young people... simply did not see the value of graduating from high school and did not think adults cared. And they lacked the kind of support they needed to help them make it through the rough times" (Collaborative, 2010) The final YouthPrint report identified its main goal was to create a comprehensive plan for an OST youth development system in Cabot. This goal hoped to achieve two outcomes; "Increased youth participation and expanded opportunities in OST programs that meet quality standards, and more youth who graduate from high school college-ready and enter college or postsecondary education" (Collaborative, 2010, p. 4).

It should be noted that the data indicate that the rallying cry or "sector failure" in the community up to this point had been educational attainment, and more specifically dropout prevention. There is a clear pivot in the content of the YouthPrint report that indicates that educational attainment was an end to be achieved through the means of OST youth development programs. This shift in focus may have been due to the creation of another organization whose sole focus was to address the "sector failure" of 
educational attainment in the Cabot community. In October 2010, shortly before the publication of the YouthPrint report, the public-private partnership called The Cabot Grad Project was formed. The goals of the Cabot Grad Project organization are to add 40,000 bachelor's degrees and 15,000 associate degrees to the Cabot community by 2020. Ronald recalls that:

Cabot Grad Project spun out of some of the mayor's roundtable work and what they call the Greater Cabot Education Commitment, which was a document that was created and signed by 20 some odd community leaders and the Cabot Grad Project was launched in, it was actually launched the month before YouthPrint was published.

The Cabot Grad Project website echoes this timeline, as it states that it was borne out of the May 2010 Greater Cabot Education Commitment, which identified five key objectives:

1. Create and support a college-going culture

2. Use the business community's unique points of leverage to accelerate attainment

3. Prepare students for success in college, career, citizenship and life

4. Make post-secondary education accessible and affordable

5. Increase educational persistence, performance and progress (Cabot Grad Project Degrees Website, 2017)

It is unclear what led to the fissure of priorities, but one informant in Case \#1 believes that YouthPrint and subsequently CARDS has lost its way. The informant states:

Then that all led to the Cabot Grad Project ...how do we, in 10 years, how do we increase the number of college degrees? This YouthPrint was part of that whole 
big system, and that's where, right now you've got CARDS. They act like they are the single only thing, I mean, that's what kind of bothers me, is whereas they're part of this huge, this big system, and it all really went back to educational attainment. It was, the focus right now is more on social emotional health, which is, I think, is happening because kids are having such trouble that it's not just the academics and the persistence that's keeping them from attaining, it's all the other things going on in their lives... (Cheryl)

As discussed in Chapter I, the YouthPrint report put forth eight recommendations to guide the creation of an out-of-school time system of youth development in Cabot. Each of these recommendations deserves some level of examination on its own, however, for the purposes of this study I will focus on the first recommendation; the creation of a decision-making body/intermediary. This intentional focus is guided by the first research question of my study, which seeks to understand why CARDS chose the multiorganizational partnership model as the coordinating structure for the initiative.

Interview data suggest that the idea of a stand-alone intermediary organization was not particularly appealing to those involved in the work on the ground. Data suggest several reasons why the idea of an intermediary organization never took hold in Cabot. One informant posits that there may have been organization fatigue:

I think part of it had to do with the hesitation of creating another standalone organization or entity... and so, it seemed to make sense to figure out how we could work together on delivering this and I'll be honest with you, I don't remember ever being in too many conversations where there was an extended debate about doing it any other way. (Ronald) 
Ann also suggests that the ambiguity of the intermediary structure may have led to hesitancy in creating one:

I think there was not clarity in that when it first started. For them to say, "Okay, let's form an intermediary," I don't think everybody was comfortable with that at that point. That's why the decision, I believe, was to, "Let's form this partnership and let's work through this together," because there were still a lot of unknowns as we were starting this up.

Suzanne also believed that a partnership climate is pervasive in the Cabot community: I don't know if it was the folks who were working together, or if it's just something innate about our community, but we valued one another. We valued the work that each other did, and we were willing to work together and it wasn't about who was in charge or who was on top. It was always about what's best for our young people. (Suzanne)

There is not clear consensus on exactly why in the early stages of this collaborative effort a partnership was chosen. However, the Dropout Prevention Summit and subsequent YouthPrint report was the moment when the approach to the public problem of increasing educational attainment in Cabot diverged; in one direction, there would be a keen focus on getting individuals into post-secondary education, in the other there was a focus on the social and emotional well-being of students before they left high school.

\section{National League of Cities Institute for Youth, Education and Families}

The preceding sections have indicated that the timeline of the antecedent conditions leading to the CARDS Partnership was incomplete. Through interviews and document analysis, I discovered that the timeline moving forward in the CARDS Partnership's history was incomplete as well. The Wallace Foundation's interest in out- 
of-school time is well documented. The dilemma in creating a clear timeline of events is how and when the Wallace Foundation came to know about the work already taking place in Cabot. The Wallace Foundation's Next-Generation funding opportunity was by invitation only, so the question remains as to how Cabot's efforts led to an invitation to apply for this grant. One informant suggests an answer:

Before we worked with Wallace...They asked [the] National League of Cities to start working with cities interested in developing these out-of-school time networks and kind of see where we were, so they did this whole profile on us and we worked with National League of Cities before that, to see who really was, instead of just getting a proposal in the mail, what they wanted was this readiness to participate. (Cheryl)

In 2010, the Wallace Foundation, in partnership with the National League of Cities Institute for Youth, Education and Families, produced a report entitled Strengthening Partnerships and Building Public Will for Out-of-School Time Programs. The Institute for Youth, Education and Families (YEF Institute) is a subsidiary of the National League of Cities (NLC) whose goal is to help city leaders around the country to act on behalf of youth and families within their communities (Strengthening, 2010). Shortly thereafter, the YEF Institute conducted a scan on behalf of the Wallace Foundation, to identify cities around the country who were already in the process of planning citywide OST systems. The document heavily references the YouthPrint report created in Cabot. Mirroring that document, the city scan states that:

Following approval of YouthPrint in December, the first step taken was creating a Coordinating Council. Comprised of representatives from Metro Government, Public Trust of Greater Cabot and Cabot Public Schools, the council will serve as 
a decision-making body/intermediary. Additionally, the council will create a

Community Advisory Coalition, including youth providers, to advise it. (National League of Cities, 2011, p.34)

Of note is how in both the YouthPrint and NLC YEF Institute documents, the notions of a stand-alone intermediary organization and what appears to be a collaborative partnership are used interchangeably. Valli et al. (2014b) note that the nomenclature regarding school-community partnerships is often an impediment. They find that stakeholders often utilize the exact same terminology, but mean vastly different things. The preceding events led to the city of Cabot, PTGC and CPS applying for the Wallace Foundation's second round of its Citywide OST Systems Building initiative. As to why CARDS chose the multi-organizational partnership model as the coordinating structure for the initiative, Appendix IV of the Wallace Grant Proposal, states:

The "intermediary question" was a sticking point throughout the YouthPrint planning process. The Forum for Youth Investment team - Cabot is one of five Southeast Challenge cities - recommended focusing on the work an intermediary needed to accomplish, rather that [sic] the formal structure. If partners could divide up the work to support key functions, the structure would work itself out. Cabot will need technical assistance and guidance in this area, but believes concentrating on the work - improving quality and increasing participation - will get us where we need to go in terms of the intermediary (Wallace Grant, 2011) Per the Wallace grant application, the decision of forming a multi-organizational partnership was a decision that turns out not to have been an intentional one; rather it was a means to an end. The data suggest that rather than stifling the creation of a citywide OST system based on what appeared to be semantics was not a reasonable outcome for 
the partners. The work of creating such a system would then be the key driver of this partnership moving forward. In that regard, the processual dimensions of the CrossSector Collaboration Framework (namely collaborative processes, leadership, governance and collaboration structures) would be of great import, and will be examined in the following section.

\section{$\underline{\text { Processual Dimensions }}$}

The previous section described in detail what the cross-sector collaboration theoretical framework recognizes as the antecedent conditions of collaboration. In the case of the CARDS Partnership, the roots of the collaboration stemmed from an agreement that the problem of educational attainment in the Cabot community was a task that no single sector could solve on its own. In this portion of Chapter IV, I will explorethe processual dimensions of collaboration, focusing on three areas of the framework's processual dimensions: the design of effective processes, the creation of effective structural and governance arrangements and the management of contingencies and constraints affecting process and structure. In so doing, I seek to answer the second research question of my study: how does cross-sector collaboration theory explain the perceived benefits and/or challenges of the CARDS multi-organizational partnership model.

\section{Symbolism over Substance}

Proposition 4 of the cross-sector collaboration theoretical framework states that:

The form and content of a collaboration's initial agreements, as well as the processes used to formulate them, will affect the outcomes of the collaboration's work. A sequence of increasingly operational agreements involving key decision 
makers, a certain degree of flexibility, and re-negotiability are likely to be important elements of the agreement process. (Bryson et al., 2015, p. 663) Following the acceptance of grant dollars from the Wallace Foundation for the purposes of building an out-of-school time coordinated system, the work began to make sense of the nebulous nature of this burgeoning collaboration. In 2012, the initial partners signed the Cabot Out-Of-School Time Coordinating Council Charter in order to accomplish this task. The charter, just one page in length, identified the partnership's founding organizations and the overarching goals of the partnership.

When asked their perspectives on the signing of the initial charter, informants from Case \#1 had the following perspectives:

It gave an overarching what the three were responsible for, but we probably should've gone back to the table and outlined a little more precisely the day-to-day workings of each organization and what each would be responsible for. We took on what we knew we had to do and what we had been doing. We did a good job of it, but we probably should've outlined a little bit more what the day-to-day was for every institution (Suzanne).

If you go back and look at that charter, I think you'll see it was really more of us committing to behave and act in a certain way as collaborative partners, there weren't things really set out specifically in terms of metrics and we had kind of these big overarching goals, but then we also were just saying, "Hey, we're committed to this." (Ronald) 
At that time it was a commitment. It was important. It was a commitment that the three partners were still invested in this, that we were still working on it, that we were wanting to make things better as a partnership. It was important that we had that, very important. Did it clarify everything? No. If you've looked at the charter and read the charter, you'll see it doesn't. There were still details that had to be worked through. I believe that CARDS is still working on those details today, which is important because nothing is ever written in stone. They should be constantly looking at revising, revamping, updating their partnership. (Ann)

Warren went further in his criticisms, suggesting that while the charter was an important symbolic gesture, the lack of specificity within was a hindrance to the collaborative's efforts. He states:

Yes, symbolically you're happy that there was a charter that the city and the school system and PTGC agreed to work together, but on the ground you would much prefer something more detailed that committed each partner and detailed what their commitment was. Am I satisfied with the charter? It was a great first step and it was very symbolic. Could it have been more detailed and committed the three partners to actually put some skin in the game? Yes, I wish it would've done that, and talked about a governing structure, and ample structure. It could've been more detailed and done stuff like that. (Warren)

The lack of specificity in the initial charter agreement speaks directly to Proposition 9 of the framework. In this proposition, it makes a distinction between two types of planning processes; deliberate and emergent. Deliberate planning calls for the 
formal articulation of goals, objectives and responsibilities at the beginning of collaborative efforts. In contrast, emergent planning has the same desired outcomes as deliberate planning, but these goals tend to be achieved over time, allowing the contextual features of the collaboration and understanding of the problem it solves to inform decision making. The framework does not advocate for one type of planning over the other, however it does state that that "emergent planning needs to be followed by formalization; too much emergent planning can undermine collaboration success" (Bryson et al., 2015, p. 663) As data will show, the lack of deliberate planning at the outset of the partnership reverberates to the current day CARDS Partnership.

The selection of the Public Trust of Greater Cabot as the convener and managing partner of the Wallace Foundation grant was an intentional decision with a clear rationale:

When we submitted our full proposal to get funded, the city of Cabot determined that Public Trust of Greater Cabot should be the fiscal ... because we wanted to make sure that it was, that the money was located at a place where it would be easier to actually access it. Being a very large institution like say CPS or like Metro Government, oftentimes it's harder to use the funds in a quick manner. You have to have you know, put out bids for this and get so many invoices and there are restrictions that say CPS and Metro Government can spend their money on. (Tammy)

Aside from that deliberate decision, it appears that much of what would come to make up the actual functionality of the partnership was still very much undetermined.

It was presumed that there was a natural progression in the evolutionary development from YouthPrint to the CARDS Partnership. However, data suggest that the 
YouthPrint document was not ultimately implemented with fidelity in the formed Out-ofSchool Time Coordinating Council. Evidence suggests that this occurred because stakeholders were taking advantage of what Bryson et al. (2015) referred to as a "window of opportunity" of the Wallace Foundation grant. Warren recalls:

The agenda was always built around the work of the Wallace grant. It was-I didn't feel like it was being, it didn't seem to me that we were building it around the larger sort of Youth Print recommendations and I get it, I know several of us would say, well, if we didn't have the Wallace grant, what would we be doing at these meetings? But, 765,000 dollars, that was a pretty good chunk of change, so, we knew we had to do work against that. So, that was a good thing, if it weren't for that grant, you know, I really question what we would've been able to do, I think that United Way probably would've gone down the road of the quality piece and done a good job with it, but, it would've been a bit more sort of unilateral type of work.

Although the Wallace Grant provided resources to begin the task of building a citywide OST system, it appears that at the beginning there was a deviation from the initial work that the YouthPrint report set out to accomplish. Another informant (Lois) who played an integral role in the creation of the YouthPrint report echoes these sentiments stating:

When the original work was done and in even in terms of structure that we were talking about, it had been laid out. I really wish I could find, I mean we had been laid out about how this would be structured, how it would be governed and within ... That was partly even in some of the proposal for Wallace, some of that stuff 
and when we started the meeting, it was like all of a sudden, what's happened here?

Though the signing of the initial charter was looked at as a significant win for the partnership, the lack of specificity within those initial agreements would soon prove to be a hindrance.

\section{A Seat at the Table_-But with Different Occupants}

It has been previously mentioned that the decision to form a multi-organizational partnership was generally agreed upon by the founding partners. This decision was made primarily to avoid stifling the progress of the system-wide effort, opting to develop the mechanisms later. The idea was to determine what the work of an intermediary would be and then parse out those responsibilities to the founding partners. Table 10 shows the responsibilities meted out in the Wallace Grant application. One informant reiterates the notion that the initial organizational structure did not appear to be a deliberate plan. Warren states that "the governance structure was more by default rather than by intention... I think it just, to a certain degree, made some assumptions that that was a given, and at the beginning turned out that that was it." 


\section{Table 10}

$\underline{\text { Roles of city and partner organizations listed in the Wallace Foundation Grant }}$

\section{All three partners}

- Engage providers of youth services, FBOs, and youth in every stage of system dev.

- Train all relevant staff in capacity and use of KidTrax, Community Compass for referrals

- Community Server for geo-mapping and analysis

\section{Public Trust of Greater Cabot}

- Convene Coordinating Council; develop MOA with partners

- Set up funding collaborative; model on Continuum of Care (homeless services)

- Support upgrade of KidTrax; house Focus KidTrax manager (Ready by 21 funding)

- Support implementation of program standards (particularly with member NPOs)

- Conduct market research

- Coordinate annual youth summit; help market NPO opportunities and YouthVision

\section{Metro Government}

- Institute YouthStat to track common measures and coordinate youth services across departments

- Use FY2011 funds to add select Community Centers to KidTrax and in consultation with CPS and PTGC, enroll more programs in KidTrax

- Ensure community data is included on Community Server

- Create web-based portal for parents/concerned adults on how to support student success (Every1Knows); connect to CPS Parent Portal

- Shepherd adoption of and begin training on program quality standards

- Lead expansion of training and development

\section{Cabot Public Schools}

- Upgrade KidTrax to include Community Compass, Community Server and one-click provider

- $\quad$ access to student data

- Connect SMART ED and KidTrax; put on school dashboards

- Form internal committee to analyze/recommend better utilization of OST funds, specifically Supplemental Education Services (SES)

- Join with Coordinating Council to attract $21^{\text {st }}$ Century Funds and other grants

- Invite youth providers to receive training in college knowledge/college counseling; train NPOs, FRYSCs, SAMs, principals thru Education Leadership Cross Training

\section{Youth Organizations and the Community}

- Become knowledgeable of quality standards as a basis for selecting programs for children

- Recognize community-wide role and responsibility in supporting youth to be confident, connected and secure (Youth Vision) 
In addition to the roles listed in Table 10, the governance structure was established. The OST Coordinating Council was recognized as the governing body. Within the OST Coordinating Council, several subcommittees were established to support the day-to-day responsibilities of the collaboration. Each subcommittee was comprised of members of the founding partners. These subcommittees were: Governance and Sustainability; Standards and Indicators; Data and Research; and Communications (Wallace Grant, 2011) In addition to these subcommittees, an additional Executive Committee was established that was to meet on a bi-weekly basis.

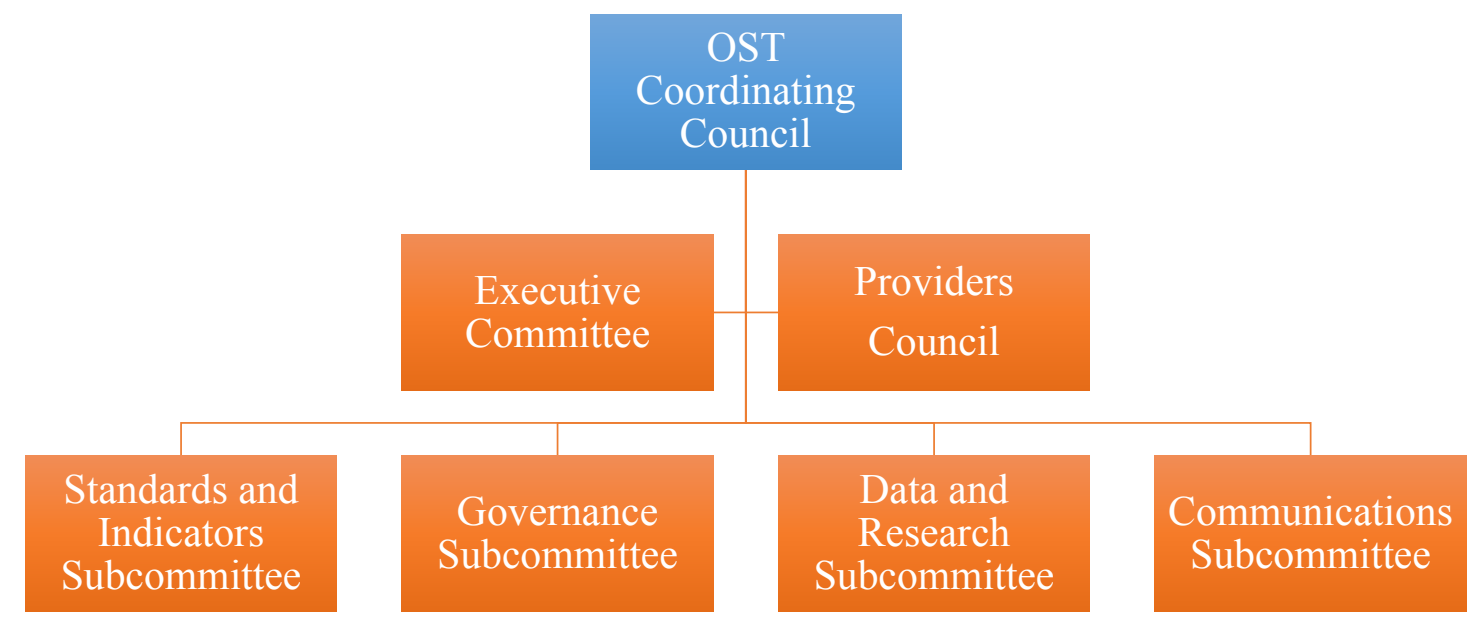

Figure 4: 2008 OST Coordinating Council Organizational Structure

The work of managing the newly formed partnership was not without its challenges. One of the main challenges was the transition of new leadership at the highest levels of the partnership. Per this study's timeline (2002 to 2016), CPS has had three superintendents, the City of Cabot (CMG) has had two mayors, with only PTGC maintaining consistent leadership over the entire period (Figure 5). In fact, two of the three signers of the OST Coordinating Council Charter had been in their respective offices for less than six months before pledging their commitment. 


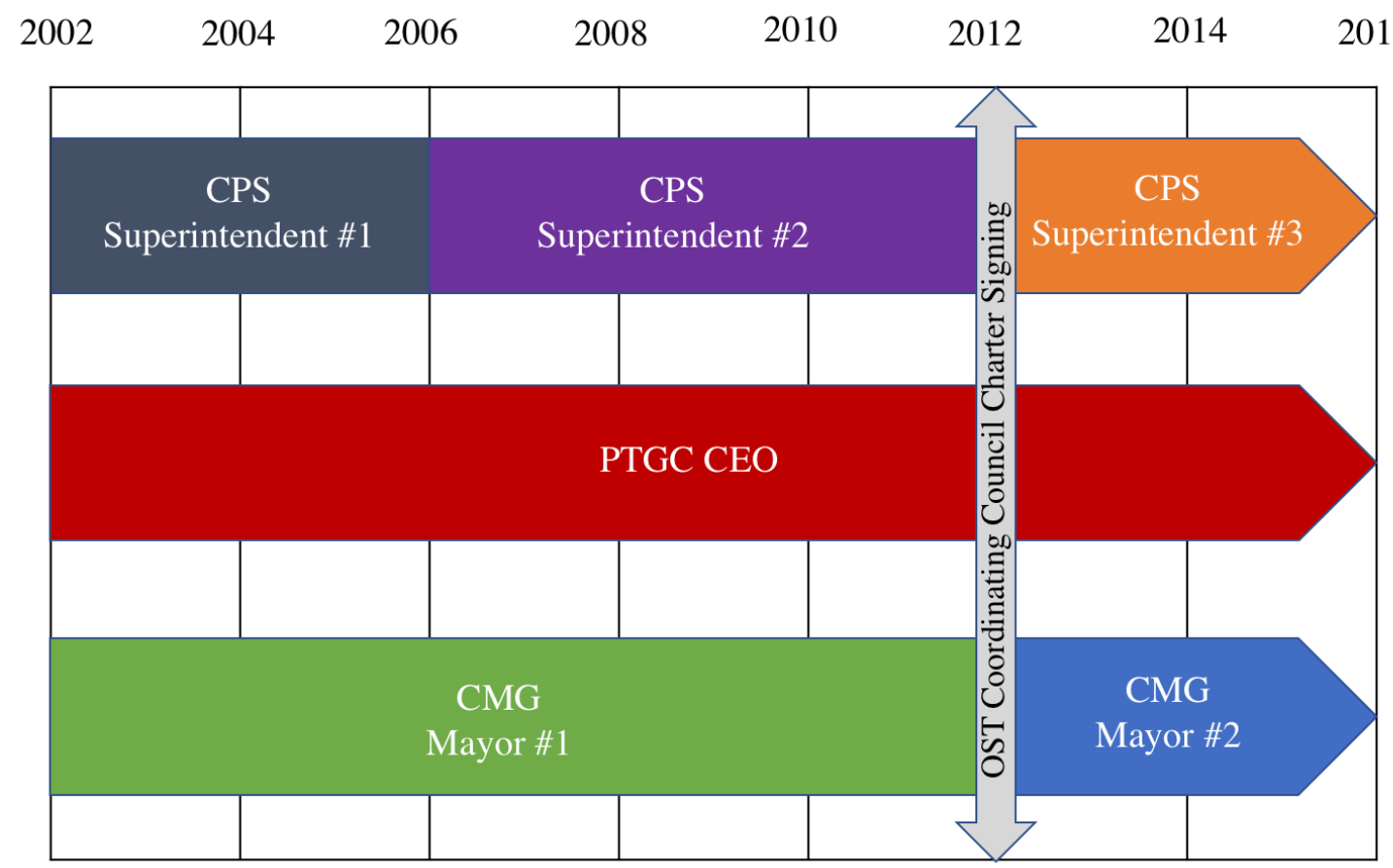

Figure 5: Leadership changes of CARDS' founding partners

Proposition fourteen of the cross-sector collaboration theoretical framework addresses turnover, and how it can lead to ambiguity in the collaborative's relationships. Bryson et al. (2015) note that transitions of not only leadership, but of key members at all levels can have an adverse impact on the institutional logics of partners. As the top leadership of the OST Coordinating Council founding partners changed, so too did leadership within many of the organizations.

Suzanne reacted to the lack of continuity in this way:

That's because people move in and out, people take different jobs or their job responsibilities change even within an organization. It was always fluid. But I cannot ever say — this is my own opinion - that anyone was given the responsibility who did not give it $110 \%$.

Tammy and Ronald both supported Suzanne's perceptions, : 
We started having this, different people showing up to represent Metro or CPS, which, that lack of continuity makes for a weaker sort of base from which to work...I started out going, but...I don't think any of the five, four of us were going regularly enough to kind of have that single representation. (Ronald)

There was a two, three year period in there were there was just a lot of constant changes. We didn't have a lot of consistent people at the table on a monthly basis for our meetings. That was where we had big breakdowns in communication, big breakdowns in that buy in for that common goal because the people, if you have a different person, if the Metro Government sent a different person every month to a meeting, then and you had separate meetings. (Tammy)

Likewise, Lois stated:

I just really felt at times when I would meet with people higher up here in the district or meet with some of the people cabinet levels, like in the city. It was having to do a whole new reeducation.

The data suggest that the challenges inherent within collaborative efforts was only exacerbated by the lack of continuity displayed within partner representation. Asthe Wallace Foundation grant's convener, fiduciary agent, and agency providing the most consistent leadership and staffing, the burdens of many day-to-day responsibilities fell to PTGC. Although not intentional, this shift of responsibilities subsequently created additional challenges within the partnership.

\section{The Power Dump}

Proposition 20 of the Bryson et al.'s cross-sector collaboration theoretical framework notes that endemic conflicts and tensions, such as power imbalances and 
competing institutional logics, can have a substantial influence on the workings of a multi-organizational partnership (2015). All informants agreed that their respective organizations had a reasonable purpose for joining this collaborative effort. From the CPS perspective, the reasons for joining were clear in that:

For benefiting the students with our students in DEP that we're most responsible for. Those are the kiddos we want to help make sure that they're getting the extracurricular activities they need to succeed in school, the social supports, emotional supports and academic supports. I think everybody's in it to make sure to give kids a safe and enriching environment outside of school. (Margie) The idea to the forefront and really pushing the importance of extended learning...You always look at how you're gonna help yourself. And that was one of the things that we were looking at. Raising test scores, and the disparity of test scores between minority students and their non-minority counterpart. (Suzanne) Representing the city of Cabot perspective, Tammy states:

Cabot Metro Government really wanted to be a part of this initiative, this collaboration, because what we discovered...during that time period is that there are hundreds of people in organizations within our community that are doing wonderful things with and for our youth but they don't talk to each other. They don't share their resources, whether the resource is actually money or whether they be locations or buildings or kids. You know, everybody was doing the work all seemed to be siloed. We wanted to find better ways to be able to work across those silos to connect people, knowing at that time that there were cuts in federal funding for programming and locally, we didn't always have the funding to 
support all the things that were out there. We were trying to find ways to build capacity within those agencies and trying to find better ways to serve our youth. While PTGC served as a key partner since the collaboration's inception, Candace feels that its participation is more pragmatic than other partners. She states:

The district works with kids, so I feel like there's more of an urgency to impact the students or Metro government to a lesser extent. They run programs. It's really important to them to be able to impact kids. I think United Way is a little bit different in the sense that we're a little bit more removed, so I think that we maybe don't have the personal drive to impact this group of kids. We just want to be able to help and have impact somewhere, and this seemed to be an area where we could. Yes, we are focused on the same thing, we have the same goals. But our motivating factors, the driving factors I think are a little bit different. I think there come times when that becomes more apparent. Our motivation is not because we are so deeply passionate and connected to kids because those are our constituents and that's who we have to help, unlike the district. With us, for our sustainability and our viability, we need to be relevant to the people who are donating money to the United Way. The issues that our constituents are pressing upon us tend to be the ones that dictate where we focus. Therefore, I would say our motivation isn't because we have this intrinsic desire to help young people. I think it's more we have an intrinsic desire to remain relevant to our constituents, and if their interests change, then our direction's going to have to change also.

Though there may have been differing reasons to partner, the data suggest that there was a general level of agreement and interest in serving youth. However, when the subject of power imbalances was addressed during interviews there is a clear and unambiguous 
realization that conflicts and power imbalances have been pervasive throughout the majority of this collaborative's existence. As Warren explained:

I don't think there's a struggle for power, because I don't think anybody wants ... To me, what's happened to PTGC has been, I don't want to say it's been dumped on PTGC, but by default PTGC is the fiscal agent, and it seems the PTGC has had more of a stake in all this. There's one organization with 16,000 employees and a 1.2 million dollar budget, another with six or eight thousand employees and a 900 million dollar budget, and there's been individual within those two organizations that have been involved, but they tend to be individuals that aren't a part of the organizational decision making. And if you're describing it in terms of power, which is I would say more a struggle for responsibility.

The "power dump" is the notion that the responsibility for the ultimate success of the CARDS Partnership inequitably shifted to PTGC. A Case \#1 informant echoed this sentiment from the city of Cabot's perspective stating:

I would maybe say, not a power imbalance, but an imbalance in the sharing of the work. Again, it's one where it's pretty clear United Way picked up the lion share of the kind of leg work and the organizing and the back office of making sure that we have coordinating council that has evolved into CARDS. So, I would say they've done most of the work. What's interesting is, this is my opinion, you know, power becomes sometimes a challenge or an issue to deal with when multiple organizations or individuals are placing a bunch of energy and effort into something and again, I don't know that there was ever a power imbalance because there were plenty of partners more than happy to let someone else have the power in that particular space. I don't think that they were ever, there was never any sort 
of jockying for power in that. So I don't know, I don't, I just have felt there was more of a imbalance in organizational effort. (Ronald)

While Ronald cited the lack of effort by other partners as a contributing factor to the "power dump", Suzanne suggested fiduciary oversight as a cause for the power imbalance stating:

Sometimes, I felt that that was because you hold the purse string, you are the one in power. Sometimes, I think that the fiduciary agent for a while took the lead more than maybe they should have. And I think it was because they held the purse string.

The cause for the "power dump" most identified by informants however was due to personality conflicts. Lois, an informant from the Partnership for Children Case \#1 informant stated:

I think there's been a lot of imbalance and I think it has shifted at different times in terms of the imbalance but I don't believe, I mean if I look at the very beginning when CARDS and the Wallace funds came in...When Ann was put in that position, that's where the imbalance started. It was like she saw herself as above rather than this is a true partnership and I believe that was one of the worst things that happened because it was like you would have meetings and if people would ask questions, really trying to get at, it was like shut them down. So then we quit having this group meet because it was almost like they were being too difficult. That was one of the biggest problems and it took Public Trust of Greater Cabot a long time to finally say she does not know how to work in a collaborative style. 
The Case \#2 informant from the city of Cabot (Tammy) provided more detail into the personal nature of these imbalances. She recalls:

Well, I think that I talked a little bit about that earlier when I talked about the fact that at one time because of personalities, people, leadership, there was one person at Public Trust of Greater Cabot that was making all the decisions about how to spend the money and what Blocks was doing and got some input from one person at Metro Government who was not in a leadership position within Metro Government. I think there was a true imbalance at that time. A lot of the issues were total non-communication, non-responses to requests, everything was driven by one person. I think that when that person is gone that then the next person that came I think immediately had some meetings with some people from the other partners and said you know we want to better communicate, we want to be open, we want transparency, we want everybody to know what's going on, we want everybody to be and the way things were handled from there on out, you know. But I do think that there was a time frame where there was a lot of tension, a lot of mistrust and you know that was a lot of money that during that time period that we have no idea how it was spent or what it was spent on or how it related to the work that we were doing.

Though not originally slated for an interview in this study, I was able to locate the individual identified by informants as a source of tension--Ann. I asked the individual to provide her perspective on any potential power imbalances in the OST Coordinating Council. Ann stated that:

I think because Public Trust of Greater Cabot was designated as the administrator for the Wallace Foundation funds, I think there was an appearance that maybe we 
had more control, but we tried very hard to make sure that wasn't happening. The other thing is when you have a partnership it's awfully hard to dictate to another partner, "Hey, you haven't done this," or, "You haven't done that. What's going on?" Sometimes that could be a hindrance as well. I think partnerships are hard. They're just really, really hard. There has to be someone at the helm holding the partners responsible. At that point in that formation, that fell very much on Public Trust of Greater Cabot's shoulders to make this all happen. Does that make sense what I'm saying? It was something that I think it just evolved because it became very much at the heart of what we were trying to do at Public Trust of Greater Cabot, around all of our youth programs. We were working with two other entities that are very large, have a lot of other responsibilities. A lot of the responsibility behind the administration work of the Coordinating Council fell to Public Trust of Greater Cabot. It may have appeared that there was an imbalance but it certainly wasn't intended. Fought against that to make sure that everybody had that voice at the table and was heard.

The individual who was the object of many informants' ire eventually moved on from PTGC. The tensions however remained even as new individuals from the founding partners came to the partnership table. The CPS informant in Case \#2 (Margie) recalls part of their orientation to CARDS:

I definitely felt like ... This is all my perception, right. I think that she thought, and she influenced my thinking that CPS was always getting slighted for whatever reasons. I don't think that. She (Suzanne) fed me that before I was really involved in CARDS too much. 
Perspectives offered about the current PTGC liaison to the CARDS partnership Candace is the polar opposite of her predecessor Ann. Candace is seen as competent, collaborative and focused. However, the concept of the power dump still informs the relationship of PTGC to the CARDS partnership at large. When asked about power imbalances, the PTGC Case \#2 informant (Candace) stated that:

Anytime somebody kicks in money, that brings power. In this case, I happen to be employed by the organization that's kicking in the most amount of money at this point, and therefore, I tend to not feel bad about maybe stretching my autonomy to the point where I'm making decisions, not in the most democratic way. I mean, I try to, to the extent that I feel like I have to, but we are kicking in north of $\$ 150,000$, and we are the only partner that's kicking in any kind of direct financial assistance. Therefore, I think the attitude around here is, if we're kicking in the money, then we can make some decisions about how that money gets spent. As a result, we are basically making the decisions about YPQI [Youth Program Quality Intervention], and when and how to expand and who to include, and how much can we include in that scope of work with the Weikart Center and what do we want the data report to look like from Weikart, not the one that you and I are working on together. I do think that we hold a lot of power there because we're the partner that's paying for it. I think that's an example of power imbalances. Money brings power.

The imbalance of responsibility has been a pervasive theme throughout the history of the CARDS initiative. It was not until 2016 that a candid conversation regarding the imbalance of partnership responsibilities occured. The impetus for this discussion was the realization that grant dollars from the Wallace Foundation were about 
to expire. Because of this, there was a very real possibility that the work of the CARDS initiative would cease without a clear plan to support the work of this collaborative effort. In 2016, with the support of an external consultant procured by the Wallace Foundation, CARDS developed a sustainability plan. Completed in June of 2016, the sustainability plan identified the strategies and activities that would form CARDS' primary work over the next three years, delineates a budget and financing plan to support that work, and details revisions to CARDS' infrastructure that will ensure it has the community support and resources to achieve its goals. To inform the work, the consultant group conducted interviews with over 20 stakeholders in the Cabot community with either current or prior engagement with the CARDS initiative. The consultants also interviewed several stakeholders who at the time of the planning process had limited or no engagement with the CARDS initiative to determine in what ways CARDS could better integrate its work into a broader cross-section of the youth development community in Cabot. Ronald, one of this study's informants from Case \#1, was a part of the convened group to assist in the sustainability planning process. After the four-month planning process, he offered these reflections on his involvement:

I think it's pretty clear that it was not inclusive enough, and then, just the simple fact that when we were doing the sustainability thing that when we started reenvisioning the governance piece of it and understanding that our old governance had just collapsed into one group. It's like, as you start separating out, now you create space to be more inclusive of other groups, so I think that's an important thing that we learned along this particular journey was that, that circle was not wide enough in the beginning and so, you know, people get curious about what you're doing, but, they're never invited in, they might just, they're like, you know, 
I've got plenty to do over here, they'll keep doing their work and go to the trainings but maybe not ever inquire beyond, you know, what is the coordinating council.

Ronald's reflections were echoed in one of the products of the sustainability planning process; the creation of a new organizational structure. One of the key findings of the sustainability planning report from the consultants was that the all the functions found within the original governance structure (Figure 4) were now solely being completed by the executive committee. The new CARDS organizational chart features three distinct levels of structure. The Leadership Board is to be comprised of top leaders in the Cabot community who provide high-level strategic leadership in the OST space. The Operation Team supplants what was previously known as the CARDS Executive Committee. The Operation Team's purpose is to manage the day-to-day functions of the CARDS initiative. A key distinction between the Operation Team in the new organizational structure and its previous iteration the Executive Committee, is that the Operations Team is comprised of a larger and more inclusive group of stakeholders, featuring membership of OST programs. Embedded within the Operations Team is a Core Team comprised of the CARDS initiative founding partners which is to be available to make time-sensitive decisions between the regular meetings of the Operations Team. Another departure from the previous organizational structure is the dismantling of standing committees and the creation of Working Groups. These Working Groups do not exist in perpetuity, but rather are developed by the Operations Team to accomplish a specified task with a specified period of time. Once the Working Group's task has been accomplished, it will be dismantled by the Operation Group. Finally, the new 
organizational structure features an OST Provider Network which seeks to intentionally re-engage OST programs en masse in providing prospective to the CARDS initiative.

A separate, but important development from the CARDS sustainability planning process was the development of a new Memorandum of Understanding (MOU). This new agreement which replaced the original OST Coordinating Committee Charter was signed by the CEO of Public Trust of Greater Cabot, the Superintendent of Cabot Public Schools, and the Mayor of Cabot Metro Government. The new MOU is in stark contrast to the original charter in that it identifies specific activities that are to be owned by each of the founding partners. PTGC would continue to lead the work of onboarding youth service organizations in improving program quality. CPS would take the lead in collecting and synthesizing data to inform the work of CARDS. Lastly, CMG would serve as the chief training organization to support employees of youth service organizations around the community. There is however a glaring omission from the new MOU between CARDS founding partners; the exclusion of the Partnership for Children. 


\section{Leadership Board (10-14 Members)}

- $\quad$ Provides high-level strategic guidance and oversight; helps with fundraising and advocacy

- Meets semi-annually (in conjunction with events like Lights On Afterschool or launch of summer program initiative)

- Membership to include:

- Mayor (or sr. level report), Superintendent (or sr. level report), CEO of PTGC

- 2-3 leaders of related initiatives, including, e.g.: 55,000 Degrees college attainment

- $\quad$ initiative; mayor's Cradle to Career Initiative; youth advocacy organization

- 1-2 private provider organizations, representing diverse provider types

- 1-2 reps from local foundations

- 1-2 reps from the college/workforce development/business community: Sr. level staff at

- Jefferson County Technical College, Kentuckiana Works, Chamber of Commerce (GLI)

- Chair of the Operations Team

- Meets semi-annually

\section{Operations Team (7-10 Members)}

\section{Core Team (4-5 Members)}

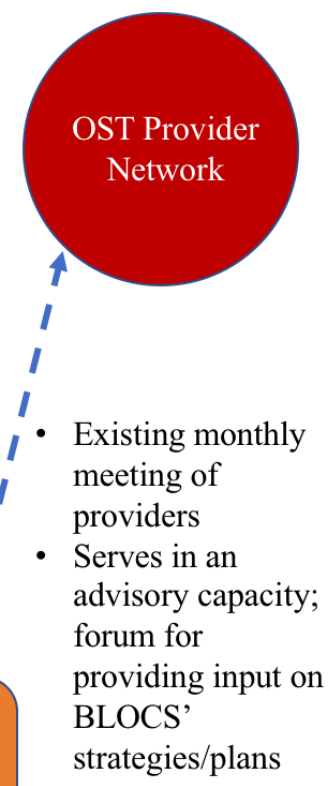

- Implements BLOCS' key strategies; manages its day-to-day operations

- Meets monthly or more frequently as needed

- Includes 2 representatives from JCPS, 1 each from Public Trust of Greater

Condon and Metro Government, 1 advocacy group (Louisville Alliance for Youth), and 2 program providers (TBD)

- May recommend the creation of ad hoc committees to deal with specific topics as needed

- The Core Team, a subset of the Ops Team, may be convened as needed to make time-sensitive decisions between meetings of the full Operations Team

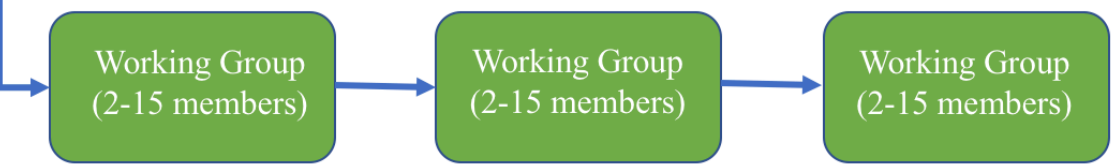

- Address specific topics identified by the Leadership Board or the Operations Team.

- Short-term, well-defined deliverable and timeline set by the Operations Team

- Reports to the Operations Team; chairs are members of the Operations Team

- Meeting scheduled determined by group and timeline

- Membership determined by topic

Figure 6: 2016 CARDS Governance Structure

nuanced discussion. The leveraging of PTGC's flexibility, once seen as an asset, has 
contributed to an imbalance of power; not necessarily due to a thirst to acquire power, but because of a lack of perceived contributions from other partners and higher financial investment from the dominant partner. To that end, even with improved collaborative culture and climate it is unclear that even in the current iteration of the CARDS partnership, increased participation from other partner organizations has fully been resolved.

\section{An Absent Voice}

Throughout the first three chapters of this study, the CARDS Partnership has been characterized as being a multi-organizational partnership consisting of four members; Cabot Public Schools, Public Trust of Greater Cabot, Cabot Metro Government and the Partnership for Children. These four founding partners are listed plainly on the current CARDS Partnership website and other relevant documents and materials. In Chapter IV of this study however, through interviews and document analysis, there is evidence that the founding partners of the OST Coordinating Council Charter agreement did not include the Partnership for Children. The question arises then as to how the Partnership for Children rose to recognition as a founding partner, when data suggest that this had not previously been the case.

The Partnership for Children was borne out of a 1998 ill passed by the state's General Assembly that provided one million dollars to curb juvenile delinquency across the state. Through the merger of several city and county agencies after the creation of the Cabot Metro Government, the Partnership for Children was created as the vehicle to accomplish the work set forth in the legislation. In 2005, the State Department of Juvenile Justice decided to end state funding, but the Partnership for Children continued their work. The Partnership for Children was asked to join in on the development of the 
YouthPrint report due to their access to research as well as their advocacy for youth and youth serving organizations. The co-chair of the Partnership for Children also eventually served as the co-chair of the YouthPrint report. Though not recognized as a founding partner, the Partnership for Children would be relied upon in the Wallace Grant for their expertise in advocacy for youth serving organizations. The Wallace Grant read that it would:

Consider the Partnership for Children and/or other existing collaborative to lead an advisory coalition for the Coordinating Council; determine new advisory coalition members, which shall include youth and providers of services to youth, and determine operation based on new role (Wallace Grant)

Data suggest that from the inception of this collaborative effort, there would be an intentional focus on engaging the voice of youth and OST programs in decision making. However, OST programs do not seem to have played a major part in the planning activities around of either the OST Coordinating Council or in its current iteration the CARDS Partnership. Warren characterizes OST programs and their relationship to the collaborative in this way:

I don't think people go out and say, "We're going to create this system, but the folks that we're supporting are not going to have a say...It's like kids. We have a youth council, which is made up of anywhere from 8 to 30 gray-haired adults, and they say, "We need to get youth voice, so we'll get the president of school government from the best school in the city or the state to be the youth voice." My data suggest that OST programs have been referred to as a "passive group" that are "beneficiaries" of services that CARDS provides. In the YouthPrint document however, youth service organizations were seen to have played a more substantial and authentic 
role in the work of the collaborative. That the Partnership for Children was to serve as the primary convener of this constituency that has never been fully engaged may be a contributing factor to the nebulous relationship of the Partnership for Children and its status as a founding partner. One informant from Case \#2 (Candace) actually questions the relevance of the Partnership for Children in CARDS. She state that:

The Partnership for Children, I'll be honest with you...I've always struggled with the Alliance. Between me and you and your recorder, the Alliance I think is a one-man show, and it's Lois. I think that we've always out of respect to Lois and her long history and involvement and commitment to this, have kind of allowed the name, the Partnership for Children, to be called a partner. But from a practical standpoint, I don't see a whole lot of substance there. Tammy's her co-chair. She invited me last year to one meeting to talk about CARDS. In that one meeting, they were unveiling their new Partnership for Children plan, and it looked like somebody had taken a page right out of the CARDS sustainability plan, literally. At that point, I pulled Tammy aside, and I was like, "Help me out here, sister, because this to me feels like a duplication of efforts. I don't care what you call CARDS, and I don't care what you call The Alliance, but why are we calling these things two different things? This seems crazy to me. Now, you're claiming your big push is going to be to engage OST providers. That is exactly what just came out of the sustainability plan. I just don't understand why we're...It didn't make any sense to me, and that's still my feeling now, is I don't see a whole lot coming out of the Alliance to make me feel like it needs to be a stand-alone thing. I think it's time for it to fold, or just join with CARDS. I don't know why we keep carving out this little space over here like a separate thing. 
The conversation about the role of the Partnership for Children connects to a larger conversation about who in fact are perceived as the internal and external stakeholders of the CARDS Partnership. Table 11 shows that there is little agreement among informants as to who are the internal and external stakeholders of the CARDS initiative.

\section{Table 11}

Cases \#1 and \#2 perspectives on CARDS Partnership Internal and External Stakeholders

\begin{tabular}{|c|c|c|}
\hline & Internal Stakeholders & External Stakeholders \\
\hline \multicolumn{3}{|l|}{ Case \#1 } \\
\hline Ann & PTGC, CPS, CMG & $\begin{array}{l}\text { Wallace Foundation, } \\
\text { Forum for Youth Investment }\end{array}$ \\
\hline Warren & PTGC, CPS, CMG & Providers, Youth, Parents, Community \\
\hline Ronald & PTGC, CPS, CMG & Providers \\
\hline Cheryl & PTGC, CPS, CMG & $\begin{array}{l}\text { Local Foundations, } \\
\text { Weikart Center, } \\
\text { PTGC Worldwide, } \\
\text { Forum for Youth Investment }\end{array}$ \\
\hline Lois & $\begin{array}{l}\text { PTGC, CPS, CMG, Local } \\
\text { Foundations }\end{array}$ & Providers, Cabot Grad Project Degrees \\
\hline Suzanne & PTGC, CPS, CMG & Youth, Parents, Providers \\
\hline \multicolumn{3}{|l|}{ Case \#2 } \\
\hline Tammy & PTGC, CPS, CMG & Youth, Parents, Providers \\
\hline Candace & PTGC, CPS, CMG & Local Foundations, Providers \\
\hline Margie & $\begin{array}{l}\text { PTGC, CPS, CMG, } \\
\text { Providers }\end{array}$ & Students, Parents \\
\hline
\end{tabular}

All informants agree that PTGC, CPS and CMG are internal stakeholders of the CARDS initiative. The stakeholder positionality that those interviewed assign to OST programs however varies, with one informant characterizing providers as an internal stakeholder and with two informants not mentioning OST programs as a stakeholder at all. The nebulous role of the Partnership for Children then may be due to the nebulous role of OST programs. Proposition 6 of the Cross-Sector Collaboration Framework states that for a partnership to succeed, it is necessary to establish with both internal and external 
stakeholders the legitimacy of a collaboration. Table 11 shows little congruence between those previously and currently affiliated with the CARDS initiative, there are questions as to how OST programs make sense of their participation in the work of this collaborative effort.

The relationship between OST programs and the larger CARDS initiative may be better understood through an allusion to the work of Arnstein (1969) in the development of a ladder of citizen participation (Figure 7). The ladder was developed primarily to examine the relationship between citizens as they interact with community development activities. The ladder has eight "rungs" that features the deepest level of authentic engagement at the top of the ladder. In Arnstein's view, the goal of this framework is to aim for the highest levels of engagement from the inception of collaborative activities. Manipulation (1) and Therapy (2) are characterized as non-participation, in which the goal is not for individuals to participate, but rather for power brokers to "educate" or "cure" participants. The next three rungs of Informing (3), Consultation (4) and Placation (5) are identified as varying degrees of tokenism. In this grouping participants are in a sense invited to the decision making table, however, decision making power is still maintained by those in control. The final grouping of Partnership (6), Delegated Power (7) and Citizen Control (8) feature differing degrees of citizen power, where citizens are empowered to not only sit at the table, but to sit in decision-making seats. 


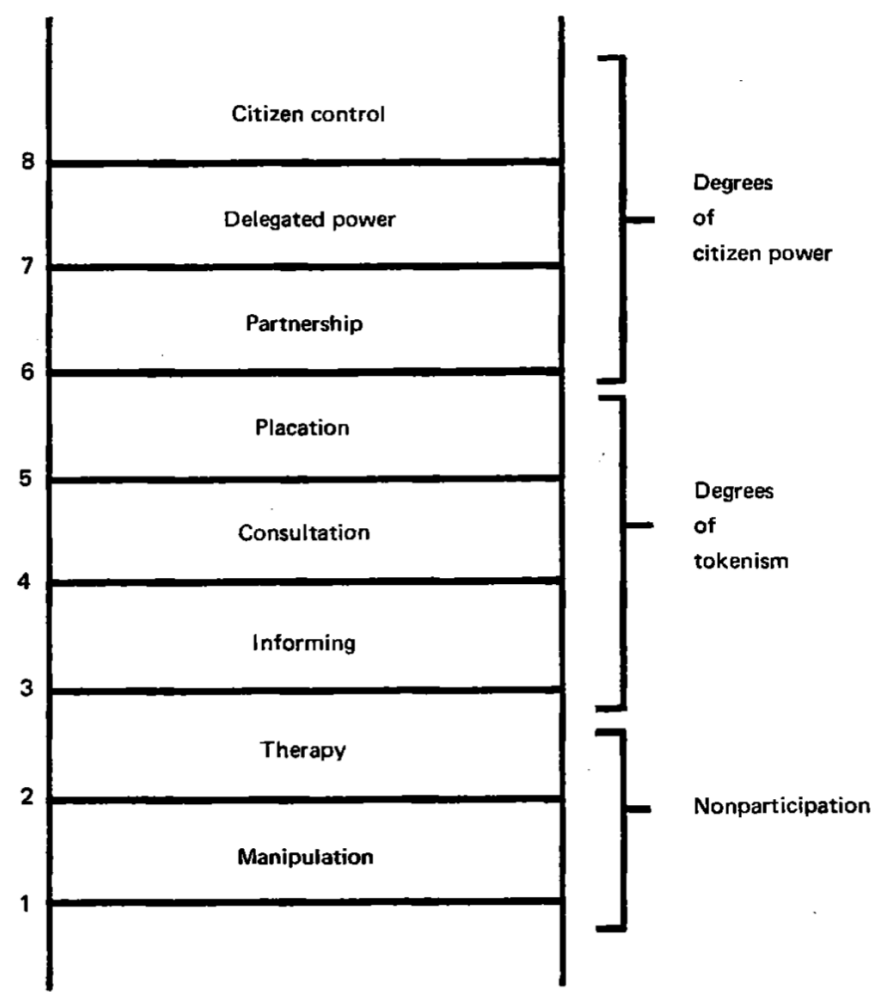

Figure 7: Ladder of Citizen Participation (Arnstein, 1969)

If the ladder of citizen participation typology were placed over the CARDS initiative, the relationship of OST programs to CARDS would most clearly resemble rung 5 which is Placation. Though not in the realm of nonparticipation, a degree of tokenism is still present. Arnstein (1969) details the placation rung as a strategy of placing a few "worthy" individuals on a larger board. Arnstein goes on to say that though these indviduals are allowed to advise activities, the powerholders retain the right to judge the legitimacy or feasibility of the advice. This narrative closely resembles the newly created Operations Team in the revHYPE CARDS governance structure. While OST programs now have a seat at the table, day-to-day responsibilities are still assigned to the Core Team, is a sub-set of the Operations Team.

Case \#1 informant Ronald alludes to a potential disconnect between the CARDS initiative and the OST programs who are intended to be beneficiaries of its services: 
The primary stakeholders, CPS, Metro Government, and United Way, they clearly are well versed in this collaborative, the people that they're interviewing know about it, but, once you take that circle outside of that, the knowledge of it just fell off a cliff. The provider side...they weren't as knowledgeable of the work that was going on, they were knowledgeable about trainings and things that were happening, but, I don't think there was a connection to out-of-school time coordinating council is, and that's part of maybe, the circle wasn't made big enough to begin with (Ronald).

With such significant fiscal and human resources contributed to the CARDS initiative, it is surprising that there might be a disconnect between the collaborative and the organizations with whom it exists to serve. The final section of my analysis will examine the perspectives of youth service organizations and the level at which they engage with the CARDS initiative.

\section{Perceptions of Public Value}

Previously, I have provided evidence of key missing voices in the work of the CARDS partnership-OST programs. In this section, the focus is turned directly to OST programs to solicit their voice in what they feel have been both the benefits and challenges of their involvement with the CARDS Partnership. As explained in Chapter III of this study, the instrument of data collection utilized to solicit the perspectives of OST programs was focus groups. The primary reason that focus groups were utilized in this section of my study is due to the heterogeneity of OST programs that are part of the CARDS initiative. To be as inclusive as possible, CARDS has historically made an effort to provide support to all organization who wish to participate in the initiative regardless of size. To that end, some organizations have a team of five or more individuals who 
assist in carrying out the necessary work within CARDS, while other organizations may only have two staff members' with time committed to the same efforts. By conducting focus groups, the perspectives of organizations with both high and low internal capacity may both be captured.

Similarly, the selection of youth service organizations to participate in focus groups was intentional in my efforts to be as inclusive as possible. It is possible that the experiences of OST programs that are part of the CARDS initiative could vary due to either their internal organizational capacity or the length of time that they have been affiliated with the CARDS. To that end, I created a typology of youth organizations in order to ensure diversity of perspectives in terms of how long the partner organizations have been associated with CARDS and organizational capacity (Figure 8).

\section{CARDS Partner Organization}

High Capacity

Long Tenure $\underline{\text { CARDS Partner Organization }}$

Low Capacity

Long Tenure
CARDS Partner Organization

High Capacity

ShortTenure

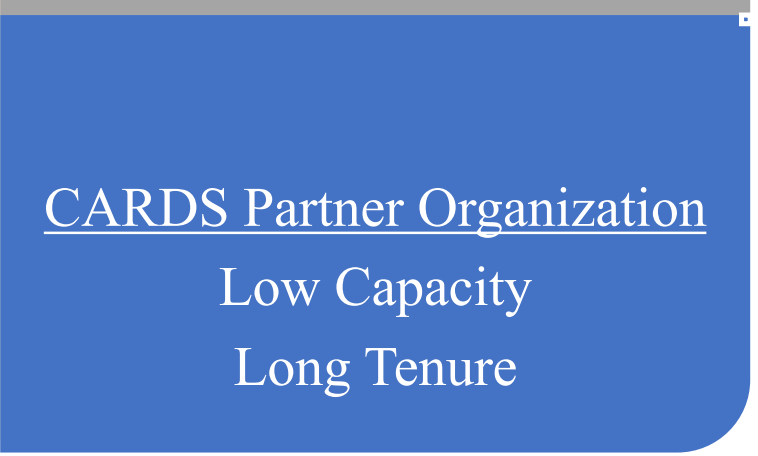

Figure 8: Typology of Embedded Case \#3 CARDS Partnership Organizations 


\section{Leveling the playing field}

In discussing the perceived benefits of the CARDS initiative from the perspective of youth serving organizations, the most recurring theme was the standardization of youth development outcomes. The funding structures of many non-profit youth development organizations requires the solicitation of resources from funders across the community to support their various programs. Prior to the advent of CARDS, there was no standard way to know whether one organization was more effective than another. Bianca from the IFC said it in this way:

It also helps us to make sure that we're held to some certain standard, that across the board, all of the organizations are on the same page and we're sharing the same language. That's helpful when it comes to ... In the bigger picture, I think when it comes to funding and receiving funds in the past, there's been some arbitrary benchmarks.

Bianca goes on to say that:

It was a guessing game in trying to figure out what words or phrases or things that the grantors were looking for. What were the funders looking for? I think it was a guessing game from a lot of different organizations of what measurements are they really looking at? How do they really see success? And so when you have this particular framework, it's saying, "Oh, okay, so now we know what they're looking for," so then we're able to write a grant or really be in compliance or be on a equal playing field with everyone else.

Andy from the YAGC agreed with Bianca sharing:

I believe in what CARDS is trying to do. Anytime I talk about it, I liken it to the Health Department when they came along and set standards for quality in 
restaurants. This, to me, feels like it goes beyond a subjective view of what quality is in a program. I feel like CARDS is really pushing a baseline quality in all of our programs. I like the idea of the data collection that goes along with that. I like the social-emotional learning component that's being implemented. I just feel like it is an organizational leap for us that knowing what that standard of quality is beyond what we think that it is, or what even in the community, kind of a center down the road would think that is, those are two very different opinions of what that is. I feel like CARDS can be this convener of what quality eventually becomes. We've got a pretty good baseline for it now with the YPQI process, I think.

Jamir from the KID'S INC. echoes these sentiments stating: From my position organizationally, I think that one of the largest benefits is really level setting, what we as a community are saying identifies quality programing. So, it sets a standard, then it allows organizations, tools and resources to meet that standard, and then really that drive in our community, how do we define quality, and then how do we identify organizations that are really ... they've taken on that due diligence to get to a level that really shows that we have a standard to measure our services against. So, for me that's where the value is.

While there is general agreement that the development of a standard has been a benefit to organizations, it appears that the organizations themselves have had little say in how the tools or implementation of those tools has occurred. Data from the YAGC focus group shared these perspectives:

Andy: I think with the founding partners of Public Trust of Greater Cabot, CPS, and city government, that there are some decisions that are made without the 
providers being consulted. It would be nice to have more of a voice in major decisions that are made, at least from my perspective.

Tracey: I can concur with what Andy said. I don't feel that we had a voice until he came on the operational team. It kind of felt like, "Here it is, this is what we're doing, and make it work for you," until we had any type of involvement in the operations side.

Andy: It might not be that big of a deal for an autonomous, smaller site, but when we have a site with $80,90,100$ kids, and we've got 50 different sites that are all going on at the same time, factoring all the variables that go along into that when you make a decision like, "What kind of data are we going to collect; How are we going to collect that; What is going to be required," it would have been nice to have a voice in there to say, "I know on paper or theoretically you might think that's not a big deal for an organization or a site, but for us, that is a big deal. Bryson et al. (2015) contend that collaborations are more likely to succeed if planning makes use of stakeholder analyses and emphasizes responsiveness to key stakeholders (Proposition 10). Proposition 11 goes further in holding that inclusive processes and structures are needed to facilitate effective collaboration. I have shown previously that planning for what would come to be known as the CARDS partnership almost exclusively took place at what Proposition 12 of the Cross-Sector Collaboration theoretical framework refers to as the system-level (Bryson et al.). As indicated by the scant role of youth development organizations in the development of CARDS, these focus group data suggest that little to no planning took place at the service delivery level.

Bianca from the IFC indicates that the founding partners are the main drivers of the work related to CARDS: 
Public Trust of Greater Cabot and Cabot Metro Government do hold the weight of what CARDS is and making those decisions about who is going to be the evaluators of the programs, choosing the Weikart Center to be the organization that we're using their evaluation tools for program quality and for doing youth methods trainings and things like that, so I think that those two organizations are given the structure of CARDS and then those other small organizations that are receiving funding are able to have a voice, but it is definitely led by those two. Jamir from the KID'S INC. agrees stating:

I do think that probably United Way and the city, those two parts drive the majority of the process. The city representation, and the United Way's representation are the most visible leads in terms of driving the direction and sort of development and initiatives of what's going on in CARDS.

Of note, when participating in focus groups, youth service organizations consistently refer to the involvement of both PTGC and CMG. It appears that youth service organization sensemaking perceives these two entities as the organizational leads of the CARDS initiative. The specific calling out of these two organizations in focus groups is consistent with other data sources (e.g., interviews and document analysis) that indicate PTGC has been responsible for driving the work around organizational quality, while CMG has been the key facilitator of the professional development training for CARDS participating organizations. Though listed as a founding partner, CPS was rarely mentioned by any organization as having a role in CARDS. The Partnership for Children, whose original role was to serve as the voice of youth service organizations, was not mentioned by any organization at all as a facilitator of the CARDS partnership. 
Although participating organizations lack a substantive role in shaping the direction of the CARDS partnership, focus group data indicate that organizations are supported in implementing the tools selected by the CARDS executive committee. The tools and resources Jamir speaks of is a comprehensive menu of training opportunities that CARDS provides. These trainings, offered to employees of CARDS partner organizations, are closely aligned with the program quality and social emotional learning assessment tools used by CARDS. For informants from organizations interviewed in my study, these trainings provide an added value for their participation in CARDS.

\section{Building organizational capacity through professional development}

CARDS' theory of change suggests that by creating high quality OST programs, these programs will in turn produce greater academic and social-emotional outcomes for the students who attend them. CARDS enacts this theory of change through its focus on regular assessment for organizations using the YPQI tool, and by offering professional development to the employees of partner organizations. The role of CARDS in creating a professional learning community for youth development professionals was a recurrent theme throughout all focus groups conducted.

This benefit is most evident in smaller organizations. The organizations interviewed with smaller capacity note that due to limited fiscal and human resources, the time and institutional knowledge to create high quality programs are not always available. Related to the notion of leveling the playing field in conversations with potential local funders, this also translates into the programmatic infrastructure created for organizations. Corey from HYPE had this to say in regards to the role CARDS has played in helping their organization's programmatic efforts: 
I think overall, it's given us more structure, because it's kind of like we know what we want to accomplish here because we're still pretty new but it kind of helps, it does kind of like guide us to like, okay, these are kind of what our rules should be based off what they look for. This is kind of how, what our instructors should do in the class. Just adapting the whole process and applying it to what we do. I think it's helped us just overall to give us some kind of structure and clear go of it, the direction we're going in.

Eric from HYPE agreed, stating:

I would say the main thing is giving us the framework to go off of what our example, expectations and goals. What I said before, because we didn't have things like the rules necessarily, like we had these ideas kind of going but we didn't really like clearly have a sit down until we sat down and looked through all of the documents and everything and we're like, okay this is what they are kind of assessing. How can we apply this to our rules, our instruction, because I think we really need a really...we did a really good job with the kids feeling welcome here and as far as skill building instruction? What I think what we lacked was some type of structure as far as kids moving around the building where they just standard protocol type stuff and I think this is clearly laid out, how we should go about all that.

The HYPE focus group was in clear agreement that the tools provided by CARDS has a positive impact on its programmatic structure. Bianca, from the IFC, shared a similar perspective:

I think it definitely does help with professional development because when it comes ... This is not only for our organization, but other organizations that are 
smaller, low-capacity. We don't have that many staff compared to a YAGC or a Big Brothers Big Sisters or a Boys and Girls Club. It helps us with professional development training, things that we wouldn't necessarily be able to do internally, but this other organization is providing those professional development trainings for us, so that's a benefit for us by participating.

Kevin from the IFC went further in affirming the impact CARDS has had in his role as a developer of programs:

For example there's a training tomorrow and it's about planning and reflection, and so me being a youth worker, I can come and I can create a lesson or I can come in and put my own spin on things, but after attending a methods training on planning and reflection, I got something in place where I have this activity in mind but because I've been to this training, now I know I can use the planning in the beginning, the reflection at the end, and then the middle piece is kind of up to me, but I have a standard that I can follow versus me just going off the top of my head and creating a lesson plan and slapping a program name on it.

After going to one of these trainings I can actually have something kind of like what Bianca said earlier about something being validated. It's like it helps validate my lesson plan more and my approach as a youth worker to my programs. For me personally that's the biggest benefit.

The benefits of the professional learning facilitated by CARDS did not only have an impact with smaller organizations. Informants from KID'S INC., one of the larger participating organizations, stated that the value added by CARDS is something unique to their local affiliate: 
Rochelle: It's that standardized process for quality improvement that we can use across organizations, multiple sites with some solidarity.

Clyde: It just adds a bit of uniformity across the board in our programming, especially with our program delivery, trainings and things like that, that are being offered for professional development for our staff, so, yeah.

Jamir: It opens up opportunities, I think for us, in this community, because I've had conversations with other boys and girls clubs that are across different parts of the country, so, because of CARDS and our relationship to CARDS, it provides us access to those things that I know other boys and girls clubs don't have. If you talk to some other sites across the nation, where they don't have coordinated systems in place that are really advocating for resources and the finances to fund this, that it's very difficult for a boys and girls club to access and utilize the tools, and to access and utilize the trainings without having a mechanism in place that's

coordinating that, that really gives us those opportunities. It's a challenge. We had to go out and view that independently. A lot of boys and girls clubs, they're not able to do so. So, when I meet with other regions and things like that, you start to see we're ahead of some of the development out there in boys and girls clubs because of the accessibility that we have to this kind of tool and process.

The access to quality tools and professional development are clearly seen as a benefit of participation with the CARDS partnership. These benefits however, do not come without their own challenges.

\section{Finding the Time}

Though the training and support offered by CARDS are seen as a benefit by all organizations, challenges seem to arise regarding the implementation of the information 
received. The participants in this study are all full-time, year-round employees. At the site level however, the majority of staff within these organizations are part-time, seasonal employees. Due to staffing constraints, the ability to imbed the tools and resources with staff practices becomes a difficult task for these organizations. The YAGC focus group engaged in a robust conversation related to the challenges of devoting staff time to implement various CARDS measures:

Tracey: To keep these folks trained and up-to-date, it drains your resources a little bit. I think the other challenge just being at the sites and the site level, is some of our staffing challenges, too, with that. That's an internal review that we have. A new person is coming in, so we have to train them on, "Okay, this is how YPQI is." It's hard to do that. It takes a lot of time. Sometimes we forget that part because there's so many other things like with all the licensing and all that. We forget to let our new staff coming in, let them know about, "Okay, this is YPQI. This is the tool. This is how we're assessed," and that type of thing. It's a highturnover industry.

Andy: Then, ultimately, you're expecting a lot from folks who aren't making a lot. I think that can contribute to some of the turnover. There's a lot of technical skill and terminology. You may have a granny that's 68 years old who just wants to take care of some babies, which, amen. We love that. But you've got a lot of technical skill, and terminology, and maybe some technology that's involved that these folks just aren't used to. That's not what they signed on for. 
Tracey: When they have to do something, Andy sits down with them for the whole day to enter something, because the technical skills aren't there.

Bianca from the smaller IFC agreed about the challenges of working with a team that is not always present:

This year, we've added GLOW, our middle school growth program has received funding, and so now we have to include those facilitators into the process and so they are becoming familiar with that and so it's starting to trickle down with them, but it's a slow process because they aren't full-time and so that can be a challenge, which I forgot to mention. Because two of them are on contract and only a few hours a week and the other one is part-time, they don't have the flexibility or sometimes the availability to be able to attend a lot of the trainings, so a lot of the information has to be...I pass that along to them with one-on-one meetings or small group meetings, but that's how it trickles down to them. Our other program, like Street Academy, isn't a part of the YPQA process yet, yet when we talk ... Because Kevin is the lead of Street Academy, I'm pretty sure you can speak more to this, but I'm pretty sure that that language is articulated down to the instructors that are only once again part-time employees so it's some challenges with that, but yeah.

The KID'S INC. focus group also talked about the challenges of implementing CARDS requirements with a mostly part time staff:

Rochelle: Yeah, for our staff to be at the table, because we deal with part-time, so making sure that we can provide it to as many, reaching it out as we need it to be, all right, and have people coming in ... and I like the professional is the Youth Development Work room position, I really like that, but getting people to buy into 
it I guess just to become knowledgeable about it and how do we train your leadership for it then to kind of saturate out. That can be a ... how do we do that? How do you do that?

Clyde: Part-time folks sometimes don't understand so you have to really work with culture, those part-time folks to get them to see the big picture and this is where we're heading and if we don't make these changes then we're not gonna be in business 'cause we're not gonna meet those standards.

Jamir: We have sort of a unique situation here that we really rely $99.9 \%$ in the clubs on part-time staff. But we also provide full-time hours for kids when schools are out. So during the summer months and breaks, we're open for 10 hour days, which then stretch our existing work force to really expand their hours. So we end up looking over the course of the year, we don't have a lot of additional hours before we are over-working our part-time and then we're susceptible to having to provide benefits and all of those sorts of things. So we have to really keep an eye on the overage of our hours, which is really hard even in normal operations. So you couple that with trying to get people involved in Youth Methods Trainings. Here in our community with CARDS, we have the opportunity to do that. They (CARDS) offer monthly trainings for that. But one, our staff have to get to those trainings. A lot of our staff have other job responsibilities, so there is sometimes a scheduling issue. But in addition to that, it's an internal issue because we have to be mindful of our own training requirements within our organization, how many hours we really have that are 
gonna end up being available to shift and give part-time staff the ability to get to all of those.

Jamir's response, reveals another theme emerged among participants from the larger organizations within this study. Specifically, he mentioned that part of the timing challenge from their organizational perspective is that CARDS is not the only entity that they are accountable to. As a national organization, there are mandated trainings that staff must also take part in, which in many respects are more vital to their organization's viability than those offered by CARDS. To that end, many of the organizations surveyed must make sense of which set of standards to adhere to at a given moment.

\section{Serving Multiple Masters}

Proposition 21 of the Cross-Sector Collaboration Theoretical Framework indicates that Competing institutional logics are likely within cross-sector collaborations and may significantly influence the extent to which collaborations can agree on essential elements of process and structure as well as outcomes Bryson et al. (2015). The present study discovered some internal competing institutional logics among the founding partners. This theme however examines competing institutional logics that exist at the service-delivery level.

As the local affiliate of a national organization, the KID'S INC. focus group participants detailed the challenges of merging local partnerships with national priorities:

Rochelle: Well, we have our own quality improvement or quality assessment too soon at a national level through our national organization. And we as National Youth Outcomes Initiative ... that's when I was going with it. I don't know. And so we administer that in March as well to our kids. And I think when we come right on top of it with the SAYO and it's very similar so I don't even ... some 
question maybe about the data or about being like right on top of each other. How pure or how real data is 'cause it comes right after our kids complete these long week long assessment and survey that we have to through our national organization. That's how it's been.

Clyde: So yeah the SAYO has been frustrating 'cause it's very much like a duplication, and I've expressed that one but that's been their mode of looking at outcome per se measurement or getting youth input into the experience or whatever that they're having at those Out-School-Town provider and locations but that's very similar.

Jamir: And so we've always struggled with participation in SAYO because we have to drive a very high level of participation in another survey which is the month prior. So we always tend to wane on participation with the SAYO and that's been a challenge. Moving into this year's cycle as we are now converting from doing the SAYO in April to doing the SRYB in October and April. So it's a huge time a year.

Andy and Tracey from the YAGC focus group conversed about the challenges from their organization's perspective:

Andy: I would say that training opportunities are definitely there, however our staff, our programs are licensed by the state. They're required to give stateapproved trainings. I'm not sure-

Tracey: They're not. 
Andy: Yeah. None of the Methods trainings are approved by the state. I don't think they can.

Tracey: They're at another level of time to trainings that don't really count for your state requirements.

Andy: When you're asking people to get so many hours a calendar year outside of their normal work hours, and then you want to add to another two to three hours on top of that, that's a big ask for somebody who is making anywhere between $\$ 9$, $\$ 13, \$ 14$ an hour.

The theme of serving multiple masters appears to have a more pronounced impact on the larger organizations within the present study. As these organizations have a larger national and statewide presence, it appears that they are beholden to more regulatory measures than their smaller counterparts. On one hand, the larger organizations consistently communicate their desire to be good partners in the work of CARDS. On the other hand however, there is some evidence of difficulty in making senseof their respective relationships between the CARDS partnership and their other regional and national commitments.

\section{The Creation of Public Value}

Proposition 23 of Bryson et al.'s (2015) Cross-Sector Collaboration Theoretical Framework states that cross-sector collaborations are most likely to create public value if they produce positive first-, second-, and third-order effects. Additionally, these positive effects should far exceed any potential negative effects of collaboration. Bartunek and Moch (1987) describe first-order effects as those that reinforce present understandings. 
Second-order effects are those that require the modification of present thinking in a particular direction. Lastly, third-order effects are those that require organizational members to take an active role in developing new thinking in order to shape the collaborative environment to best achieve agreed upon goals. Moving from first- to third- order effects requires that an organization or collaborative take an increasingly active role in shaping the outcomes of a partnership. Innes and Booher (1999) developed a framework by which to evaluate collaborative planning efforts. Figure 9 identifies observable indicators by which to assess the success of a collaborative effort.

\begin{tabular}{|c|c|c|}
\hline First-Order Effects & Second-Order Effects & Third-Order Effects \\
\hline - Social Capital: Trust, & - New Partnerships & - New Collaborations \\
\hline $\begin{array}{l}\text { Intellectual Capital: } \\
\text { Mutual Understanding, } \\
\text { Shared Problem Frames, } \\
\text { Agreed Upon Data }\end{array}$ & $\begin{array}{l}\text { - Coordination and Joint } \\
\text { Action } \\
\text { - Joint Learning Extends } \\
\text { Into the Community }\end{array}$ & $\begin{array}{l}\text { More Coevolution, Less } \\
\text { Destructive Conflict } \\
\text { - Results on the Ground: } \\
\text { Adaptation of Cities, } \\
\text { Regions, Resources, } \\
\text { Services }\end{array}$ \\
\hline $\begin{array}{l}\text { - Political Capital: Ability } \\
\text { to Work Together for } \\
\text { Agreed Ends }\end{array}$ & $\begin{array}{l}\text { - Changes in Practices } \\
\text { - Changes in Perceptions }\end{array}$ & $\begin{array}{l}\text { - } \\
\text { - } \\
\text { - New Institutions } \\
\text { Norms and }\end{array}$ \\
\hline - High-Quality Agreements & & Heuristics \\
\hline - Innovative Strategies & & - New Discourses \\
\hline
\end{tabular}

Figure 9: Innes and Booher (1999) Potential Outcomes of Collaborative Planning Efforts

Focus group data were analyzed to determine whether first-, second- or third-order effects have been produced as evidence of public value created by the CARDS initiative (Figure 10). 
First-Order Effects

- Development of informal youth-service organization network

- Agreed upon quality tools (YPQI, SAYO, CASCADE) $\underline{\text { Second-Order Effects }}$

- CARDS

- Adoption of YPQI

Quality Assessments

- CARDStar Organization Certification $\underline{\text { Third-Order Effects }}$

- Youth Development Certificate

- Development of CARDS

Partnership

- Development of CARDS theory of change

- Renewing of CARDS

MOU replete with additional detail and accountability

Figure 10: Reported CARDS First, Second and Third Order Effects

Data collected in this study suggests that CARDS has done much, particularly in recent years to address the structural challenges that have hampered the initiative's progress in the past. Such changes have produced renewed commitment between CARDS' founding partners, as evidenced by the renewal of the 2016 CARDS memorandum of understanding (MOU). However, focus group data indicate that there is a substantial disconnect between how organizations who are a part of CARDS make sense of the larger initiative itself. Although youth-service organizations find many tangible benefits for their participation in CARDS, those interviewed at best possess only a cursory knowledge of the inner-workings of CARDS, and at worst possess no such knowledge at all. It is not clear whether this gap in knowledge is of particular concern to CARDS' founding partners or current operations team. It appears that any attention devoted to closing the information gap would be a worthwhile investment in months and years to come. 


\section{A Lasting Impact}

In conducting both semi-structured interviews and focus groups, informants and participants from all three cases were asked to give their perspectives on the long-term viability of the CARDS partnership. This question speaks to Proposition 24 of Bryson et al.'s Cross-Sector Collaboration Theoretical Framework which states that cross-sector collaborations are most likely to create public value if they are long-lived, resilient and engage in regular assessments.

As previously mentioned, the same question was asked of each individual interviewed in Cases \#1 \& \#2, as well as the Case \#3 focus groups with youth-service organizations. While reviewing the responses of participants, a number of themes began to emerge. Some participants provided very direct answers to the question, while others' responses were more layered. Because of the nuance within responses, it became more difficult to assign a definitive answer as to how informants perceived these questions. Four perspectives were identified to categorize the responses of informants. The four perspectives are: Pragmatic, Aspirational, Pessimistic and With Caveats. The pragmatic category are responses that believe CARDS will be a long-term institution, not necessarily because of the initiative's own virtue, but because of other contextual factors. The aspirational category captures responses that believe in the value and long-term viability of the CARDS partnership. Responses in the pessimistic category do not necessarily want CARDS to go away, but have concerns about its ability to maintain its current place in the community. Lastly, the category "with caveats" believes in the longterm viability of CARDS, but do so with thoughtful reflection of details that must be considered in evaluating the long-term future of CARDS. Figure 12 shows the coded responses to the discussion of CARDS' long-term status in the Cabot community. As 
Figure 12 indicates, the aspirational category garnered the most coded responses from study participants. The next most cited category was "with caveats". The pragmatic and pessimistic responses were third and fourth on the list respectively. These data indicate that although most participants in this study believe in the long-term viability of CARDS

\begin{tabular}{|lllll|}
\hline & Pragmatic & Aspirational & Pessimistic & With Caveats \\
\hline Case 1 & & & & \\
CMG & & $\mathrm{xx}$ & & \\
CPS & & $\mathrm{x}$ & & \\
PTGC & & $\mathrm{x}$ & & \\
PFC & $\mathrm{x}$ & & & \\
Case 2 & & & $\mathrm{x}$ & \\
CMG & & & $\mathrm{x}$ & $\mathrm{x}$ \\
CPS & & & \\
PTGC & & & \\
PFC & $\mathrm{x}$ & & \\
Case 3 & & $\mathrm{x}$ & $\mathrm{x}$ \\
YAGC & $\mathrm{x}$ & $\mathrm{x}$ & & \\
KID'S INC. & $\mathrm{x}$ & $\mathrm{xx}$ & & $\mathrm{x}$ \\
HYPE & & $\mathrm{xx}$ & 2 & 7 \\
IFC & & 9 & & \\
\hline Total Count & 4 & & & \\
\hline
\end{tabular}

Figure 12: Coded responses to CARDS' Long-Term Institutional Viability

in the Cabot community, palpable concern exists over the future of CARDS.

To buttress the findings presented in Figure 12, supporting quotes will be provided in each category to display the breadth of participant perspectives.

Pragmatic

Tracy's pragmatism arises from the understanding that CARDS is currently girded by the significant support of one of its founding partners, stating:

I think so because the United Way funding tied to it. If it does fold out that way, which I have everything to believe that it would be, that if the Public Trust of Greater Cabot funding is tied to it, then people will get on and support it. If that 
wasn't tied into it, I don't know if my answer would change. I think it might change if PTGC funding wasn't (attached).

Clyde believes that the components of CARDS, particularly those that support the development of high quality out-of-school time programs are what will drive its sustainability:

I mean I would say so. I think that it's quality driven. I think anything that's quality driven, it has scores like I said earlier, it has scores to organizations to step-up their game, as far as standards and services that we're providing to our children after school, outcomes, trainings for staff all those things, I think it's definitely quality driven enough and I don't think it's going anywhere.

These responses are an example of the practical perspectives offered in in this thematic section.

\section{Aspirational}

The theme that featured the most responses was Aspirational. These responses felt that the long term viability of CARDS will be due to its inherent virture and not because of some other extenuating circumstance. Bianca believes that the CARDS model should be utilized in other community contexts stating:

I think to Kevin's point, I think it should be a model that is replicated in a lot of other cities because when I've had the opportunity to go to different states, different cities for whether it's a national Urban League conference or it's another conference for another grant that we have and we talk about the partnership with our school district and then with a United Way and then with the city government, it's unheard of. They would love and dream to have some type of just a small fragment of what we're able to do in the city. Just from data sharing to just 
collaborating to professional development, all the things that CARDS is accomplishing and is trying to accomplish in the future I think is definitely a model that should be replicated. To me it has sustainability.

Suzanne also expresses belief in the work of CARDS despite her past challenges with the partnership:

Yes, in some form. I think it goes back to who we are. We just seem to be able to work together. Despite the personality changes and the little hiccups along the way, I think it's still solid because, at the end of the day, the three entities are still very committed to student success. I think the district realizes that we can't do it all by ourselves, just within the short time that we have students. We have to work closely with the community because so many of our students are involved in outof-school time programs. We can't provide it all. We need to work with our outof-school time partners. That's where the community and Public Trust of Greater Cabot and Metro Government come in. That's where we all sit.

Other responses echo the previously stated sentiments. Informants in this theme saw true value in the work that CARDS has sought to undertake since its inception.

Pessimistic

The pessimistic theme does not share the optimistic outlook of the previous responses. Candace offered the following perspective:

I don't know. I don't know. The cynical part of me says, "Honestly, probably not. Not forever." But the person on the ground part of me says, "As long as the data's there to tell you that it's working, and there's a demand for it, and funders or United Way sees the data and wants to keep investing in it, then logically, it will never go away." I kind of feel like that's where we're at. I don't see it going away 
anytime soon because we're just scratching the surface of some really powerful data results.

Lois' pessimism is driven by questions of whether individuals and organizational partners will continue to see the long-term value in CARDS:

I see things change. You can have change in administration, in the city, where they say well why are we funding this stuff? Why are we investing so much? The school district would change, it has. I'm still not sure yet, that the school district and the board sees the value in how important out-of-school time programming is. So, that worries me in terms of will they stay and will they be putting staff, time and the data, that bothers me. Public Trust of Greater Cabot, the way they fund I see CARDS staying with them because of the funding, the same thing. They have some way now of ensuring that they're funding programs of quality and having the kind of outcomes we would like to see for those kids that are involved in those programs. To me any time, anytime when I think about things sustaining, is you have to show value. You have to be able to say this investment is giving you this as a community so it's worth the investment and I'm just not sure where the district is about that.

Though small in number, these responses should not be completely ignored. If paired with pragmatic responses, there are six informants who have real concern over the future viability of the CARDS partnership.

\section{$\underline{\text { With Caveats }}$}

The final identified theme in this section features responses that believe in CARDS but with caveats. These caveats are structural, tied to funding or related to personnel. Ronald's caveats are focused on the human resources within the partnership: 
So much of this is dependent on the people, you know? As long as the group continues to get populated by people that are engaged like that, then yeah, I think that's probably where the best opportunity lies.

Joyce emphasized the fiscal resources that will be needed to support CARDS in the future:

I think that's a really interesting question. It would need investment, and if multiple layers, multiple partners, are invested and a clarity of why there is a need for either coordinating council or a intermediary, and that is something that people can rattle off the back of their ... Without much thought of what that value is, then yes.

Finally, Warren's caveats, are related to the public's will to support CARDS long-term: Will there be the will for CARDS to be here consistently for 20 years? I don't know. It's possible. It's certainly not inevitable. If you want to know the truth, if the will is there, the city and the school system would actually support CARDS' sustainability with more than just pieces of some people's time when they're not doing other stuff.

The responses in this theme comprise the second highest response count. The diverse perspectives related to the long-term viability of CARDS as an entity indicate that key stakeholders are not monolithic in their views. This lack of congruence is a trend that has permeated the past, present and seemingly the future of the CARDS partnership.

\section{Summary}

Chapter IV presented the narratives and findings that were derived from the transcripts and analysis of data obtained during this study. Case \#1 was comprised of six individual semi-structured interviews; Case \#2 was comprised of four individual semi- 
structured interviews; and Case \#3 was comprised of four focus groups, with a total of 12 individual participants. Their perspectives provided answers to the three research questions posed by this study.

The first research question sought to understand why the CARDS partnership chose the multi-organizational partnership model. It was discovered that the decision to form a multi-organizational partnership in part was made to capitalize on a window of opportunity that allowed those at the table to apply for a substantial external grant to support the work. Rather than be bogged down in the minutia of partnership agreements or the lack of understanding of intermediary workings, stakeholders essentially decided to move forward with the grant and figure the details out at a later date.

The second research question explored the benefits and/or challenges of the multiorganizational partnership model. Data showed many challenges in establishing the CARDS partnership. From the beginning, CARDS did not dedicate the necessary time to form high-quality agreements that clearly identified the expectations of partner organizations. The lack of specificity has also led to questions of not only who the internal stakeholders are, but of who the external stakeholders of CARDS are as well and how best to serve them.

The third and final research question shifts the lens from organizations who were involved in the formation of CARDS, to those organizations who are seen as beneficiaries of CARDS' work. Data shows that out-of-school time programs believe the work of CARDS has helped them to make sense of what quality means in youth development programs. Before the advent of CARDS, there was no way organizations could communicate their effectiveness to local funders in relation to like programs. Through a robust series of professional development, data shows that CARDS has helped 
to increase organizational capacity via the conduit of professional development. This benefit was particularly evident in organizations with smaller staff sizes. Though participation in CARDS for organizations carries no fees, said participation does carry a cost of time. For out-of-time programs in this study, there is an equilibrium that must be maintained between serving youth and satisfying the requirements necessary for participation in CARDS. This challenge is particularly evident in the larger organizations in my study who have regional and national requirements to attend to as well. In Chapter V, I will compare my findings to trends found in the extant research on community wide partnerships and collaborations. I will discuss the implications of my study for policy, practice, and future research. 


\section{$\underline{\text { Additional Findings }}$}

To this point in my study, Bryson et al.’s (2015) Cross-Sector Collaboration Theoretical Framework has provided the lens by which the data have been analyzed and themed. In Chapter III, it was suggested that additional themes may arise from the data. To capture any emerging themes, a second round of inductive coding was undertaken after the data were analyzed and coded deductively. The results of this second round of coding will be discussed in the following section.

\section{Loose Coupling}

The data suggest that organizational relationships between CARDS' partnering organizations shares features of loosely coupled systems. Glassman (1973) argues that the degree to which systems are coupled, depends upon how many variables they share. Systems that have few variables in common experience loose-coupling while systems that have many variables in common experience tighter coupling. Weick (1976) uses the example of a principal's office and a counselor's office to describe loose-coupling in the context of educational organizations:

The image is that the principal and the counselor are somehow attached, but that each retains some identity and separateness and that their attachment may be circumscribed, infrequent, weak in its mutual effects, unimportant, and/or slow to respond. (p.3)

Weick notes several reasons why organizations may choose to operate within a loosely coupled system. Among them are an organization's ability to be fluid in the face of change, the relatively inexpensive nature of the model, and the ability for the entire organization to persist, even if other portions of the organization cease to exist. 
Figure 11 provides a visual image of the loosely coupled nature of the CARDS initiative. The CARDS multi-organizational partnership model inherently boasts

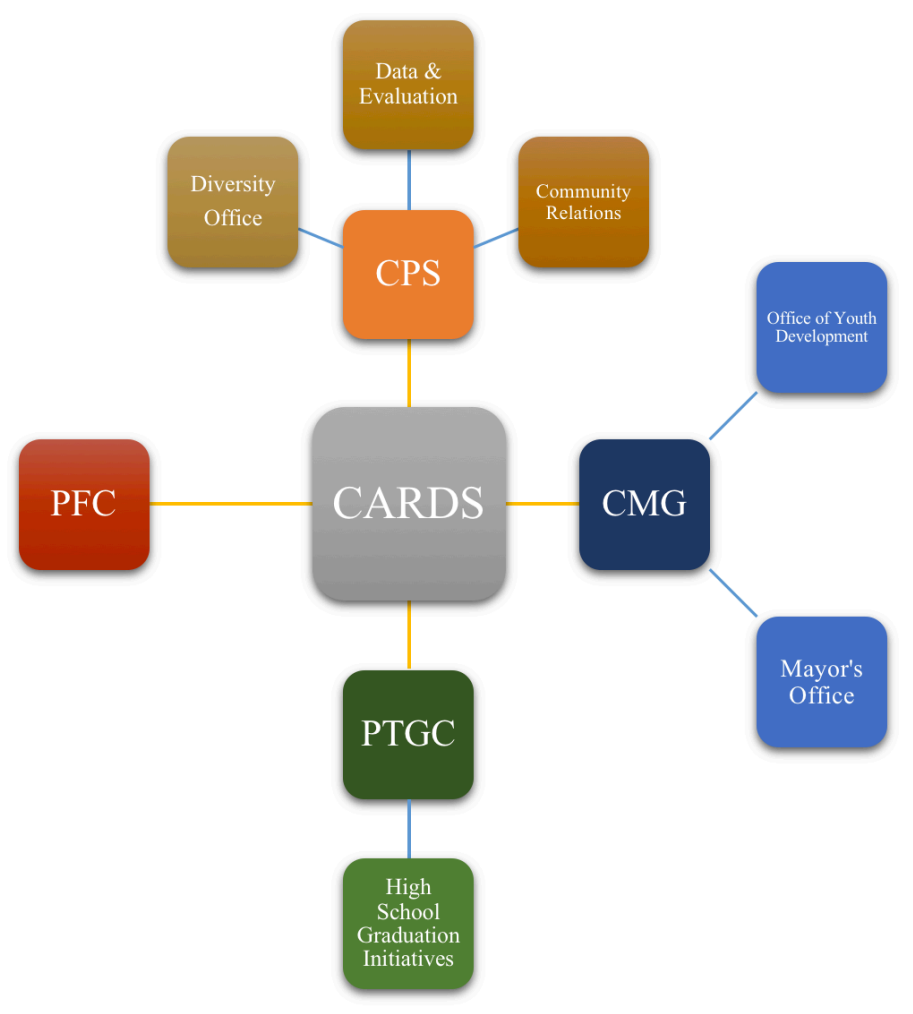

\section{Figure 11: CARDS' Loose Coupled Organizational Structure}

features of a loosely coupled system. An added layer of complexity is found however in the fact that departments that have worked with CARDS are loosely coupled within the partner organizations themselves. Two of the founding partners, namely CPS and CMG, are much larger organizations than their counterparts of PTGC and PFC. Tammy suggests that these multiple layers of bureaucracy may also contribute to the perception of PTGC being the de facto organizational leader in CARDS. She states:

What I mean by that is at Public Trust of Greater Cabot, I think it's because they're smaller, they see each other every day. They're all right there. You know? I work for the city but I'm the director of the Office of Development...I am not downtown in the mayor's office. I don't see the mayor every day to have 
communications with him. Whereas, [PTGC Staff] are right there and their CEO is right down the hall. Passes right by him every day. I think they have that constant contact so therefore there's that constant opportunity to be able to constantly to inform and to get buy in and to engage people at all levels.

The loosely coupled nature of the multi-organizational partnership model between and within partners, echoes the previously identified continuity challenges within the partnership. Ronald also spoke to the continuity challenges in his interview. He stated:

The challenge was ...we started having this, different people showing up to represent Metro or CPS, which, that lack of continuity makes for a weaker sort of base from which to work. The folks that had historically represented Cabot Metro Government and these conversations were going, but I don't think any of the five, four of us were going regularly enough to kind of have that single representation. And then, one the CPS side, sort of the same issue.

As Glassman (1973) notes, the degree of coupling is directly informed by how many variables organizations share. In the case of CARDS, although departments that are subunits of the founding organizational partners experience more tightly coupled relationships with the CARDS initiative itself than they seem to experience within their host organizations. To that end, it is possible that loose-coupling theory provides a more tangible explanation of why the lack of continuity within CARDS apparently has had detrimental effects. 


\section{CHAPTER V DISCUSSION}

The purpose of this qualitative research study was to utilize Bryson et al.'s (2015) Cross-Sector Collaboration Theoretical framework to understand a multi-organizational partnership for school-aged youth. As previously mentioned, the Cross-Sector Collaboration Theoretical Framework provided a means to not simply observe this collaborative effort in its totality, but to examine the mechanisms that reveal the context of its inception, inform its current work and shape its future viability. By utilizing the propositions contained within the framework, this study could situate the experiences and perspectives of key informants within the larger bounded case.

An embedded multiple case study was selected as the methodology by which to examine this case. The selected methodological approach employed semi-structured interviews, focus group responses and document analysis. Embedded within the larger case of the CARDS initiative were three separate cases. The first case was comprised of individuals who were involved in the formation of the CARDS initiative, but may not be involved in its current day-to-day functions. The second case was comprised of individuals who were not necessarily present during the inception of the CARDS initiative, but are active in its current form. The third and final case was comprised of youth service organizations of varying capacities who are involved as external stakeholders of the CARDS initiative. 
My study sorted the propositions of the Cross-Sector Collaboration Theoretical Framework into three categories - one category, which examined the antecedent conditions of collaboration; one category, which examined the processual dimensions of collaboration; and the final category, which examined the public value created by collaborations. The following section discusses the findings for my three research questions and a discussion of how these findings compare to those in the existing research on community wide partnerships and collaborations. This is followed by a discussion of the implications that my study's findings have for policy, practice, and future research.

\section{Discussion and Interpretation of Findings}

Research Question 1: Why did CARDS choose the multi-organizational partnership model as the coordinating structure for the initiative?

As previously stated, my study began with the premise that the YouthPrint report was the catalyst for the work regarding OST programming in the Cabot Community. The data suggest that while important, the YouthPrint report was not the beginning point for this work. The antecedent of CARDS traces its roots to 2002, eight years before the publication of the YouthPrint report (2010), with the identification of what the CrossSector Collaboration Theoretical Framework calls a "sector failure"; in this case the sector failure was that of educational attainment in the Cabot Community. Several reports were commissioned to discuss the implications of both high dropout rates and low educational attainment in the Cabot community. The findings from these documents and Cabot's rising prominence on a national scale regarding work on these issues led to the community hosting one of the first Grad Nation Dropout Prevention Summits sponsored by the America's Promise Alliance. It was this summit from which the YouthPrint report 
was born. Though the Grad Nation Dropout Prevention Summit was focused specifically on preventing students from dropping out of high school, there was a realization in the community that academic proficiency was not the only issue at play. There were also social and emotional challenges that students faced, which adversely impacted their educational attainment. At this point, two specific initiatives were created: The Cabot Grad Project, which focused solely on higher-educational attainment, and one which focused on empowering OST youth service organizations to support the social and emotional needs of students. The latter initiative would go on to become what is now known as CARDS.

As momentum grew around the OST collaborative, the Cabot community was invited to apply for a grant from the Wallace Foundation in its second round of funding to support systems-building work around OST. The grant called for communities to identify methods to support the quality of OST programs, identify a data system by which to analyze this work and lastly to identify a governance structure by which to analyze this work. Though the majority of communities funded through the Wallace Foundation chose to create a separate entity commonly known as an "Intermediary", the Cabot community chose a multi-organizational partnership. Data suggests that this decision could have been for many reasons. Within the Cabot community there is a general willingness for organizations to partner with one another. Additionally, as the Cabot community does not boast a particularly robust funding community, there is the sense that there may have been organizational fatigue, with many local benefactors supporting the launch of the brand new Cabot Grad Project. There was also a lack understanding of the implications of the intermediary model. The definitive reason for choosing the multiorganizational partnership model was to take advantage of what the Cross-Sector 
Collaboration Theoretical Framework calls a "window of opportunity". Rather than allowing the work to stagnate and miss out on a potential funding opportunity, the Cabot community decided to work together on the initiative as a partnership by identifying what the work of an intermediary would be and parsing out those responsibilities to the founding partners.

These findings are consistent with existing literature. Mintzbery and Waters (1985) suggest that deliberate planning strategies occur in more tightly coupled organizational contexts while emergent planning is the more likely choice in loosely coupled decentralized organizations. Morrison and Salipante (2007) advocate the blending both deliberate and emergent planning. Proposition 9 of the Cross-Sector Collaboration Theoretical Framework, however cautions that an imbalance between either deliberate and emergent planning can undermine the collaboration's success. In the case of CARDS, data indicates that there was indeed an imbalance skewed more towards emergent planning. The deliberate steps to allay confusion ultimately never came to the fore.

Research Question 2: How does cross-sector collaboration theory explain the perceived benefits and/or challenges of the CARDS multi-organizational partnership model?

The following major themes emerged from the responses of study participants in regards to how Cross-Sector Collaboration Theory explains the benefits and challenges of the CARDS multi-organizational partnership model: Symbolism over Substance, A Seat at the Table, The Power Dump, An Absent Voice and A Lasting Impact. I will provide a brief review of each of these themes and how they relate to the present study.

Proposition 4 of the Cross-Sector Collaboration Theoretical Framework addresses the importance of a collaboration's initial agreements. These agreements should identify 
key decision makers as well as the processes that will inform the work of the partnership. This theme is named Symbolism over Substance as study informants overwhelmingly indicate that the initial agreements which governed the CARDS initiative were inadequate. What was most important at the inception of the CARDS initiative was for the community to recognize that the founding organizations were equally committed to supporting the work of OST youth service organizations in the community. These initial agreements however lacked specificity regarding what fiscal and human resources each organization would contribute to ensure the viability of the collaboration.

Due to the nebulous nature of initial relationships, there was a general lack of continuity that plagued the early iterations of CARDS. This theme is named A Seat at the Table, because data shows that at every level of the partnership, there was never a clear understanding of who the decision makers were. Within the respective partner organizations, data indicate that between three and five different individuals were representing each organization at any given time. Moreover, the information disseminated at partnership meetings did not appear to diffuse effectively within organizations to ensure continuity. Clarke and Fuller (2010) found that in successful multi-organizational partnerships implementation occurs at two levels. The first level of implementation occurs at what Cross Sector Collaboration Theoretical framework calls the network partnership level. In this study, the implementation of the CARDS initiative would begin with the Coordinating Council. Clark and Fuller note however that this level of planning does not occur in isolation. A second level of implementation must occur within the organizational structures of the individual partners. At the top levels of organizational leadership, the metro government experienced a mayoral change, while the school district changed superintendents three times from the inception of this work. Only 
the Public Trust of Greater Cabot maintained continuous organizational leadership from 2002 to 2016. As previously discussed, the loosely coupled nature of the CARDS partnership may have been a contributing factor in the lack of planning.

The lack of permanence within and between organizations contributed to the most steadfast founding partner taking on the majority of the responsibility for the collaboration. The Power Dump as this theme is called refers to two of the founding partners unloading most of the responsibility for maintaining the collaboration on the remaining partner. Proposition 20 of the Cross-Sector Collaboration Theoretical Framework states that conflicts and tensions in collaboration often arise due to power imbalances. These tensions however are often driven by money or prestige. In the case of CARDS because neither of these factors were necessarily at play, the imbalance in this circumstance is one of responsibility.

The final theme is termed an Absent Voice. The impetus of CARDS' work is to support OST youth service organizations in increasing their program quality. From the beginning of these efforts however, OST programs have played a minimal role in shaping the activities of the CARDS partnership. This lack of influence is perhaps best expressed in the unclear and minimized role of the Partnership for Children. The Partnership for Children has been a key player in the development of CARDS and over time has come to be recognized as a founding partner of the initiative. In its founding documents, the Partnership for Children was to serve as the chief organ of the youth service community to ensure that their needs were being met as they supported youth and families. Over time however, this intention has waned, as more attention has been given to the sustainability of the CARDS partnership. Though attempts have been made recently to 
solicit the voice of OST programs, the relationship of the Partnership for Children and OST programs to the CARDS initiative has been tenuous at best.

Research Question 3: How do out-of-school time partner organizations make sense of the various components of the CARDS initiative?

The final research question of the present study sought to explore how OST programs which are participants in CARDS understand the initiative. After conducting focus group interviews with staff members from four OST programs of varying capacities, the benefits that themes that emerged were leveling the playing field, building organizational capacity through professional development, finding the time and serving multiple masters.

The most widely agreed upon benefit of the CARDS initiative is the standardization of what it means to be a quality OST program in the community. As nonprofit entities, most funding from OST programs comes from grants and proposals from local foundations. OST programs in this study have found that historically it has been difficult to communicate the impact that they are having with their students. As CARDS has served as an umbrella organization for OST programs, there is a general feeling that the standardization of language and understanding of what is a quality program has been welcome.

The next theme discusses OST programs' increased ability to build organizational capacity through professional development. As non-profit entities, the organizations sampled share agreement that resources are not always available to provide staff with timely training on the best ways to serve their constituents. As CARDS provides a series of professional development, data suggest that participating organizations are well served. CARDS training sessions appear to support increased capacity by assisting 
participating organizations in creating deliberate programming which attends to the social and emotional well-being of youth. Closely related, opportunities such as the CARDS Youth Development Certificate provide an incentive to staff at youth service organizations as they seek to professionalize their occupation.

Additionally, the organizations view the opportunity to network with other organizations as an ancillary benefit for their participation in CARDS. By virtue of participating in the battery of trainings facilitated by CARDS, the sampled organizations indicate that they have begun to build relationships with other youth service organizations in the Cabot community. This phenomenon might well be looked at as an unintended benefit, as data suggest that particularly at the CARDS leadership level, little attention has been given to the creation of intentional spaces for youth service organizations to convene. The organizations sampled indicate that due to the nature of their work, they infrequently have the opportunity to interact with other organizations. The opportunity to network has created an informal professional learning community by which organizations can connect with one another, share resources as well as form new collaborations.

Though there are benefits, OST programs sampled also experience challenges in their participation in the CARDS initiative. In the theme entitled finding the time, organizations lament the amount of time needed to dedicate to fulfilling all of the requirements for participation in CARDS. Interestingly, this challenge, as well as that of serving multiple masters seemed to disproportionately affect the larger capacity organizations in this study. Due to the fact that these larger organization must coordinate activities at several sites, more consideration must be made in planning the diffusion of activities throughout their network. Also, these organizations are part of larger national 
organizations, and must find the balance between their state and national requirements, and the local responsibilities of being a CARDS affiliated organization.

The benefits of collaboration balanced with its challenges are a theme that exists in current research. Page, Stone, Bryson, and Crosby (2015) indicate that the balance of this study, for two reasons. The first is that it is often difficult to reconcile the necessary activities of the system-level partnership with the realities of stakeholder preferences. That is to say that the dynamics which make collaborations possible, may not always be congruent with the desires of its consumers. Closely related, the second reason is that the aforementioned responsibilities often create a situation where trade-offs may occur. These trade-offs are often difficult as the pursuit of one set of goals may compromise the realization of others.

\section{Implications}

Based on my study's findings and conclusions, I will discuss the implications of my study on policy, practice, and future research. Each of these implications is discussed in depth below.

Policy

Findings indicate that a watershed moment in the CARDS collaborative history was the decision to not commit the necessary time to develop partnership agreements which would have provided clarity as to how each founding partner would contribute to the initiative's success. As the initial OST Coordinating Council Charter did not include any measures of fiscal support, human resource or partnership accountability, it allowed the founding partners to participate as they saw fit. In the end, the colloquial idiom of "flying a plane while it's being built" turned out to be false; CARDS could not fully function as a collaborative without the necessary infrastructure previously having being 
built. As the Cross-Sector Collaboration Theoretical Framework indicates, the creation of high quality agreements can do much to allay this circumstance as such agreements clearly delineate roles and responsibilities before resources are allocated and the true work begins.

One area where a high-quality agreement could have potentially supported this collaborative is in articulating the role of the school district in supporting this partnership. Data collected for this study suggests that while CPS has the most financial and human resources of any partner available, it has arguably contributed the least amount of either asset to CARDS. Part of this disparity could be to the relationship between school districts and external initiatives. Hall (2017) suggests that though districts may be large in size, their capacity to engage with external partners is limited. Therefore, the needed top-down push previously indicated is not always possible. Hall uses the example of the $\mathrm{CEO}$ of a major corporation being unaware of - let alone intimately involved in - every external initiative in which a district is involved. This example does not fully bear out in the CARDS partnership as the Superintendent has consistently played a role from even the early stages of the partnership. Farrell and Coburn (2017) suggest that districts need to examine their own readiness to partner. Understanding the capacity of key internal stakeholders who will likely be charged with managing partnerships, will position school districts to fully understand the necessary financial and human resources needed to ensure an external initiative's success.

My study covers a fifteen-year span which began with the conceptualization of a community problem of interest and ended with a functioning collaborative effort. Within that time-frame, the funding obtained to support the eventual development of the CARDS initiative was a total of five years. It can be argued that only within the last 18 months of 
that five-year span have tangible actions been taken to support the future viability of the CARDS partnership. As the grant dollars, which once supported this initiative's work have now expired, there is a concerted effort to identify a funding strategy to further the work that has already begun. One can only imagine how much further along the CARDS initiative in its development had a clearer understanding of its challenges and plans to overcome them been developed sooner. Other collaborations would do well to learn from these lessons by taking the time to flesh out structural features so that when opportunities arise, they may take full advantage of resources provided.

\section{$\underline{\text { Practice }}$}

Part of the challenges discussed in the previous implication are that it was difficult for CARDS to conceive partnership structures because they did not know where to begin. In applying for grant dollars, it was left up to all cities who were awarded to decide what organizational structure best fit their community context. While providing flexibility and latitude to communities has its benefit, there is also something to be said about offering research-based exemplars about what challenges a community may encounter in developing a new collaborative effort. The Cross-Sector Collaboration Theoretical Framework provided at the very least perspective on the possible pitfalls in community collaboration. Conducting a review of literature is no insignificant task. However, the time spent on reviewing and implementing best practices versus squandering time spent within the actual grant funding period may in the end prove to be a wiser investment.

Another level of ambiguity in the CARDS partnership was the over-reliance on emergent planning versus deliberate planning. As previously stated, the cross-sector collaboration theoretical framework does not advocate for one type of planning over the 
other. The framework does however make the clear recommendation that a collaboration should eventually move from emergent to deliberate planning. Kamuzinzi (2016) found that the behavior of initiative planners depends greatly on the types of uncertaintly an initiative faces. In environments of external uncertainty, similar to the unclear beginnnings of CARDS, planners act without clearly defined goals. Futhermore, when uncertainty is internal to an initiative, the planners of an initiatve act as negotiators with the aim of reaching a concensus, focusing later on legitimizing their decisions. Conversely, Kamuzinzi found that in more stable environments, planning efforts feature realistic goals that can be achieved with the assistance of the stakeholders at the planning level. In the case of CARDS, deliberate planning efforts did not take place until nearly a decade into the formation of the partnership. The data shows a high level of uncertainty around the formation of the partnership initiative, and in that respect shows agreemeng with literature which predicts a planning focus dedicated to getting various partners on the same page. Cross-sector collaborations may gain much from having a realistic view of what internal and external factors comprise their community context. Understanding what environmental factors may be at play, may help those developing a partnership inititaves to assume the appropriate planning posture.

One of the key outputs of effective planning practices is the development of trustworthiness in partner organizations, which helps to serve as an additional linking mechanism in cross-sector collaborations (Bryson et al., 2006). The relationships that were initially seen as a natural driver of collaboration in the Cabot community, ultimately did not translate into the trust needed to ensure that each partner would contribute equally to the partnership's success. Suseno and Ratten (2007) found that trust in alliances can be enhanced or diminished as a result of the partnership's performance. As the 
imbalance of responsibility in CARDS has become more and more prevalent, the data indicates that the trustworthiness, a key linking mechanism, has eroded over time. Additional research in the area partnership formation also agrees that trust between participants in a collaboration is a key component of maintaining positive, cohesive working relationships (Vlaar, Bosch, \& Volberda, 2006; Yang, 2006). The relational aspects of cross-sector collaborations should not be given short shrift. As collaboratives are typically not short-term endeavors, those seeking to enter into these relationships should do work to ensure that all members of the partnership feel valued, and that trust across and between organizations is always held in high regard.

Finally, the intentional development of spaces for youth-service organizations was to be one of the greatest benefits of the CARDS partnership. A key recommendation of the YouthPrint report was an intentional focus on providing youth-service providers with not only an active voice, but with a mechanism by which to learn from one another. As the CARDS initiative evolved, it strayed away from that aim. Youth-service providers may currently be looked at more as consumers of CARDS rather than a driving force behind the initiative. In its recent iteration however, data suggests that one of the key benefits youth-service organizations receive from CARDS is the opportunity to network with one another and also to share knowledge and best practices. The dissemination of best practices across a network can help to provide youth-service organizations with strategies to overcome challenges. As youth-service organizations exist to provide resources and supports to youth in the community, the opportunity to learn from one another and collaborate in new ways may help to serve more youth in increasingly productive ways. 


\section{$\underline{\text { Recommendations for Future Research }}$}

The cross-sector collaboration theoretical framework states that one of the driving forces behind collaboration is the identification of a sector failure. Data show that as the CARDS partnership evolved over time, so too did the sector failure that was initially identified. The partnership began under the premise that the Cabot community was deeply concerned about the high school drop-out rate of students in Cabot Public Schools. After analyzing the problem further, there was the realization that other social and/or emotional factors may have contributed to the high drop-out rate for students in CPS. Utilizing additional information to provide more context to the identified sector failure was not inherently problematic. What did prove to be a challenge however was that the collective synergy that once served as a driver of collaboraiton was divided into two disparate approaches, and the champions of each individual approach ultimately devoted little time and attention to the other approach. Crosby \& Bryson (2005) indicate the powerful sponsors in a collaborative effort being on the same page in order to help bring together stakeholders. To that end, additional research should be directed to understanding how communities in a potential cross-sector collaboration make sense of what sector failure is identified as the driving factor for partnership. By having clear understanding of what antecedent conditions are agreed upon shared among the various actors in a partnership can help to ensure that the proper attention is given to solutionObased planning activities.

Bryson et al. (2006) state that a key problem of research in the area of CrossSector Collaboration is that research in this space often examines either the theoretical underpinnings of collaboration without considering the processes that occur within collaborative efforts or focuses on the practical implications completely divorced of 
theoretically grounded research. This study has attempted to merge both theory and practice by placing the Cross-Sector Theoretical Framework overtop an existing multiorganizational partnership. In this regard, it is the researcher's hope that this study may serve as an exemplar of integrating theory into practice.

The key recommendation for future research is the need for replication of studies such as this. In Chapter I, I discussed my study's limitations. I indicated that the bounding of this case was intentional to prevent the scope of the research from diverging from the research questions which were posed. This is primarily because many of the contextual factors that informed the present study are endemic to this community. Conversely, this is not the only community where collaborative efforts between local educational agencies and their surrounding communities occur. There is then the opportunity to utilize the framework of this study as a model for understanding not only the practical mechanisms that drive collaboration, but also to understand why collaboration happens in the first place and how both internal and external stakeholders may derive value from their partnership.

\section{Conclusion}

Proposition 26 of the Cross-Sector Collaboration Theoretical Framework states that "the normal expectation ought to be that success will be very difficult to achieve in cross-sector collaborations" (Bryson et al., 2015, p. 663). Because an activity is difficult should not serve as a deterrent for pursuing something that may be worthwhile and beneficial to the stakeholders. The very nature of research is to not simply seek answers, but to use existing research to continuously mine for new questions that deserve to be asked. As public education plays an increasingly important role in communities, it is not likely that local education agencies will cease their partnership efforts. As this is the 
case, continued research and attention should be paid to ensure that when schools and the communities in which they reside do choose to collaborate, each iteration of such partnerships should strive towards their own zenith of possibility. 


\section{REFERENCES}

Adobor, H. (2005). Trust as sensemaking: The microdynamics of trust in interfirm alliances. Journal of Business Research, 58(3), 330-337.

Ang, K C S, Killen, C P, Sankaran S, (2015). Unanticipated value creation: Sensemaking and the value spectrum in partnership projects, The Power of Projects, Proceedings of IRNOP 2015, International Research Network on Organising by Projects, London, UK, June 22-24, 2015.

Ansell, C., \& Gash, A. (2008). Collaborative governance in theory and practice. Journal of Public Administration Research and Theory, 18(4), 543-571.

Arnstein, S. R. (1969). A ladder of citizen participation. Journal of the American Institute of Planners, 35(4), 216-224.

Barnard, H. (1856). Graduation of public schools with special reference to cities and large villages. American Journal of Education, 2 455-464.

Bartunek, J. M., \& Moch, M. K. (1987). First-order, second-order, and third-order change and organization development interventions: A cognitive approach. The Journal of Applied Behavioral Science, 23(4), 483-500.

Baxter, P., \& Jack, S. (2008). Qualitative case study methodology: Study design and implementation for novice researchers. The qualitative report, 13(4), 544-559.

Bengtsson, P. (1999). Multiple case studies-not just more data points. Term paper in graduate course in Research Methodology., 1-9.

Bozeman, B. (2002). Public-value failure: When efficient markets may not do. Public Administration Review, 62(2), 145-161.

Bronfenbrenner, U. (1979). The ecology of human development : Experiments by nature and design. Cambridge, MA.: Harvard University Press.

Bronfenbrenner, U. (1986). Ecology of the family as a context for human development: Research perspectives. Developmental Psychology, 22(6), 723-742.

Brown, A. D., \& Humphreys, M. (2003). Epic and tragic tales making sense of change. The Journal of Applied Behavioral Science, 39(2), 121-144.

Brown, A. J. (2002). Collaborative governance versus constitutional politics: decision rules for sustainability from Australia's South East Queensland forest agreement. Environmental Science \& Policy, 5(1), 19-32.

Bryson, J. M., Crosby, B. C., \& Stone, M. M. (2006). The design and implementation of 
cross-sector collaborations: Propositions from the literature. Public Administration Review, 66(1), 44-55.

Bryson, J. M., Crosby, B. C., \& Stone, M. M. (2015). Designing and implementing crosssector collaborations: needed and challenging. Public Administration Review, 75(5), 647-663.

Clarke, A., \& Fuller, M. (2010). Collaborative strategic management: Strategy formulation and implementation by multi-organizational cross-sector social partnerships. Journal of Business Ethics, 94(1), 85-101.

Cooper, C. R., Chavira, G., \& Mena, D. D. (2005). From pipelines to partnerships: A synthesis of research on how diverse families, schools, and communities support children's pathways through school. Journal of Education for Students Placed at Risk, 10(4), 407-430.

Crosby, B., \& Bryson, J. (2005). Leadership for the common good : Tackling public problems in a shared-power world(2nd ed). San Francisco: Jossey-Bass.

Creswell, J. W. (2012). Qualitative inquiry and research design: Choosing among five approaches: Sage.

Dewey, J. (1902). The school as social center. The Elementary School Teacher, 73-86. Donahue, J. (2004). On collaborative governance. Working paper, John F. Kennedy School of Government, Harvard University.

Dryfoos, J. (2002). Full-service community schools: Creating new institutions. Phi Delta Kappan, 83(5).

Durlak, J. A., Weissberg, R. P., Dymnicki, A. B., Taylor, R. D., \& Schellinger, K. B. (2011). The impact of enhancing students' social and emotional learning: A metaanalysis of school-based universal interventions. Child Development, 82(1), 405432.

Emerson, K., Nabatchi, T., \& Balogh, S. (2012). An integrative framework for collaborative governance. Journal of Public Administration Research and Theory, 22(1), 1-29.

Epstein, J. L. (1987). Toward a theory of family-school connections: Teacher practices and parent involvement. Social intervention: Potential and Constraints, pp. 121136.

Epstein, J. L., \& Sanders, M. G. (2000). Connecting home, school, and community. Handbook of the Sociology of Education, 285-306: Springer.

Epstein, J. L., \& Sanders, M. G. (2002). Family, school, and community partnerships. Practical Issues in Parenting, 5, 406. 
Farrell, C. C., \& Coburn, C. E. (2017). Absorptive capacity: A conceptual framework for understanding district central office learning. Journal of Educational Change, 18(2), 135-159.

Fawcett, S. B., Boothroyd, R., Schultz, J. A., Francisco, V. T., Carson, V., \& Bremby, R. (2003). Building capacity for participatory evaluation within community initiatives. Journal of Prevention \& Intervention in the Community, 26(2), 21-36.

Gifford, B., \& Evans, K. (2011). America's promise alliance dropout prevention summits: mobilizing action to address the high school dropout crisis across the nation. Retrieved from http://www.americaspromise.org

Glassman, R. B. (1973). Persistence and loose coupling in living systems. Behavioral Science, 18(2), 83-98.

Golob, U., Johansen, T. S., Nielsen, A. E., \& Podnar, K. (2014). Corporate social responsibility as a messy problem: Linking systems and sensemaking perspectives. Systemic Practice and Action Research, 27(4), 363-376.

Griffin, D. S. S. (2010). School-family-community partnerships: Applying Epstein's theory of the six types of involvement to school counselor practice. Professional School Counseling, 13(4).

Gustafsson, J. (2017). Single case studies vs. multiple case studies: A comparative study. Hall, J. J. (2017). There's a consultant for that: When school districts are doing too much but can't help themselves. Phi Delta Kappan, 99(4), 60-65.

Henig, J. R., Riehl, C. J., Rebell, M. A., \& Wolff, J. R. (2015). Putting collective impact in context: A review of the literature on local cross-sector collaboration to improve education. New York, NY: Teachers College, Department of Education Policy \& Social Analysis.

Imperial, M. T. (2005). Using collaboration as a governance strategy lessons from six watershed management programs. Administration \& Society, 37(3), 281-320.

Innes, J. E., \& Booher, D. E. (1999). Consensus building and complex adaptive systems: A framework for evaluating collaborative planning. Journal of the American Planning Association, 65(4), 412-423.

Ishak, N. M., \& Bakar, A. Y. A. (2014). Developing sampling frame for case study: challenges and conditions. World Journal of Education, 4(3), 29.

Kamuzinzi, M. (2016). Dealing with the three facets of uncertainty in planning: Evidences from a processual study on basic education in rwanda. Rwanda Journal, 3(1), 5-15

Katz, M. B. (1987). Reconstructing American education. Cambridge, Mass. :: Harvard University Press. 
Koschmann, M. A., Kuhn, T. R., \& Pfarrer, M. D. (2012). A communicative framework of value in cross-sector partnerships. Academy of Management Review, 37(3), 332-354.

Koyama, J. (2014). Principals as bricoleurs: Making sense and making do in an era of accountability. Educational Administration Quarterly, 50(2), 279-304.

Labaree, D. F. (2012). Someone has to fail: Harvard University Press.

Lambert, S. D., \& Loiselle, C. G. (2008). Combining individual interviews and focus groups to enhance data richness. Journal of Advanced Nursing, 62(2), 228-237.

Leonard, J. (2011). Using Bronfenbrenner's ecological theory to understand community partnerships: A historical case study of one urban high school. Urban Education, 46(5), 987-1010.

Leone, P. E., Lane, S. A., Arllen, N., \& Arllen, N. (1996). School-linked services in context: A formative evaluation of Linkages to Learning. Special Services in the Schools, 11(1-2), 119-133.

Lin, M. B., Alan. (2010). Home visits: How do they affect teachers' beliefs about teaching and diversity? Early Childhood Education Journal, 38(3), 179-185.

Lincoln, Y. S., \& Guba, E. G. (1985). Naturalistic inquiry (Vol. 75): Sage

Louis, K. S., \& Robinson, V. M. (2012). External mandates and instructional leadership: School leaders as mediating agents. Journal of Educational Administration, 50(5), 629-665.

Mann, H. (1848). Twelfth annual report of Horace Mann as secretary of Massachusetts state board of education. Retrieved from https://usa.usembassy.de/etexts

Milner IV, H. R. (2007). Race, culture, and researcher positionality: Working through dangers seen, unseen, and unforeseen. Educational Researcher, 36(7), 388-400.

Mintzberg, H., \& Waters, J. A. (1985). Of strategies, deliberate and emergent. Strategic Management Journal, 6(3), 257-272.

Morrison, J. B., \& Salipante, P. (2007). Governance for broadened accountability: Blending deliberate and emergent strategizing. Nonprofit and Voluntary Sector Quarterly, 36(2), 195-217.

Ostrom, E. (1990). Governing the commons: The evolution of institutions for collective action: Cambridge University Press Cambridge:

Page, S. B., Stone, M. M., Bryson, J. M., \& Crosby, B. C. (2015). Public value creation by cross-sector collaborations: A framework and challenges of assessment. Public 
Administration, 93(3), 715-732.

Patton, M. Q. (1990). Qualitative evaluation and research methods: Sage

Popp, J., MacKean, G. L., Casebeer, A., Milward, H. B., \& Lindstrom, R. R. (2014). Inter-organizational networks: A critical review of the literature to Inform practice.

Quane, J. M., \& Wilson, W. J. (2011). Improving grades: Urban public schools, racial and socioeconomic segregation, and the promise of innovation. Frontiers in Sociology of Education, 265-272: Springer.

Samberg, L., \& Sheeran, M. (2000). Community school models. Retrieved from http://www.communityschools.org

Sanders, M. G. (2012). Sustaining programs of school, family, and community partnerships: A qualitative longitudinal study of two districts. Educational Policy, 26(6), 845-869.

Schutz, A. (2006). Home is a prison in the global city: The tragic failure of school-based community engagement strategies. Review of Educational Research, 76(4), 691743.

Shenton, A. K. (2004). Strategies for ensuring trustworthiness in qualitative research projects. Education for Information, 22(2), 63-75.

Simkin, L., Charner, I., Dailey, C., Watts, E., Taub, H., \& Adelaja, A. (2013). Is citywide afterschool coordination going nationwide? An exploratory study in large cities: Durham, NC

Suseno, Y., \& Ratten, V. (2007). A theoretical framework of alliance performance: The role of trust, social capital and knowledge development. Journal of Management \& Organization, 13(1), 4-23.

Termeer, C. J. (2009). Barriers to new modes of horizontal governance: A sense-making perspective. Public Management Review, 11(3), 299-316.

Thomson, A. M. (2001). Collaboration: Meaning and measurement: Indiana University.

Thomson, A. M., \& Perry, J. L. (2006). Collaboration processes: Inside the black box. Public Administration Review, 66(1), 20-32.

Tyack, D. B., \& Cuban, L. (1995). Tinkering toward utopia: Harvard University Press.

Valli, L., Stefanski, A., \& Jacobson, R. (2014a). School-community partnerships: A typology for guiding systemic educational reform.

Valli, L., Stefanski, A., \& Jacobson, R. (2014b). Typologizing school-community 
partnerships: A framework for analysis and action. Urban Education.

Vandell, D. L., Reisner, E. R., \& Pierce, K. M. (2007). Outcomes linked to high-quality afterschool programs: Longitudinal findings from the study of promising afterschool programs. Policy Studies Associates, Inc.

Vlaar, P., Bosch, V., \& Volberda, H. (2007). On the evolution of trust, distrust, and formal coordination and control in interorganizational relationships: Towards an integrative framework. Group and Organization Management, 32(4).

Vigoda-Gadot, E. (2003). Managing collaboration in public administration: the promise of alliance among governance, citizens, and businesses: Greenwood Publishing Group.

Warren, M. R. (2005). Communities and schools: A new view of urban education reform. Harvard Educational Review, 75(2), 133-173.

Weick, K. E. (1976). Educational organizations as loosely coupled systems. Administrative Science Quarterly, 1-19.

Weick, K. E. (1993). The collapse of sensemaking in organizations: The Mann Gulch disaster. Administrative Science Quarterly, 628-652.

Weick, K. E. (1995). Sensemaking in organizations (Vol. 3): Sage.

Wood, D. J., \& Gray, B. (1991). Toward a comprehensive theory of collaboration. The Journal of Applied Behavioral Science, 27(2), 139-162.

Yang, K. (2006). Trust and citizen involvement decisions: Trust in citizens, trust in institutions, and propensity to trust. Administration \& Society, 38(5), 573-595.

Yin, R. K. (2009). Case study research : design and methods (Fourth edition. ed.). Los Angeles :: SAGE.

Yin, R. K., \& Davis, D. (2007). Adding new dimensions to case study evaluations: The case of evaluating comprehensive reforms. New Directions for Evaluation, 2007 (113), 75-93. 
INFORMED CONSENT DOCUMENT

Project Title:

\section{CONSTRUCTS OF COLLABORATION: A MULTI-CASE EMBEDDED STUDY OFA COMMUNITY-WIDE PARTNERSHIP FOR SCHOOL-AGE YOUTH}

Investigator(s) name \& address:

Co-Advisor and Principal Investigator:

W. Kyle Ingle, Ph.D.

College of Education and Human Development

University of Louisville

1905 South 1st Street

Louisville, KY 40292

william.ingle@louisville.edu

Charles Davis, Jr.

University of Louisville

4832 South $5^{\text {th }}$ St.

Louisville, KY 40214

charles.davisjr@louisville.edu

Site(s) where study is to be conducted: University of Louisville, Jefferson County Public Schools.

Phone number for subjects to call for questions: W. Kyle Ingle (502) 852-6097

Introduction and Background Information

You are invited to participate in a research study. The study is being conducted by Charles Davis. The study is sponsored by the University of Louisville, Department of Education Leadership, Evaluation, and Organizational Development. The study will take place at the University of Louisville and Jefferson County Public Schools.

Approximately 15 subjects will be invited to participate.

\section{$\underline{\text { Purpose }}$}

The purpose of this study is to examine how a biennial leadership audit affects principals' ability to foster improvement in low performing schools.

\section{$\underline{\text { Procedures }}$}

In this study, you will be asked to provide demographic information and information about your past experiences in school-community partnerships. You will also be asked to provide responses to several questions about your experiences working with the BLOCS partnership. Your participation will include a 90-minute interview to collect 
demographic and some contextual information. The interview will be audio recorded. I am highly flexible and am willing to meet with at your convenience. You may decline to answer any questions that make you feel uncomfortable.

\section{$\underline{\text { Potential Risks }}$}

There are no foreseeable risks other than possible discomfort in answering personal questions.

\section{$\underline{\text { Benefits }}$}

The possible benefits of this study to the participants include the opportunity for a deeper understanding of how collaborative efforts between schools and the communities in which they reside can serve as a driver of student achievement.

\section{Compensation}

You will not be compensated for your time, inconvenience, or expenses while you are in this study.

\section{Confidentiality}

Total privacy cannot be guaranteed. Your privacy will be protected to the extent permitted by law. If the results from this study are published, your name will not be made public. While unlikely, the following may look at the study records:

The University of Louisville Institutional Review Board, and the Human Subjects Protection Program Office. People who are responsible for research and HIPAA oversight at the institutions where the study is conducted. Government agencies, such as: Office for Human Research Protections (OHRP)

\section{$\underline{\text { Conflict of Interest }}$}

This study involves no foreseeable conflict of interest.

Security

All data will be stored on a password-protected computer and will be destroyed after the study is complete.

\section{Voluntary Participation}

Taking part in this study is voluntary. You may choose not to take part at all. If you decide to be in this study you may stop taking part at any time. If you decide not to be in this study or if you stop taking part at any time, you will not lose any benefits for which you may qualify.

You will be told about any changes that may affect your decision to continue in the study. 


\section{U.S. Department of Education (DOE) Funded Studies}

Because school system receives funding from the DOE, we are required to tell you the following information.

The information we collect from the study may only be used to meet the purposes of the study as stated in this consent. We will conduct this study in a manner that does not allow identification of you by anyone other than study team members or others who may have a legitimate reason to know. All instructional materials or survey instruments used for the research are available for you to see before the study begins if you ask to see it. If you want to see any of this information, please contact Charles Davis, (513) 324-5924 and they will give you a date and time where it will be available for you to review. Once we have completed this study, we are required by the U.S. Department of Education to destroy or return to the school system all personally identifiable information when no longer needed for the purposes of the study. We expect this study to last for five months and when the study is finished, we will delete any identifying information. All digital recordings will be destroyed by 2019 and all digital transcriptions will destroyed by 2026 .

\section{Contact Persons, Research Subject's Rights, Questions, Concerns, and Complaints}

If you have any concerns or complaints about the study or the study staff, you have three options.

You may contact the principal investigator at (502) 852-6097 or william.ingle@louisville.edu

If you have any questions about your rights as a study subject, questions, concerns or complaints, you may call the Human Subjects Protection Program Office (HSPPO) (502) 852-5188. You may discuss any questions about your rights as a subject, in secret, with a member of the Institutional Review Board (IRB) or the HSPPO staff. The IRB is an independent committee composed of members of the University community, staff of the institutions, as well as lay members of the community not connected with these institutions. The IRB has reviewed this study.

If you want to speak to a person outside the University, you may call 1-877-852-1167. You will be given the chance to talk about any questions, concerns or complaints in secret. This is a 24-hour hot line answered by people who do not work at the University of Louisville. 


\section{Acknowledgment and Signatures}

This informed consent document is not a contract. This document tells you what will happen during the study if you choose to take part. Your signature indicates that this study has been explained to you, that your questions have been answered, and that you agree to take part in the study. You are not giving up any legal rights to which you are entitled by signing this informed consent document. You will be given a copy of this consent form to keep for your records.

Subject Name (Please Print)

Printed Name of Legal

Representative (if applicable)

Relationship of Legal Representative to Subject

Printed Name of Person Explaining Consent Form
Signature of Subject

Signature of Legal Representative
Date Signed

Date Signed
Signature of Person Explaining Consent Form (if other than the Investigator)

Signature of Investigator
Date Signed

Date Signed

Printed Name of Investigator

Phone Numbers

(502) 852-6097

W. Kyle Ingle

(513) 324-5924

Charles Davis, Jr. 


\section{APPENDIX B \\ RECRUITMENT CORRESPONDENCE}

Hello

I hope this e-mail finds you well. My name is Charles Davis, and I am a Doctoral Candidate in the College of Educational Leadership Foundations and Human Resource at The University of Louisville. I am writing as I am conducting a case study on the BLOCS partnership in Louisville and believe you would be able to provide critical insight.

The primary goal of my study is to investigate the city-wide partnership between the community and local educational agency through the lens of the cross-sector collaboration theoretical framework. Thus, I am seeking to interview internal and external stakeholders who have been involved with the BLOCS partnership. Your voice is of considerable importance to the study. My hope is that I might chat with you in person to gain a better understanding about your own personal experiences with the BLOCS partnership.

I am asking that you participate in a 60-minute interview. My schedule to conduct an interview with you is flexible and can be scheduled at a time, date, and location of your convenience. If you have additional questions, please contact me via e-mail at charles.davis@louisville.edu or call(513)324-5924.

Thank you in advance and I look forward to your response.

Sincerely,

Charles C. Davis, Jr.

Doctoral Candidate, Educational Leadership Foundations and Human Resource University of Louisville 


\section{APPENDIX C \\ INTERVIEW PROTOCOL FOR EMBEDDED CASE \#1}

Question

Number

Question

1A What was YouthPrint, and why was it formed? How did YouthPrint transform into BLOCS?

2A Who comprised the YouthPrint working group, and how were these individuals and/or groups chosen?

3A Of the available governance structures, why did BLOCS choose the partnership model?

4A How did the initial charter come about? Do you feel it was sufficient? If not, was another agreement created to take its place?

5A Who would you say are the "champions" of BLOCS?

6A Who would you characterize as BLOCS' internal stakeholders? External stakeholders?

7A Do you feel that there have been power imbalances at any point during the formation of BLOCS? If so, how have these been addressed?

8A Do you feel that BLOCS began with a solid, deliberate plan, or do you perceive that they emerged over time?

9A Do you feel that planning processes have been inclusive of all stakeholders? Or have those responsibilities been relegated to a select group?

10A Do you see the BLOCS collaborative as being a long-term institution in the Louisville community? 


\section{APPENDIX D}

\section{INTERVIEW PROTOCOL FOR EMBEDDED CASE \#2}

Question

Number

$1 \mathrm{~B}$

$10 \mathrm{~B}$

$11 \mathrm{~B}$

$12 \mathrm{~B}$

13B

14B

$15 B$

\section{Question}

Do you feel that BLOCS began with a solid, deliberate plan, or do you perceive that they emerged over time?

What is your entities' primary goal for participating in BLOCS? Do you feel these goals are congruent with others in the collaborative?

What is the governance structure of BLOCS?

Has the governance structure of BLOCS changed over time? If so, how?

Do you feel that the BLOCS governance structure is malleable enough to address changes?

How does/did the governance structure of BLOCS allow the collaboration to handle an array of tasks?

Do you feel that the most planning for BLOCS has taken place at the system level, the administrative level or the service delivery level?

Do you feel that planning processes have been inclusive of all stakeholders? Or have those responsibilities been relegated to a select group?

Who would you say are the "champions" of BLOCS?

Who would you characterize as BLOCS' internal stakeholders? External stakeholders?

Is there an accountability system in place for BLOCS for either partners or participating organizations?

Do you feel that there have been power imbalances at any point during the formation of BLOCS? If so, how have these been addressed?

Do you feel BLOCS has all the resources that it needs to succeed? What do you feel has been the greatest value of the BLOCS partnership?

Do you see the BLOCS collaborative as being a long-term institution in the Louisville community? 


\section{APPENDIX E}

\section{FOCUS GROUP INTERVIEW PROTOCOL FOR CASE \#3}

Question

Number

$1 \mathrm{C}$

$3 \mathrm{C}$

$4 \mathrm{C}$

$5 \mathrm{C}$
2C What is your entities' primary goal for participating in BLOCS? Do you

\section{Question}

Do you feel that planning processes have been inclusive of all stakeholders? Or have those responsibilities been relegated to a select group? feel these goals are congruent with others in the collaborative?

What do you feel has been the greatest value of the BLOCS partnership?

C Is there an accountability system in place for BLOCS for either partners or participating organizations?

the Louisville community? 


\section{APPENDIX F \\ RESEARCHER POSITIONALITY}

An important component of this study is to thoroughly examine my positionality as a researcher to this study. To accomplish this task, I will utilize a methodological framework developed by Milner (2007) to examine my own positionality in four areas, namely; researching the self, researching the self in relation to others, engaged reflection and representation and shifting from self to system.

\section{Researching the Self}

Long before I even began the process of developing my initial proposal to this research, I had anxiety about choosing to examine the CARDS partnership as a dissertation topic. My concerns were that I may be too close to this work. In 2014, I was identified by CPS to serve as the district representative to the CARDS initiative. During the first few meetings, I had very grave concerns as to whether participating in CARDS was the best use of my professional time. What kept me engaged was my belief in the benefits of OST programming for youth in our district, and my own professional experiences working with collaborations such as this; though admittedly on a much smaller scale. I put aside my apprehensions and became fully engaged in the initiative. I can say without ego, that my addition, along with another colleague, began the turnaround of the CARDS initiative from a place of stagnation to substantive progress. It was in fact my work with CARDS that led me to asking the research questions posed in this study. Because everyone in the leadership of CARDS seemed so passionate and willing to work together, I just could not understand why the initiative existed in such a beleaguered form. 
My close involvement with the operations of CARDS did indeed present a challenge, though not an insurmountable one. Often during interviews or focus groups, participants would refer specifically to my work, influence or role in helping to right-size the CARDS partnership. Additionally, there were times where the lines between researcher and colleague sometimes blurred, when study participants would ask my opinion on a particular topic, or seek affirmation. In these instances, I made it my duty as a researcher to re-focus discussions, and to recuse myself from offering opinions on any particular matter. Additionally, any instances where responses did refer specifically to me were not included in this present study. In the end, what I found in this study is that the success or failings of CARDS had less to do with any particular individual and more to do with the desire of the institutions who comprise CARDS to see the partnership succeed.

\section{Researching the Self in Relation to Others}

Before engaging in the formal interview and focus group protocols, I procured demographic data from participants. I asked participants questions such as whether they were natives of Cabot, and their length of involvement with the CARDS initiative. As I am not originally from Cabot, I recognize that my lens and the lens individuals who are from Cabot may be different. Additionally, participants who are also not from Cabot or have varying degrees of personal interaction with youth development organizations as a participant may have differing views as well.

The nature of cross-sector collaboration, is that various actors from differing sectors are all brought together to accomplish some common good. Inherent in differing sectors is also difference of perspective. The aims of the philanthropic sector are not necessarily the aims of the public education sector, while the aims of the non-profit sector 
are not necessarily aligned with that of county government. Each of these perspectives carries with it a distinct culture informed by policies, procedures, acronyms and governance structures. The questions posed in this research will seek to elucidate where coherence or dissonance exists in relation to the proposed research questions.

A key component of qualitative case study research is the need to bracket the case. By doing this, I as a researcher can intentionally communicate exactly what and whom I am studying, so as not to allow for the conflation of my own perspectives or those of participants. One of the strategies that assisted me in successfully accomplishing this task is the use of a theoretical framework. By utilizing the Cross-Sector Collaboration theoretical framework of Bryson, Crosby and Stone, I was able to create interview and focus group questions that were closely tied to the framework's propositions. To that end, a discrete set of propositions used to guide conversations will helped allay concerns of the interjection of my own personal agendas into the research itself.

Inherent to qualitative research however, is the notion that the researcher is the instrument. To ensure transparency in the process of negotiating this research, I maintained a reflexive journal as part of my data collection activities. The purpose of the reflexive journal was to capture the thoughts and perspectives that I may have had as researcher in relation to the data and analysis of this research. For instance, after an interview, I may have recapped my thoughts related to the non-verbal cues that I may have noticed in a participant. Such cues may be perceived discomfort when answering some questions, or a theme of silence in response to a certain question that occurs with every participant. 


\section{Engaged Reflection and Representation}

In discussing my own positionality, I noted that I took great care to make sure that participants in this study saw me as a researcher, rather than as a colleague. What I did not mention was that this process was a two-part exercise. As colleagues working together on a project, I indeed have developed relationships with many of the participants in this study. Over the months and years not all of my conversations with participants have been strictly work related; and indeed, they were often collegial. In that respect, I as a researcher had to consistently ensure that my personal knowledge or conversations did not bleed over into the collection of data.

As a researcher, it was not my job to interpret whether or not the recollections of participants were hyperbolic or half-truths. My responsibility was to corroborate the veracity of statements offered with supporting data, or to use other perspectives or data to present an alternative view. Assisting me in this effort, the Cross-Sector Collaboration Theoretical Framework served as a boon. In the end, by tying questions to the framework, I was able to mitigate much subjectivity in the present study. Also, by allowing myself the opportunity as a researcher to engage in a second-round of inductive coding, I was granted the intellectual freedom to use my own interpretations and perspectives to discover any additional findings that did not fit discreetly into the framework.

\section{Shifting from Self to System}

In reflecting on my process of research, I feel that an important overarching theme was the existing systemic and organizational barriers which may have shaped the perspectives of my informants. Bryson et al.'s Cross-Sector Collaboration Framework calls attention to the various tensions and conflicts that may arise in developing 
collaborative efforts. To that end, I asked informants questions that sought to discuss what those relationships and power dynamics might be. For example, with the recognitions as a founding partner of the CARDS partnership, four separate entities have equal claim to starting the organization. A more robust examination of this partnership determined that there are differences in financial commitments, infrastructure and staffing, and data sharing. These systemic and organizational barriers may impact how participants view their experiences participating in a partnership; even if the partnership ultimately serves their organization's goals.

Other barriers that may have potentially impacted the perspectives of informants are more external in nature. The partnership climate in Cabot has shifted in recent months. Several new local initiatives, namely Say Yes to Education and Harvard By All Means, have sought to increase the levels of partnership engagement within the city. Thus, partner organizations in the community could potentially be faced with decisions regarding their levels of involvement in CARDS versus one of these other new initiatives. Organizations may choose to stay with and bolster existing relationships, seek out new partnerships or try a mixture of varying perspectives. These varying perspectives again may be impacted more by cultural aspects; though access to participating in larger initiatives, particularly those that may potentially come with funding.

\section{Conclusion}

In the end, I found the entire process of research to be extremely worthwhile. What I initially looked at as a daunting and perhaps insurmountable task turned into one of excitement as I coded interviews, pored through documents and made connections to research. What has been most satisfying about the research process is realizing that my work may someday help other communities who seek to pursue collaborative efforts. I 
have repeatedly noted that collaborations are not easy and can often be daunting tasks. If however, future partnership initiatives engage in their own processes of reflection and research, they may find that the work they set out to do may be made easier by learning lessons from those that have come before. 


\section{CURRICULUM VITAE}

NAME: Charles Curtis Davis, Jr.

ADDRESS: 5407 Hickory Hill Road

Louisville, KY 40214

DOB: Dayton, Ohio

EDUCATION

\& TRAINING B.S., History

Eastern Michigan University

1997-2004

M.Ed., Educational Leadership Antioch University McGregor

2005-07

Ed.D. Educational Leadership

University of Louisville

2014-18 